\title{
Successful Cognitive Aging
}

Memory, determinants and interventions 
(c) S.A.M. Valentijn, Maastricht 2004

$\begin{array}{ll}\text { Cover design } & \text { Johannes Verheijen } \\ \text { Cover photography } & \text { Ton van Zantvoort } \\ \text { Layout } & \text { Alard Weisscher } \\ \text { Production } & \text { Ponsen \& Looijen BV, Wageningen } \\ \text { ISBN } & 90-75579-22-5\end{array}$

Neuropsych Publishers is a nonprofit organisation, which aims at promoting the science of 'Brain and Behaviour' and improving the application of the products of this science in health care and education. Neuropsych Publishers accomplishes these aims by publishing books, dissertations and other products of scientific activity, by disseminating educational materials and publication of tests, assessment scales and other psychometric instruments in the field of Neuropsychology, Neuropsychiatry and other areas within the domain of Brain and Behaviour.

Postal address: Neuropsych Publishers

Department of Psychiatry and Neuropsychiatry

Maastricht University

P.O. Box 616

NL-6200 MD Maastricht

The Netherlands

www-np.unimaas.nl 


\section{Successful Cognitive Aging}

Memory, determinants and interventions

\section{PROEFSCHRIFT}

ter verkrijging van de graad van doctor aan de Universiteit Maastricht, op gezag van de Rector Magnificus, Prof. mr. G.P.M.F. Mols, volgens het besluit van het college van Decanen, in het openbaar te verdedigen op donderdag 16 december 2004 om 14:00 uur

door

Susanne Adriana Maria Valentijn

Geboren op 19 maart 1976 te Oss 


\section{Promotor}

Prof. dr. J. Jolles

\section{Co-promotores}

Dr. M.P.J. van Boxtel

Dr. R.W.H.M. Ponds

\section{Beoordelingscommissie}

Prof. dr. F.R.J. Verhey (voorzitter)

Dr. H.C. Comijs (VU Medisch Centrum)

Prof. dr. D.J.H. Deeg (VU Medisch Centrum)

Dr. J.B. Dijkstra

Prof. dr. J. Th. M. van Eijk

The studies described in this thesis were carried out at the Maastricht Brain \& Behaviour Institute, the department of Psychiatry \& Neuropsychology of the University Maastricht and at the Psychomedical Centre Vijverdal and the Academic Hospital Maastricht. The research was facilitated by the 'Wetenschapskring', a research body which promotes scientific research within the domain of mental health care in the province of Limburg, the Netherlands.

The Netherlands Organisation for Scientific Research (NW0: 014-91-047) funded this study.

Financial support for the publication of this thesis was provided by Stichting Ab Laane, Stichting voor Ooglijders, Radboud Stichting, Sigma Tau Ethifarma BV, Internationale Stichting Alzheimer Onderzoek, Alzheimer Nederland, Bristol-Meyers Squibb, Stichting Licht en Liefde, Janssen-Cilag BV, Groene Kruis Heuvelland. 


\section{Contents}

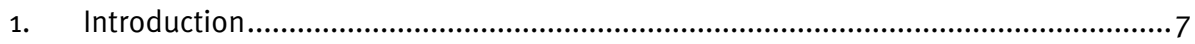

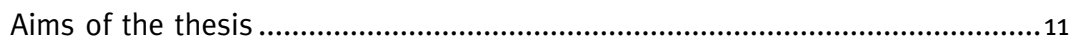

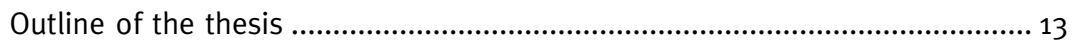

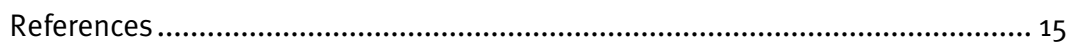

2. Memory self-efficacy predicts memory performance .............................................. 19

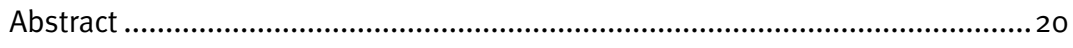

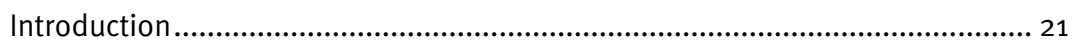

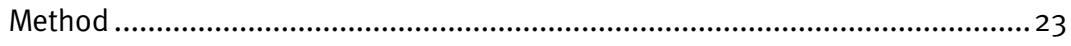

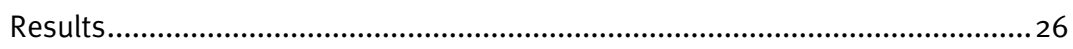

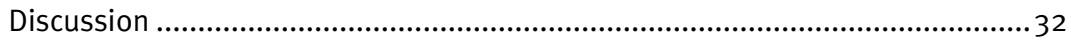

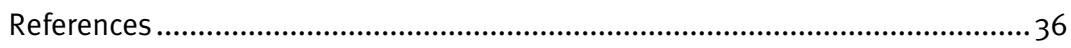

3. Change in sensory functioning predicts change in cognitive functioning ...............39

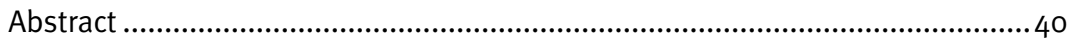

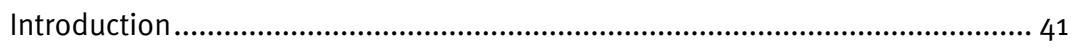

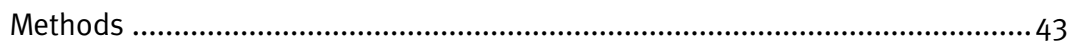

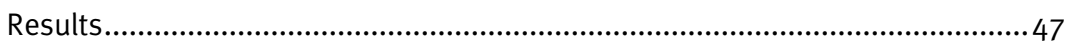

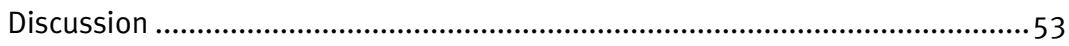

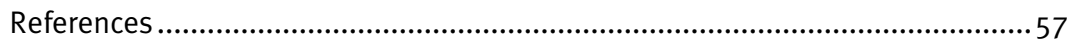

4. The SF-36 as a precursory measure of adaptive functioning in normal aging ....... 61

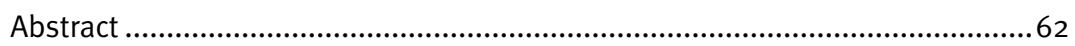

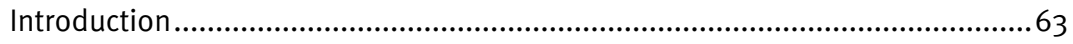

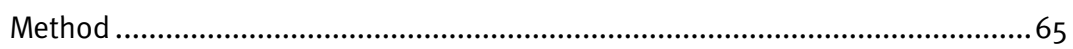

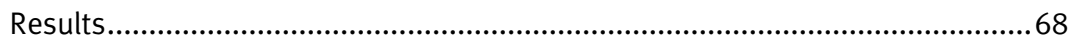

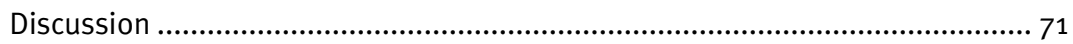

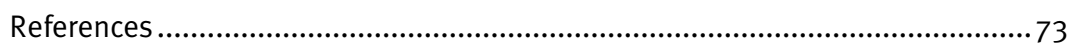

5. The effect of two types of memory training on memory performance ....................75

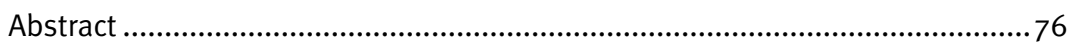

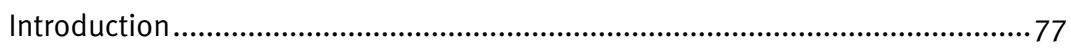

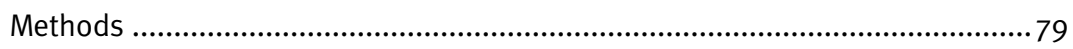

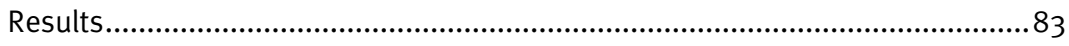

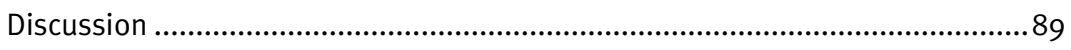

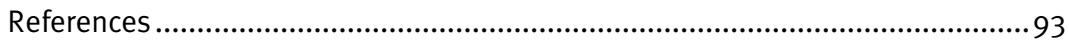

6. Characteristics of participants of a memory training program and predictors of

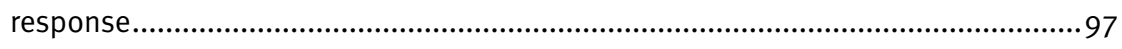

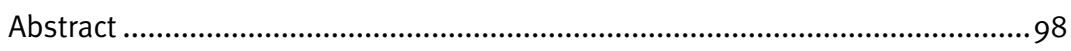

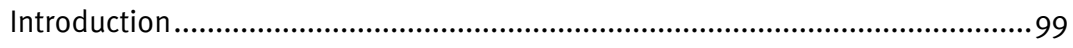

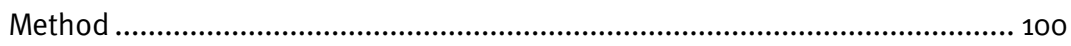

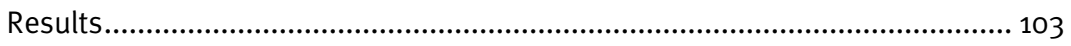

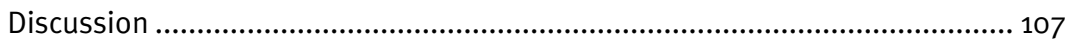

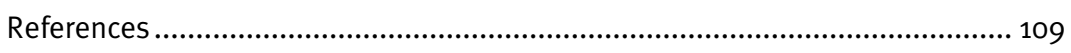


7. The effect of cataract surgery on cognitive functioning in older adults 111

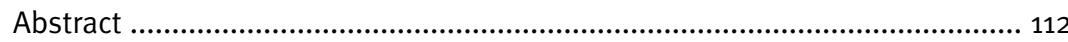

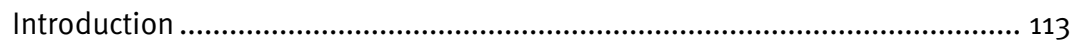

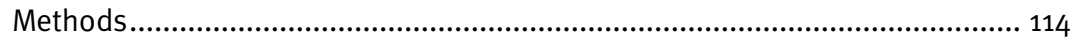

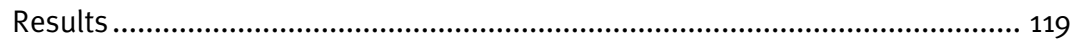

Discussion..................................................................................... 122

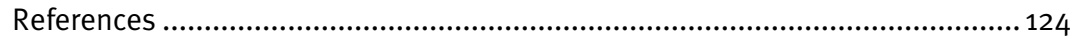

8. The effect of cataract surgery on visual functioning and quality of life ................127

Abstract .................................................................................................. 128

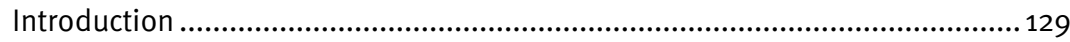

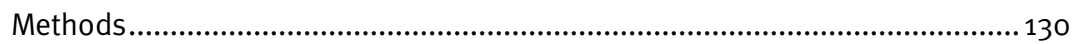

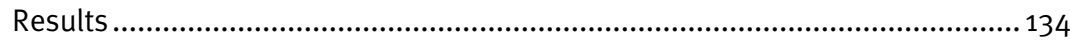

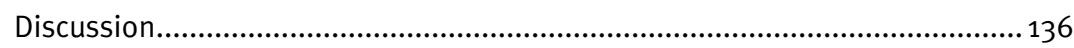

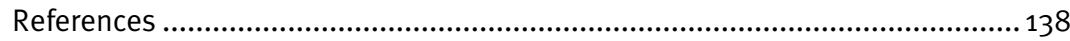

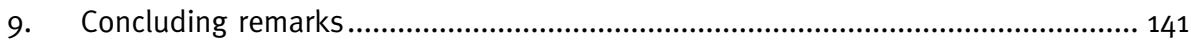

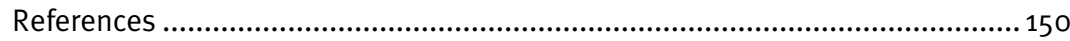

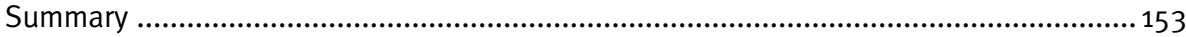

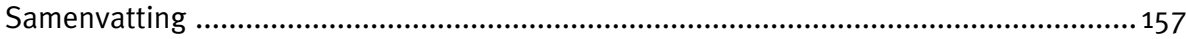

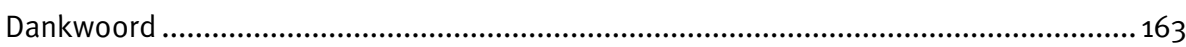

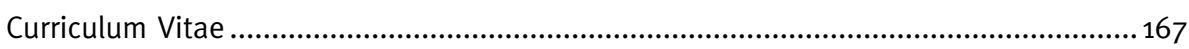




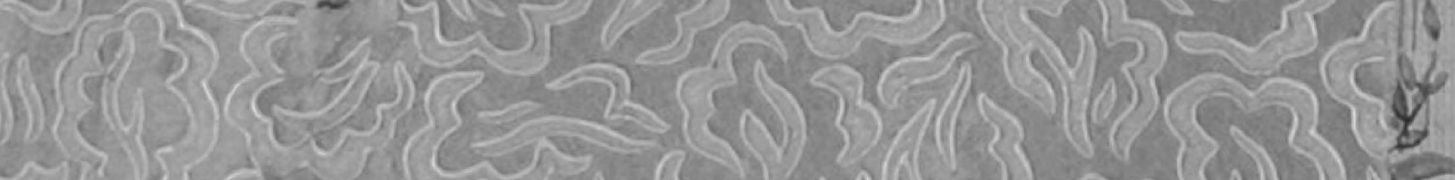

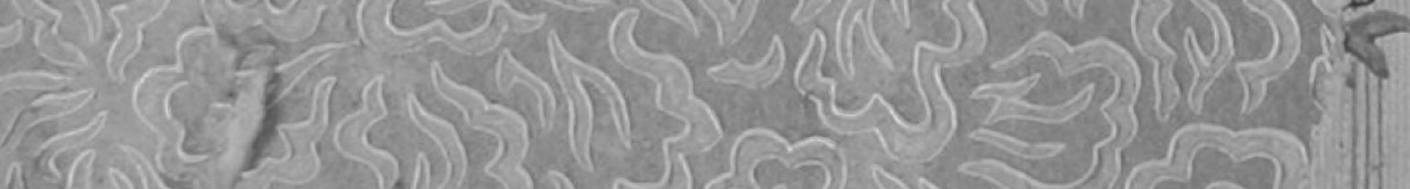
$-5 n$

\section{CHAPTER 1.}

$$
\text { rens? } 20
$$

2. ( ) $>2$ ? Introdugtion

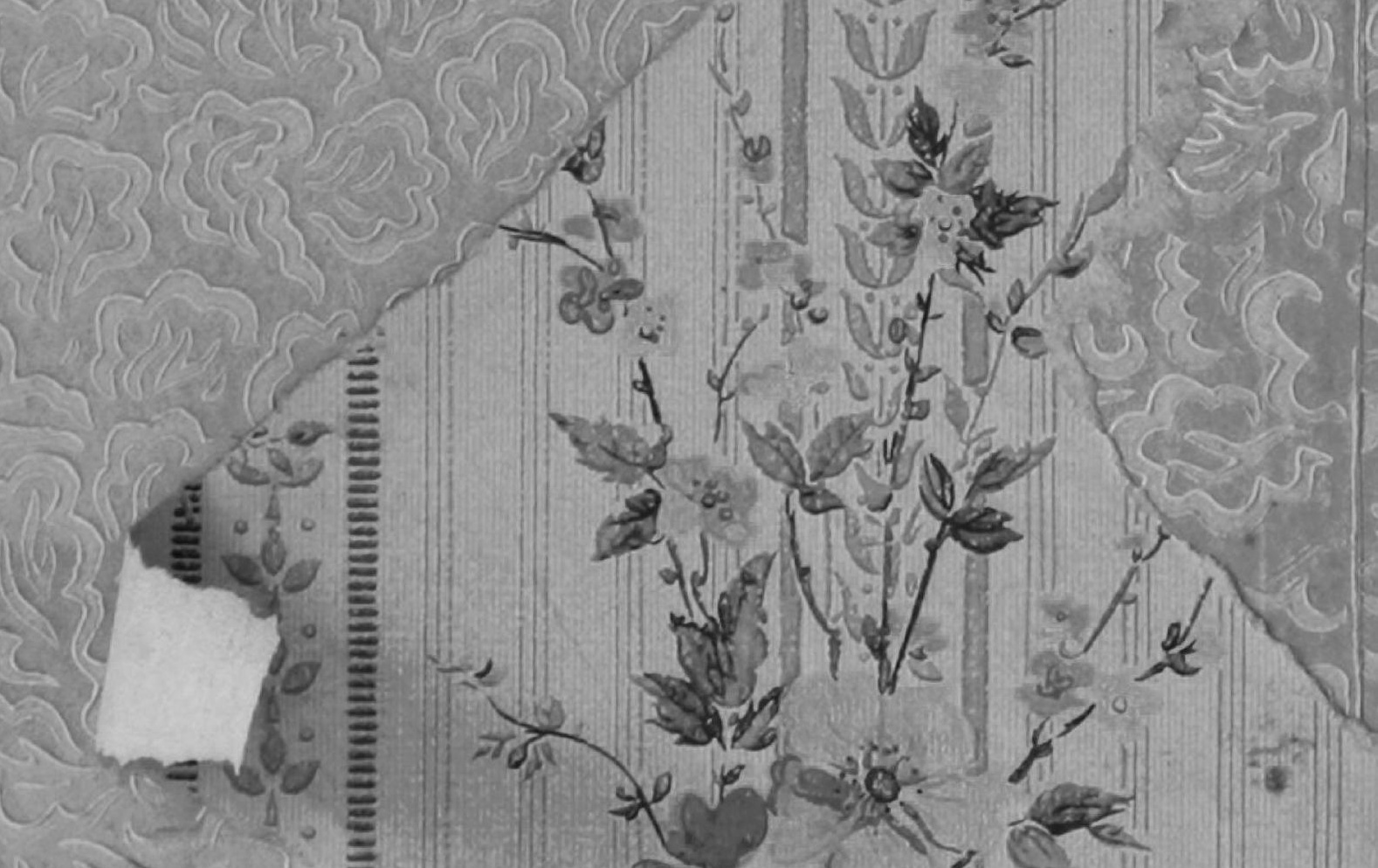


In the last decade the number of individuals in the Netherlands aged 65 years and older increased with more than 200 thousand individuals. Moreover, in addition to the absolute number of older people, the average age of this group is also increasing (Statistics Netherlands). In the recent gerontological research literature, the focus has shifted from the mere extension of life expectancy to increasing quality of life, a notion that is elegantly expressed by the motto 'adding life to years, not just more years to life' (Fries, 1990; Vaillant \& Mukamal, 2001).

According to aging researchers Rowe and Kahn one can clearly distinguish between a pathological aging and a non-pathological, or normal aging process. However, they also emphasize that the group of individuals who age normally is very heterogeneous and that even within the normal aging category a clear distinction should be made between a usual aging process and a successful aging process (Rowe \& Kahn, 1987, 1997, 2000). Their definition of successful aging is multidimensional and includes three important components, namely low probability of disease and disease-related disability, high cognitive and physical functional capacity and active engagement with life. Some authors have characterized successful aging as a concept related to subjective feelings of well-being, positive emotions, and the absence of loneliness (Freund \& Baltes, 1998), whereas others operationalized successful aging as living to an advanced age, functioning independently at home and remaining mentally alert (Roos \& Havens, 1991). These definitions are not always overlapping and do not always correspond to definitions of successful aging used by older individuals themselves (Phelan, Anderson, LaCroix, \& Larson, 2004). This is illustrated by studies that found that older people themselves regarded successful aging to comprise features like interactions with others, a sense of purpose, selfacceptance, personal growth, and autonomy (Fisher, 1995), or considered it to be a process of adaptation, rather than a state of being (von Faber et al., 2001). One of the major concerns that older individuals have with respect to aging is that their mental abilities will deteriorate, with memory complaints being the most prominent feature (Lovelace, 1990). As stated above, Rowe and Kahn already noted that one aspect of successful aging involves cognitive functioning. Cognition is a function of major concern that enables individuals to acquire, process, integrate, learn and retrieve information. It is 
therefore pre-eminently an ability that is important for functioning independently, engaging with others, or functioning autonomously; features that are central in many definitions of 'successful aging'. However, relatively little research has been done on the concept of successful cognitive aging. In recent years, many studies have shown that cognitive functioning declines with advancing age (Jolles et al., 2001; Verhaeghen \& Salthouse, 1997). It is also known, however, that the individual differences in the rate of cognitive decline increase as individuals grow older (Birren \& Schaie, 1996). Exactly these differences indicate that there may be various factors that influence cognitive functioning in old age. If such factors are amenable to intervention this may provide opportunities to bend cognitive aging trajectories of unsuccessful aging individuals towards a more favourable profile.

Therefore, the focus of the present thesis is on finding effective interventions and determinants to promote successful cognitive aging. In the following section the process of cognitive aging, and in particular age-related memory function will be further discussed within a context of possible determinants and interventions that may improve or maintain cognitive functioning in later life. Although objectively measured cognition is the central theme, related topics, such as the subjective evaluation of cognition, quality of life and functional independence will also be addressed. The aims and research methods of the present thesis follow from this discussion.

\section{Cognitive aging and memory}

Cognition is a concept that encompasses many higher order psychological functions and processes. It is known that many aspects of cognitive abilities deteriorate with increasing age. One of the domains that manifest declines as individuals grow older involves memory. Older individuals show increasingly more problems with recalling and recognizing new information (Craik \& Jennings, 1992). In addition, memory is also the cognitive domain that older individuals most often complain and worry about (Commissaris, Verhey, Ponds, Jolles, \& Kok, 1994; Cutler \& Grams, 1988). This is nicely illustrated by reports from the Maastricht Aging Study where it was found that almost 50 percent of individuals aged 50 years and older feel that their memory is getting worse (Ponds, 1998). Recent research shows that memory complaints are not always caused by an actual decline of objective memory, but can be 
influenced by several other factors, including Memory Self-Efficacy (MSE) (Dixon, 1989; Jolles, van Boxtel, Ponds, Metsemakers, \& Houx, 1998; LevyCushman \& Abeles, 1998; Ponds, 1998). MSE is defined as the confidence and/or belief that a person espouses regarding the effectiveness of his or her own memory function in anticipated situations. It would therefore be very well possible that low MSE could weaken motivation to engage in memory tasks or undermine performance on a given task (Cavanaugh, 1996). In other words, low MSE could be an underlying factor that precipitates avoidance of cognitively challenging tasks (Berry, 1999). According to the definition of Rowe and Kahn (1997), active engagement with life is an important prerequisite for successful aging and recent studies have shown that engagement in cognitively challenging activities may serve as a buffer against cognitive decline in old age (Coyle, 2003; Hultsch, Hertzog, Small, \& Dixon, 1999; Verghese et al., 2003). This makes it important to examine how individuals behave based on their MSE and what may be possible consequences of these judgments on performance outcomes. Moreover, if memory complaints are indeed determined by psychological factors such as MSE, this should be given considerable attention when designing interventions aimed at improving memory function. Interestingly, little research has been performed on memory interventions with a focus on enhancing MSE (Floyd \& Scogin, 1997).

\section{Sensory function and cognition}

With respect to other variables that may affect cognition, recent studies have strongly stressed the robust negative association between sensory function and cognitive abilities (Anstey, Luszcz, \& Sanchez, 2001; Lindenberger, Scherer, \& Baltes, 2001). Several possible explanations for this relationship have been put forward, such as the 'sensory deprivation' hypothesis which states that a lack of adequate sensory input will result in cognitive deterioration due to neuronal atrophy (Lindenberger \& Baltes, 1994; Sekuler \& Blake, 1987), or the 'common cause' hypothesis that assumes the association between sensory function and cognition is confounded by a third common factor which is involved in central nervous system efficiency (Anstey, Lord, \& Williams, 1997; Christensen, Mackinnon, Korten, \& Jorm, 2001; Lindenberger \& Baltes, 1994). However, up until now, only few prospective 
studies have investigated the predictive value of sensory impairment on subsequent cognitive functioning. With respect to visual function, one of the most common problems in old age is senile cataract. Cataract can seriously compromise visual acuity and contrast sensitivity and without adequate treatment will ultimately result in blindness (Steinberg et al., 1994). In cataract surgery the opaque lens is replaced by an artificial lens, which is a highly effective treatment with a very low rate of complications (Powe et al., 1994). Because visual function plays an important role in cognitive aging and related quality of life (for example: Lindenberger \& Baltes, 1994; Wallhagen, Strawbridge, Shema, Kurata, \& Kaplan, 2001) it is of importance to evaluate the possible effect of surgical correction of cataract on both cognition and quality of life of older individuals.

\section{Functional independence}

In addition to examining factors that can influence cognitive performance and quality of life, a final related topic involves functional independence. This can be described as an individual's capability to negotiate self-care and domestic tasks essential in everyday life, which is germane to the concept of successful aging. If it is possible to identify individual characteristics as possible predictors of disablement at an early stage, this could provide valuable information, which can be used to shape future intervention programs. However, most measures of independent functioning discriminate only between individuals who explicitly express the need for assistance in performing activities and people who do not (Reuben, Valle, Hays, \& Siu, 1995). There is therefore a need for a screening instrument that is sufficiently sensitive to detect small changes in individuals' capability to perform an everyday task.

\section{Aims of the thesis}

The objective of the present thesis is twofold; the first aim is to identify determinants of successful cognitive aging and the second is to examine intervention strategies that may have a positive effect on cognition, and in particular on memory. The first objective will be addressed by examining the predictive value of MSE and sensory function on cognitive performance, more specifically verbal memory function. In addition, it will be investigated 
whether a measure of general health is a suitable instrument to predict change in individuals' capabilities to function independently.

The second aim of the thesis will be addressed by examining the effects of a memory intervention with a strong focus on the enhancement of MSE. Furthermore, a study will be conducted into the effect of improving visual function by means of cataract surgery on cognitive functioning and quality of life.

\section{Approach}

This study is part of a larger research program, funded by the Dutch Research Council (NWO), called 'Successful aging, cognitive aging, and experimental intervention studies related to the Maastricht Aging Study (MAAS). A complementary thesis by Susan van Hooren*, which is also part of this research program, addresses successful cognitive aging as well. However, the focus of this complementary thesis is on executive functioning and auditory function.

The MAAS is a longitudinal investigation on the determinants and consequences of pathological and successful aging with respect to cognitive functioning. The study covers the whole adult life span in a large sample of Dutch individuals (Jolles, Houx, van Boxtel, \& Ponds, 1995). The MAAS has a long history on cognitive aging research and because of its multidisciplinary design many biological, social and psychological factors associated with cognition have been identified and systematically studied, including mental stimulation (Bosma et al., 2003), vascular risk factors (van Boxtel et al., 1998), health (Houx, Vreeling, \& Jolles, 1991), and depression (Den Hartog, Derix, Van Bemmel, Kremer, \& Jolles, 2003).

This approach offers the opportunity to answer our research questions from two different perspectives, i.e. by studying potential determinants of successful aging in both longitudinal observational studies and randomised controlled experiments. Moreover, care was taken to avoid methodological drawbacks apparent in earlier intervention studies, such as a small sample (Rasmusson, Rebok, Bylsma, \& Brandt, 1999; Rebok, Rasmusson, Bylsma, \& Brandt, 1997), the absence of a control group (Caprio-Prevette \& Fry, 1996;

\footnotetext{
* Successful Cognitive Aging: Executive functioning, determinants, and interventions. Susan A.H. van Hooren. Thesis
} 
Mamidipudi, Vasavada, Merchant, Namboodiri, \& Ravilla, 2003; Mangione et al., 1994), a short follow-up duration (Andrewes, Kinsella, \& Murphy, 1996; Dellefield \& McDougall, 1996), the use of evaluation measurements with a strong resemblance to the material used in the intervention (Brooks, Friedman, Pearman, Gray, \& Yesavage, 1999), and the use of cross-sectional retrospective designs (He et al., 1999; Lau, Michon, Chan, \& Ellwein, 2002).

\section{Outline of the thesis}

This thesis is divided in two parts. Part 1 addresses the studies on potential determinants of successful aging, using longitudinal data from the MAAS and in part 2 several intervention studies, which are part of the successful aging program, will be described.

\section{Part 1: Determinants}

In Chapter 2 we examined if MSE measured at baseline can predict objective memory performance 6 years later. This was done using data from MAAS on a large group of healthy older individuals.

In Chapter 3 we investigated not only the relationship between sensory function and a broad range of cognitive functions after a 6-years follow-up, but also whether natural spontaneously occurring (self-initiated) interventions that may improve sensory function, i.e. vision or hearing, can affect cognition. This study was again conducted with data from the MAAS.

Finally, in Chapter 4, the predictive value of a general measure of quality of life (the MOS 36-item Short-Form Health Survey (SF-36)) on functional independence was explored (Zee, Xanderman, \& Heyink, 1993). In the MAAS population it was investigated whether this particular instrument is predictive of changes in peoples need for assistance in daily life activities.

\section{Part 2: Intervention studies}

In Chapter 5, a training program aimed at improving both objective memory function as well as MSE is described and evaluated. In this program a key element is explaining how MSE works in relation to everyday memory performance. In addition, memory skills are trained by teaching the participants internal and external memory strategies. This memory program 
was offered as a group-training program, and as an individual self-taught training program, in which the participants study independently a memory handbook.

In addition, we were interested in specific characteristics of individuals who participated in this memory-training program and they were therefore compared with healthy older individuals enrolled in the MAAS. More specifically, we examined if memory-training participants differed from healthy MAAS participants with respect to personality (neuroticism) and mood (anxiety, depression). Furthermore, it was investigated whether these variables were able to predict which individuals will benefit most from the memory intervention program (Chapter 6).

Chapters 7 and 8 describe a controlled study into the effects of cataract surgery by comparing two groups of individuals, namely, patients who underwent cataract surgery, and cataract patients in a waiting list control group. The outcome measures of interest were a broad range of cognitive abilities (Chapter 7) and both vision related and general quality of life (Chapter 8).

Finally, in Chapter 9 the results of the experimental studies will be integrated and discussed with respect to the implications, methodology and future research. 


\section{References}

Andrewes, D. G., Kinsella, G., \& Murphy, M. (1996). Using a memory handbook to improve everyday memory in community-based older adults with memory complaints. Experimental Aging Research, 22, 305-322.

Anstey, K. J., Lord, S. R., \& Williams, P. (1997). Strength in the lower limbs, visual contrast sensitivity, and simple reaction time predict cognition in older women. Psychology and Aging, 12(1), 137-144.

Anstey, K. J., Luszcz, M. A., \& Sanchez, L. (2001). Two-year decline in vision but not hearing is associated with memory decline in very old adults in a population-based sample. Gerontology, 47(5), 289-293.

Berry, J. M. (1999). Memory self-efficacy in its social cognitive context. In T. H. Hess \& F. Blanchard-Fields (Eds.), Social cognition and aging (pp. 70-96). San Diego: Academic Press.

Birren, J. E., \& Schaie, K. W. E. (1996). Handbook of the psychology of aging (4 ed.). San Diego: Academic Press.

Bosma, H., van Boxtel, M. P., Ponds, R. W., Houx, P. J., Burdorf, A., \& Jolles, J. (2003). Mental work demands protect against cognitive impairment: MAAS prospective cohort study. Experimental Aging Research, 29(1), 33-45.

Brooks, J. 0., 3rd, Friedman, L., Pearman, A. M., Gray, C., \& Yesavage, J. A. (1999). Mnemonic training in older adults: effects of age, length of training, and type of cognitive pretraining. International Psychogeriatrics, 11(1), 75-84.

Caprio-Prevette, M. D., \& Fry, P. S. (1996). Memory enhancement program for community-based older adults: Development and evaluation. Experimental Aging Research, 22, 281-303.

Cavanaugh, J. C. (1996). Memory self-efficacy as a moderator of memory change. In F. Blanchard-Fields \& T. H. Hess (Eds.), Perspectives on Cognitive Change in Adulthood and Aging (pp. 488-507). New York: The McGraw-Hill Compagnies.

Christensen, H., Mackinnon, A. J., Korten, A., \& Jorm, A. F. (2001). The "common cause hypothesis" of cognitive aging: evidence for not only a common factor but also specific associations of age with vision and grip strength in a cross-sectional analysis. Psychology and Aging, 16(4), 588-599.

Commissaris, C. J. A. M., Verhey, F. R. J., Ponds, R. W. H. M., Jolles, J., \& Kok, G. J. (1994). Public education about normal forgetfulness and dementia: importance and effects. Patient Education and Counseling, 24, 109-115.

Coyle, J. T. (2003). Use it or lose it--do effortful mental activities protect against dementia? New England Journal of Medicine, 348(25), 2489-2490.

Craik, F. I. M., \& Jennings, J. M. (1992). Human memory. In F. I. M. Craik \& T. A. Salthouse (Eds.), Handbook of aging and cognition (pp. 51-110). Hillsdale: Lawrence Erlbaum.

Cutler, S. J., \& Grams, A. E. (1988). Correlates of self-reported everyday memory problems. Journal of Gerontology: Social Sciences, 43(3), 82-90.

Dellefield, K. S., \& McDougall, G. J. (1996). Increasing metamemory in older adults. Nursing Research, 45, 284-290.

Den Hartog, H. M., Derix, M. M., Van Bemmel, A. L., Kremer, B., \& Jolles, J. (2003). Cognitive functioning in young and middle-aged unmedicated out-patients with major depression: testing the effort and cognitive speed hypotheses. Psychological Medicine., 33(8), 1443-1451.

Dixon, R. A. (1989). Questionnaire research on metamemory and aging: issues of structure and function. In L. W. Poon, D. C. Rubin \& B. A. Wilson (Eds.), Everyday cognition in adulthood and late life (pp. 394-415). Cambridge: Cambridge University Press.

Fisher, B. J. (1995). Successful aging, life satisfaction, and generativity in later life. International Journal of Aging \& Human Development, 41(3), 239-250. 


\section{CHAPTER 1. INTRODUCTION}

Floyd, M., \& Scogin, F. (1997). Effects of memory training on the subjective memory functioning and mental health of older adults: a meta-analysis. Psychology and Aging, 12(1), 150-161.

Freund, A. M., \& Baltes, P. B. (1998). Selection, optimization, and compensation as strategies of life management: correlations with subjective indicators of successful aging [published erratum appears in Psychology and Aging 1999 Dec;14(4):700-2]. Psychology and Aging, 13(4), 531-543.

Fries, J. F. (1990). Medical perspectives upon successful aging. In P. B. Baltes \& M. M. Baltes (Eds.), Successful aging: Perspectives from the behavioral sciences (pp. 35-49). Cambridge: Cambridge University Press.

He, M., Xu, J., Li, S., Wu, K., Munoz, S. R., \& Ellwein, L. B. (1999). Visual acuity and quality of life in patients with cataract in Doumen County, China. Ophthalmology, 106(8), 1609-1615.

Houx, P. J., Vreeling, F. W., \& Jolles, J. (1991). Rigorous health screening reduces age effect on memory scanning task. Brain and Cognition, 15(2), 246-260.

Hultsch, D. F., Hertzog, C., Small, B. J., \& Dixon, R. A. (1999). Use it or lose it: engaged lifestyle as a buffer of cognitive decline in aging? Psychology and Aging, 14(2), 245-263.

Jolles, J., Commissaris, C. J. A. M., Bosma, H., van Boxtel, M. P. J., Ponds, R. W. H. M., Metsemakers, J. F. M., et al. (2001). De Maastricht Aging Study en het longitudinale perspectief van cognitieve veroudering. In A. H. Schene, F. Boer, T. J. Heeren, H. W. J. Henselmans, R. W. Trijsburg, W. Vandereycken \& K. van der Velden (Eds.), Jaarboek voor Psychiatrie en Psychotherapie (Vol. 7, pp. 175-193). Houten/Giegem: Bohn Stafleu Van Loghum.

Jolles, J., Houx, P. J., van Boxtel, M. P. J., \& Ponds, R. W. H. M. (Eds.). (1995). Maastricht Aging Study: Determinants of cognitive aging. Maastricht: Neuropsych Publishers.

Jolles, J., van Boxtel, M. P., Ponds, R. W., Metsemakers, J. F., \& Houx, P. J. (1998). [The Maastricht aging study (MAAS). The longitudinal perspective of cognitive aging]. Tijdschrift voor Gerontologie en Geriatrie, 29(3), 120129.

Lau, J., Michon, J. J., Chan, W. S., \& Ellwein, L. B. (2002). Visual acuity and quality of life outcomes in cataract surgery patients in Hong Kong. The British Journal of Ophthalmology, 86(1), 12-17.

Levy-Cushman, J., \& Abeles, N. (1998). Memory complaints in the able elderly. Clinical Gerontologist, 19, 3-24.

Lindenberger, U., \& Baltes, P. B. (1994). Sensory functioning and intelligence in old age: a strong connection. Psychology and Aging, 9(3), 339-355.

Lindenberger, U., Scherer, H., \& Baltes, P. B. (2001). The strong connection between sensory and cognitive performance in old age: not due to sensory acuity reductions operating during cognitive assessment. Psycholgy and Aging, 16(2), 196-205.

Lovelace, E. A. (1990). Aging and metacognitions concerning memory function. In E. A. Lovelace (Ed.), Aging and cognition: mental processes, self awareness and interventions (pp. 157-188). Amsterdam, the Netherlands: Elsevier Science.

Mamidipudi, P. R., Vasavada, A. R., Merchant, S. V., Namboodiri, V., \& Ravilla, T. D. (2003). Quality-of-life and visual function assessment after phacoemulsification in an urban indian population. Journal of Cataract and Refractive Surgery, 29(6), 1143-1151.

Mangione, C. M., Phillips, R. S., Lawrence, M. G., Seddon, J. M., Orav, E. J., \& Goldman, L. (1994). Improved visual function and attenuation of declines in health-related quality of life after cataract extraction. Archives of Ophthalmology, 112(11), 1419-1425. 
Phelan, E. A., Anderson, L. A., LaCroix, A. Z., \& Larson, E. B. (2004). Older adults' views of "successful aging"--how do they compare with researchers' definitions? Journal of the American Geriatrics Society, 52(2), 211-216.

Ponds, R. W. H. M. (1998). Forgetfulness and cognitive aging: Prevalence, characteristics, and determinants (Thesis). Maastricht University.

Powe, N. R., Schein, 0. D., Gieser, S. C., Tielsch, J. M., Luthra, R., Javitt, J., et al. (1994). Synthesis of the literature on visual acuity and complications following cataract extraction with intraocular lens implantation. Cataract Patient Outcome Research Team. Archives of Ophthalmology, 112(2), 239-252.

Rasmusson, D. X., Rebok, G. W., Bylsma, F. W., \& Brandt, J. (1999). Effects of three types of memory training in normal elderly. Aging, Neuropsychology, and Cognition, 6, 56-66.

Rebok, G. W., Rasmusson, D. X., Bylsma, F. W., \& Brandt, J. (1997). Memory improvement tapes: How effective for elderly adults? Aging, Neuropsychology, and Cognition, 4, 304-311.

Reuben, D. B., Valle, L. A., Hays, R. D., \& Siu, A. L. (1995). Measuring physical function in community-dwelling older persons: A comparison of self-administered, interviewer-administered, and performance-based measures. Journal of the American Geriatrics Society, 43(17-23).

Roos, N. P., \& Havens, B. (1991). Predictors of successful aging: a twelve-year study of Manitoba elderly. American Journal of Public Health, 81(1), 63-68.

Rowe, J. W., \& Kahn, R. L. (1987). Human aging: usual and successful. Science, 237(4811), 143-149.

Rowe, J. W., \& Kahn, R. L. (1997). Successful aging [see comments]. Gerontologist, 37(4), 433-440.

Rowe, J. W., \& Kahn, R. L. (2000). Successful aging and disease prevention. Advances in Renal Replacement Therapy, 7(1), 70-77.

Sekuler, R., \& Blake, R. (1987). Sensory underload. Psychology Today, 21, 48-51.

Steinberg, E. P., Tielsch, J. M., Schein, O. D., Javitt, J. C., Sharkey, P., Cassard, S. D., et al. (1994). The VF-14. An index of functional impairment in patients with cataract. Archives of Ophthalmology, 112(5), 630-638.

Vaillant, G. E., \& Mukamal, K. (2001). Successful aging. The American Journal of Psychiatry, 158(6), 839-847.

Van Boxtel, M. P., Gaillard, C., Houx, P. J., Buntinx, F., de Leeuw, P. W., \& Jolles, J. (1998). Is nondipping in $24 \mathrm{~h}$ ambulatory blood pressure related to cognitive dysfunction? Journal of Hypertension, 16(10), 1425-1432.

Verghese, J., Lipton, R. B., Katz, M. J., Hall, C. B., Derby, C. A., Kuslansky, G., et al. (2003). Leisure activities and the risk of dementia in the elderly. The New England Journal of Medicine, 348(25), 2508-2516.

Verhaeghen, P., \& Salthouse, T. A. (1997). Meta-analyses of age-cognition relations in adulthood: estimates of linear and nonlinear age effects and structural models. Psychological Bulletin, 122(3), 231-249.

Von Faber, M., Bootsma-van der Wiel, A., van Exel, E., Gussekloo, J., Lagaay, A. M., van Dongen, E., et al. (2001). Successful aging in the oldest old: Who can be characterized as successfully aged? Archives of Internal Medicine, 161(22), 2694-2700.

Wallhagen, M. I., Strawbridge, W. J., Shema, S. J., Kurata, J., \& Kaplan, G. A. (2001). Comparative impact of hearing and vision impairment on subsequent functioning. Journal of the American Geriatrics Society, 49(8), 1086-1092

Zee, K. I. v. d., Xanderman, R., \& Heyink, J. (1993). psychometrische kwaliteiten van de MOS 36-item Short Form Health Survey (SF-36) in een Nederlandse populaties. .T. v. Sociale Gezondheidzorg, 71, 183-191. 
CHAPTER 1. INTRODUCTION 


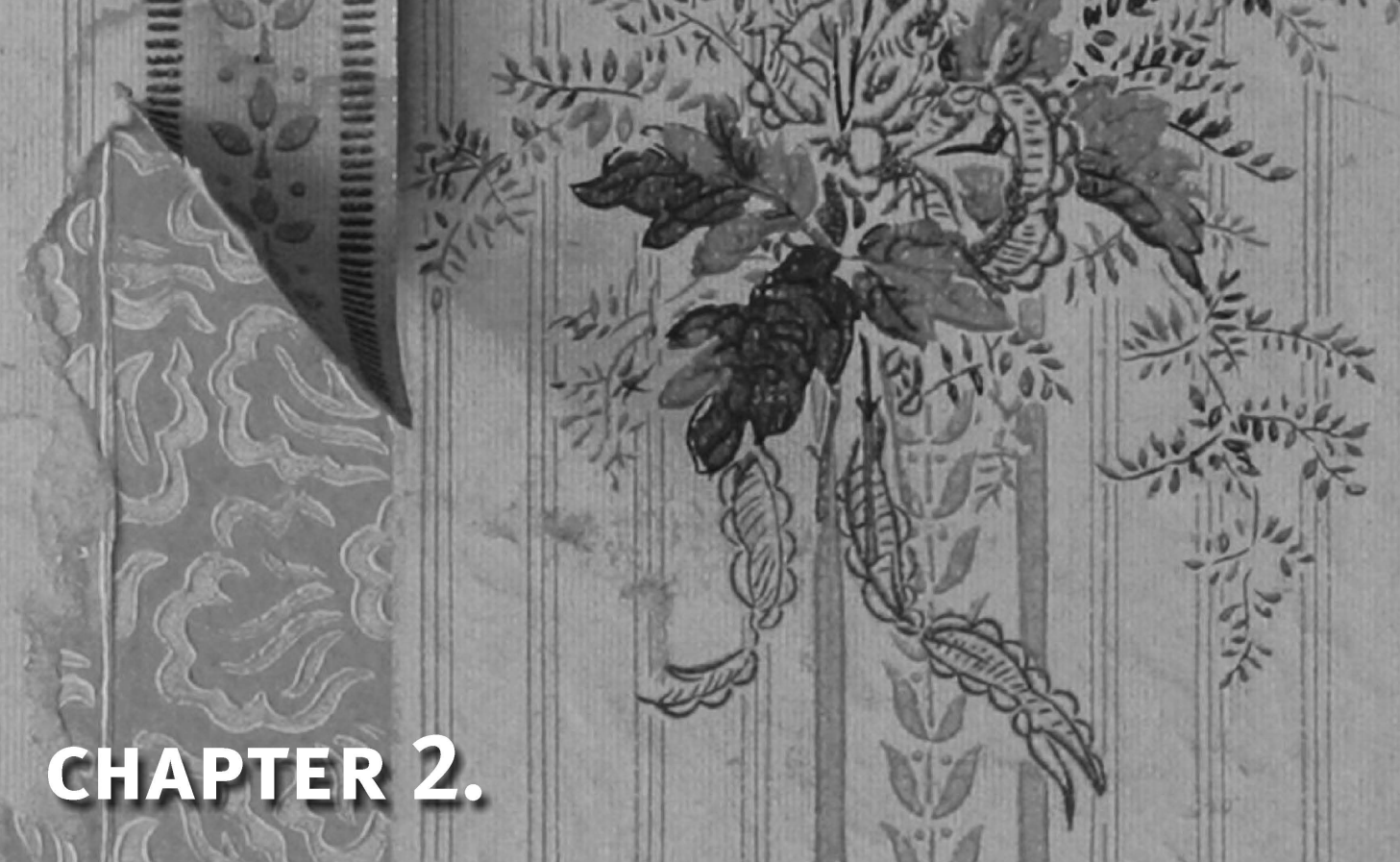

E Memony selfiefficasy

\section{predifats memory} performance
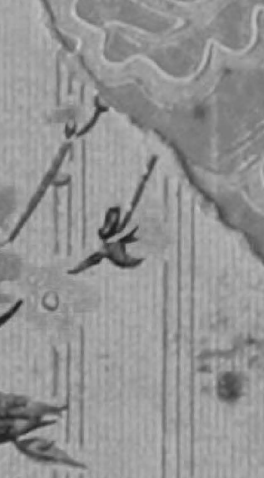


\section{Abstract}

The purpose of this study was to examine the relationship between memory self-efficacy (MSE) and a 6-year follow-up assessment of memory functioning in a sample of Dutch older adults. MSE was assessed by a Dutch abridged version of the Metamemory in Adulthood questionnaire (MIA). The total MSE score predicted memory performance at six years, as measured by the Visual Verbal Learning Task (VVLT). A separate analysis of the different MSE subscales indicated that the MIA Change score was the most salient feature of MSE. An extreme group analysis of the MIA Change score revealed a pattern of performance for those who perceived that their memory was deteriorating, improving less at 6 years across the three trials of the VVLT. 


\section{Introduction}

Metamemory is a latent construct that has emerged from the early developmental literature to describe the knowledge, perceptions and beliefs individuals have about their own memory and the systemic function their memory in more general terms (Hultsch, Hertzog, Dixon, \& Davidson, 1988). A specific dimension of metamemory that is relevant to everyday memory functioning in old age is Memory Self-Efficacy (MSE), defined as the confidence and/or belief that a person espouses regarding the effectiveness of his or her own memory function in anticipated situations (Cavanaugh, 1996).

As an extension of self-efficacy theory, MSE involves efficacy judgments that individuals make about their own memory ability in future situations. Self-efficacy theory posits that efficacy judgments are often based on multiple sources of environmental input, including mastery experiences of previous performance tasks, vicarious observation of a relevant reference group, social persuasion, and physiological information such as arousal or anxiety (Bandura, 1977, 1989; Berry, 1999). With respect to older adults, it could be assumed that low efficacy ratings of successful memory functioning could weaken motivation to engage in memory tasks or undermine performance on a given task. Such behavior could generate substantial anticipatory anxiety, particularly if the memory task is judged as essential for everyday living. In other words, low MSE could be an underlying factor that precipitates avoidance of cognitively challenging situations, or the reliance on inefficient strategies on everyday memory tasks (Berry, 1999).

Active engagement in situations that require memory proficiency is an important prerequisite for successful aging. Recent efforts to elucidate the relationship between engagement in cognitively challenging activities and mental functioning have shown that active engagement may serve as a buffer against premature cognitive decline in old age (Coyle, 2003; Hultsch, Hertzog, Small, \& Dixon, 1999; Verghese et al., 2003). It is therefore important to examine more focal dimensions of MSE that should be associated not only with how individuals behave based on MSE, but with the possible consequences on performance outcomes.

With respect to the linkage between MSE and objective memory performance, previous cross-sectional (Cavanaugh \& Poon, 1989; Fisk \& 
Warr, 1996; Hertzog, Dixon, \& Hultsch, 1990; Luszcz, 1993; Seeman, Rodin, \& Albert, 1993) and longitudinal (Albert et al., 1995) studies have identified an association between measures of self-efficacy and performance on a range of cognitive tasks. For example, in a longitudinal study of high functioning older people from the MacArthur Studies of Successful Aging, it was demonstrated that positive efficacy beliefs predicted better verbal memory performance in men at a 2.5-year follow-up. However, in this study, no associations were found for women or in other domains of cognitive function (Seeman, McAvay, Merrill, Albert, \& Rodin, 1996). Self-efficacy was operationalized in this study as a generic versus a domain-specific construct. However, consistent with self-efficacy theory, domain-specific measures are better predictors of behavioral outcomes with respect to cognitive performance, particularly when the outcome matches the domain (Bandura, 1989; Bandura, Adams, Hardy, \& Howells, 1980; Berry \& West, 1993; Welch \& West, 1995). It is arguable, therefore, that the association between MSE and memory functioning should be the strongest when the MSE construct is specific to the targeted memory task. To this end, Hertzog et al. (1989) found that in their measure of MSE, the Metamemory in Adulthood Questionnaire (Dixon, Hultsch, \& Hertzog, 1988) three domain-specific factors were present, namely (a) beliefs about one's current level of memory ability (Capacity) and (b) beliefs about change in one's memory ability from early adulthood (Change) and (c) perceived anxiety in relation to memory (Anxiety). Hertzog et al. (1989) also noted that the MSE capacity domain had the strongest factor loading in relation to the overall MSE score, although no attempt was made in this validation study to empirically test the differential associations among these component domains of MSE and objective memory performance.

The goal of the current study, therefore, was to examine the relationship between domain-specific measures of MSE as defined through the Capacity, Change, and Anxiety subscores of the MIA, and their relationship to a 6-year follow-up measure of episodic memory functioning in a sample of relatively healthy older Dutch adults. It was specifically hypothesized that in this sample not only would a general measure of MSE predict overall memory functioning after six years, but that with respect to its component dimensions, a measure reflective of one's perceived MSE for change in memory functioning over time would be a particularly salient 
predictor of objective change in one's memory performance in contrast to other less related domains (e.g., the MIA Capacity or Anxiety subscales). In this respect, the Change scale is not only a representation of perceived change in memory functioning, but also a sense of how one will perform in future situations, derived from past experiences. In addition, it was postulated that those individuals who reported negative self-efficacy judgments for change in their memory at a later point in time, would be less proficient in the actual retrieval of stimulus material from a memory task administered at a six-year follow-up interval than those with more positive MSE ratings for change per se.

In the present investigation, data were obtained from the Maastricht Aging Study (MAAS), a longitudinal study of normal aging in a large sample of Dutch individuals across the adult life span (Jolles, Houx, van Boxtel, \& Ponds, 1995; Van Boxtel et al., 1998). A specific goal of the MAAS was to assess relationships among psychological constructs, such as metamemory, and objective indices of memory performance. In a cross sectional panel of MAAS participants, Ponds et al. (1996) validated a Dutch abridged version of the MIA. In brief, they found that the number of individual MIA items could be reduced by 34 percent, without disturbing its factor structure. In other words, this shortened Dutch MIA matched the factorial organization of the English-language questionnaire, including preservation of the domain scores that measured MSE, namely the Capacity, Anxiety and Change subscales. Therefore, in addition to examining MSE as a single construct, the current study employed the specific Dutch MIA subscales to assess the extent to which domain-specific MSE ratings could predict objective memory performance after six years.

\section{Method}

\section{Participants}

Participants were those persons 55 years and older from the Maastricht Aging Study (MAAS), a longitudinal investigation on the determinants and consequences of pathological and successful aging with respect to cognitive functioning. The 1823 individuals who initially enrolled in the baseline period of the MAAS were selected from a register of 15 family practices in the South 
of the Netherlands and were between 24 and 81 years old (Metsemakers, Höppener, Knottnerus, Kocken, \& Limonard, 1992). Participants were at the point of inclusion without medical conditions known to interfere with normal cognitive functioning. Exclusion criteria were overt cerebrovascular disease, chronic neurological pathology, mental retardation, and major psychiatric disorders. All participants had a score of 24 or more on the Mini-Mental State Examination (MMSE; (Folstein, Folstein, \& McHugh, 1975). The study population was stratified for age group, sex, and general ability. More details on the study population can be found elsewhere (Bosma et al., 2003; Jolles et al., 1995; Van Boxtel et al., 1998). Of interest in the current investigation was a follow-up assessment that occurred six years later for all persons enrolled in the MAAS at baseline. In this instance, baseline participants were contacted and again invited to participate in a follow-up neuropsychological examination. As a result of refusal (274), death (116), loss to follow-up (37), medical exclusion (15), or other reasons (5), 1376 persons were actually examined. In the present study, analyses were based on the subset of 557 individuals who were aged 55 years and older, with a mean age of 66.09 years ( $S D=6.89$ years, range 55 to 82 ). Of this sample, 284 individuals were men $(50.99 \%)$, with a mean level of education, based on the Dutch educational system that ranges from $1=$ primary education to $8=$ university education, of 3.01 ( $S D=1.77$ ). This score is comparable to 10 years of age (De Bie, 1987). Participants rated themselves as healthy based on a 1 to 5 rating of perceived health, $1=$ very poor health to $5=$ very good health ( $M$ =3.70; SD =0.63). It should also be noted that the sample was cognitively intact as demonstrated by the fact that 57 percent of the participants had MMSE scores of 28 or higher $(M=27.9$; $S D=1.76)$.

\section{Measures}

The Visual Verbal Learning Test (VVLT; (Brand \& Jolles, 1985)) is a verbal memory task designed to measure the ability to learn new verbal information and to retrieve this information from memory. Fifteen low-associative words are presented to the participant five times in subsequent fashion. After each presentation the subject is asked to recall as many words as possible, with no restriction on the order of recall (immediate recall). No feedback was provided and participants were required to recall all 15 words at each trial. 
Because of possible ceiling effects, in the present study the scores of the first three trials were used as the estimation of maximal learning and were summed to produce an immediate VVLT recall score, the maximum of which after three successive trials is 45 . Twenty minutes after the last presentation the subject is again requested to recall as many correct words as possible (the delayed recall trial). Because of the serial re-presentation interval, the VVLT has been used as a measure of memory consolidation.

The Dutch abridged Metamemory in Adulthood questionnaire (MIA; (Dixon et al., 1988; Hertzog, Hultsch, \& Dixon, 1989; Ponds \& Jolles, 1996) consists of eight subscales (Task, Capacity, Change, Anxiety, Achievement, Locus, Strategy-external, and Strategy-internal). With respect to the response format of the MIA, participants rate self-statements on a 5 -point Likert scale ( $1=$ strongly agree, 2 = agree, $3=$ undecided, 4 = disagree, 5 = strongly disagree). Three subscales isolate a self-efficacy factor; namely, Capacity, Change, and Anxiety (Hertzog et al., 1989). These three subscales were employed to define the construct Memory Self-Efficacy (MSE). Higher MIA MSE scores indicate higher self-efficacy ratings for memory (range 1 to 5). Specifically, the Capacity scale consists of 12 items and higher scores on this subscale indicate greater perceived memory capacity (e.g. 'I am good at remembering birthdays'). The Change scale consists of 10 items with higher scores indicating less perceived decline (or more stability) in memory functioning (e.g. 'I am less efficient at remembering things now than I used to be'). The MIA Anxiety scale includes 12 items reflecting of feelings of anxiety and/or stress about one's memory functioning (e.g. 'I get anxious when I am asked to remember something'). Higher scores indicate more feelings of anxiety and/or stress.

In addition to obtaining specific demographic information from all participants; namely, age, sex, and educational attainment, the remaining measures that were used in this study included the Mini-Mental State Examination (MMSE; (Folstein et al., 1975) that was employed primarily as a screening instrument for cognitive dysfunction and/or the presence of dementia symptomatology. Self-rated health on a 5-point scale ranging from very poor (1) to very good (5) was also obtained in addition to scores from the depression subscale of the Symptom Checklist-90 (SCL-90; (Derogatis, 1977). 


\section{Procedure}

The outcome variables were obtained from a neuropsychological test battery that included the VVLT. On average, completion of the entire test session required 2.5 hours, with a rest period of 20 minutes. All participants were tested in a standardized context located in a neuropsychological test laboratory of the University Hospital Maastricht. All tests were administered by trained assistants under supervision of licensed neuropsychologists who were members of the project staff. The MIA questionnaire was mailed to each participant who completed it at home.

\section{Results}

The zero-order correlations among the MIA scores and its respective subscales are summarized in Table 1 . As has been reported in previous studies, these scores were highly interrelated, with zero-order correlations ranging from 0.21 to $0.88, p<0.05$. With respect to the relationships among the SCL depression subscale and VVLT performance, several were noteworthy; namely, the correlations between the $\mathrm{SCL}$ depression subscale at baseline and the (6 year) immediate VVLT recall score, $r=-0.11$; pro.05, and (6 year) delayed VVLT recall scores, $r=-0.12$; pro.05, at the six year followup. Therefore, the SCL depression score was included as a predictor variable only in the regression analyses that utilized six years follow-up VVLT scores as dependent variables.

From the cross-sectional data, in order to isolate the explanatory variance of MSE on memory performance, a hierarchical regression strategy was employed with the immediate VVLT recall score and delayed VVLT recall scores at baseline as the respective dependent variables. The entry sequence of predictor variables was as follows: (1) the relevant demographic variables including age, sex and educational attainment were entered as a first block, (2) followed by the total MSE score. 


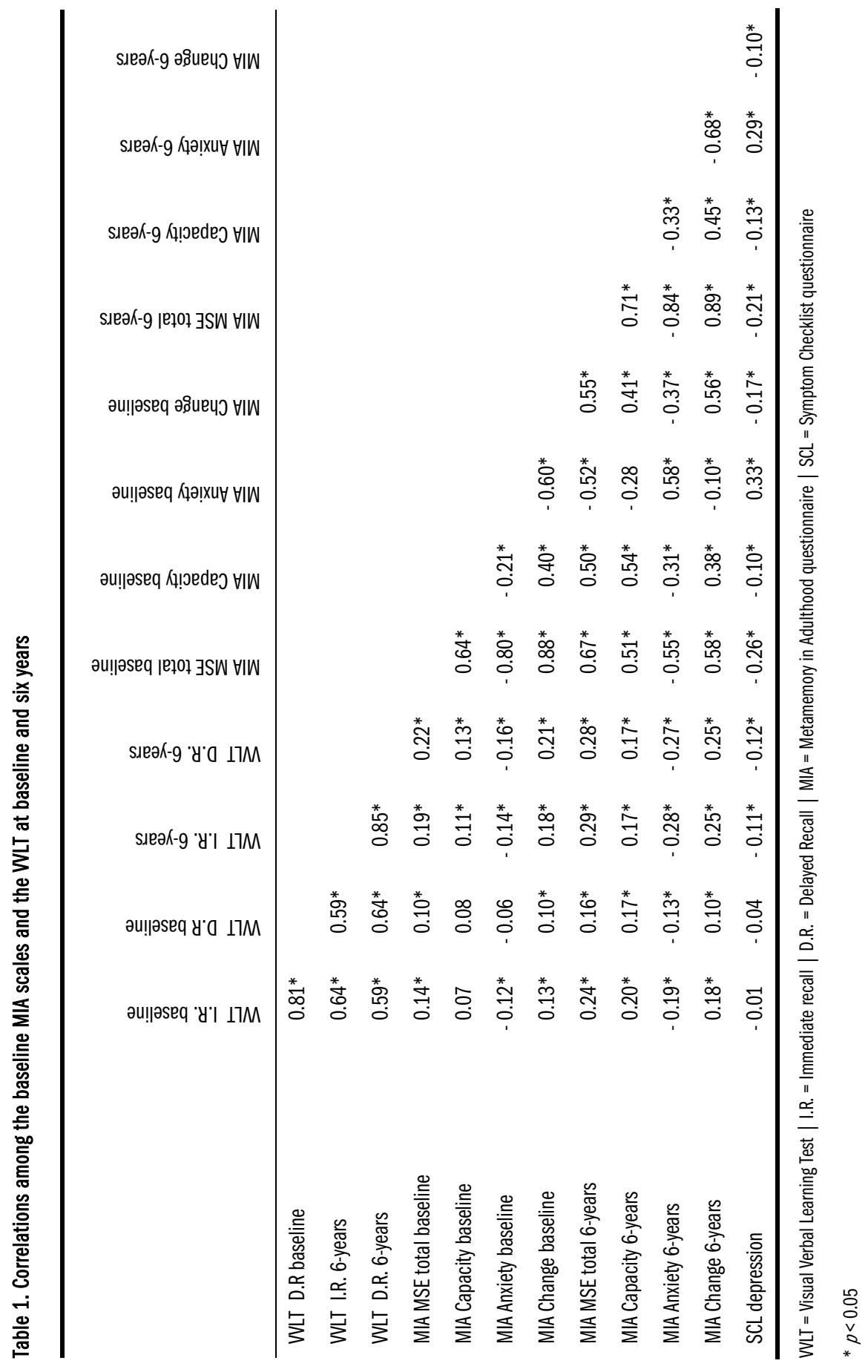


The results of this first analysis revealed that the MSE total score was a significant predictor of memory performance at baseline, however, this effect was only found for the immediate VVLT recall score, that accounted for a modest $0.6 \%$ of the variance, Beta $=0.08 ; \mathrm{t}=2.06, \mathrm{p}=0.04$. These results are summarized in Table 2.

Table 2. The cross-sectional association between MSE and VLT performance at baseline, adjusted for age, education and sex

\begin{tabular}{|c|c|c|c|c|c|c|}
\hline & \multicolumn{3}{|c|}{ Immediate WLT recall } & \multicolumn{3}{|c|}{ Delayed WLT recall } \\
\hline & $\mathrm{R}^{2}$ change & Beta value & $p$ value & $\mathrm{R}^{2}$ change & Beta value & $p$ value \\
\hline \multicolumn{7}{|l|}{ Step 1} \\
\hline Age & & -0.30 & $<0.01$ & & -0.26 & $<0.01$ \\
\hline Education & & 0.22 & $<0.01$ & & 0.20 & $<0.01$ \\
\hline Sex & & 0.22 & $<0.01$ & & 0.25 & $<0.01$ \\
\hline Step 2 & $0.006^{*}$ & & & 0.005 & & \\
\hline MSE total & & 0.08 & 0.04 & & 0.07 & 0.07 \\
\hline \multicolumn{7}{|l|}{ Overall } \\
\hline $\mathrm{R}^{2}$ overall model & 0.18 & & & 0.16 & & \\
\hline
\end{tabular}

WLT= Visual Verbal Learning Test $\mid$ MSE= Memory Self-Efficacy | SCL= Symptom Checklist questionnaire $* p<0.05$

A second set of planned regression analyses was employed to examine whether MSE at baseline was predictive of change in memory performance after six years. In this regard, because self-reported depressive symptomatology was significantly correlated with VVLT performance at six years, it was included as a control variable. The entry strategy of predictors in this regression analysis is summarized in Table 3 and included four blocks of predictors: Step 1; demographics (age, education, sex), Step 2; baseline memory performance, Step 3; SCL-9o depression score, and Step 4; the MSE total score at baseline. The MSE score was a significant predictor of VVLT performance at six years, accounting for $0.5 \%$ of the explanatory variance in the immediate VVLT recall score and $1.3 \%$ of the explanatory variance in the delayed VVLT recall scores at six years respectively. A positive $B$ value in both instances indicated that an increment of one point on the MSE score 
yielded in an increase of 0.85 additional words recalled on the immediate VVLT recall score $(t=2.03, p=0.04)$. This same relationship was noted for the delayed VVLT recall score; scoring one point more on the memory selfefficacy questionnaire resulted in an increase of 0.78 words recalled on the delayed recall score $(t=3.51$, p<0.01).

Table 3. The association between MSE and VLT performance after six years follow-up adjusted for age, education and sex, baseline performance, and depressive symptoms

\begin{tabular}{|c|c|c|c|c|c|c|}
\hline & \multicolumn{3}{|c|}{ Immediate WLT recall } & \multicolumn{3}{|c|}{ Delayed VLTT recall } \\
\hline & $\mathrm{R}^{2}$ change & Beta value & $p$ value & $\mathrm{R}^{2}$ change & Beta value & $p$ value \\
\hline \multicolumn{7}{|l|}{ Step1 } \\
\hline Age & & -0.18 & $<0.01$ & & -0.17 & $<0.01$ \\
\hline Education & & 0.10 & $<0.01$ & & 0.07 & 0.03 \\
\hline Sex & & 0.09 & 0.02 & & 0.06 & 0.08 \\
\hline Step 2 & $0.22^{* *}$ & & & $0.28^{* *}$ & & \\
\hline $\begin{array}{l}\text { WLT baseline } \\
\text { performance }\end{array}$ & & 0.50 & $<0.01$ & & 0.56 & $<0.01$ \\
\hline Step 3 & $0.01 * *$ & & & $0.01^{* *}$ & & \\
\hline SCL depression & & -0.12 & $<0.01$ & & -0.09 & $<0.01$ \\
\hline Step 4 & $0.005^{*}$ & & & $0.01 * *$ & & \\
\hline MSE total & & 0.07 & 0.04 & & 0.12 & $<0.01$ \\
\hline \multicolumn{7}{|l|}{ Overall } \\
\hline $\mathrm{R}^{2}$ overall model & 0.42 & & & 0.46 & & \\
\hline
\end{tabular}

WLT= Visual Verbal Learning Test | MSE= Memory Self-Efficacy | SCL=Symptom Checklist questionnaire

${ }^{*} p<\left.0.05\right|^{* *} p<0.01$

With regard to the specific MIA subscales Anxiety, Change and Capacity, Table 4 depicts the predictive relationship of these scores on immediate and delayed VVLT recall scores. As was the case in the previous regression analyses that utilized the MSE total score as the final predictor, the order of predictors in this regression were the demographic variables entered as a first block, followed by entry of VVLT score at baseline as the second step. The SCL-9o depression score was entered in the third step, and finally the three baseline MIA subscales Anxiety, Change and Capacity were entered (as 
a block) in the fourth step. Noteworthy in this analysis was that the baseline MIA Change scale was the only subscale that predicted the delayed VVLT recall score at six years follow-up, Beta $=0.09 ; t=2.19, p=0.03$. Unlike the MSE total score, none of the three separate subscales were predictive of the immediate VVLT recall score at six years.

Table 4. The association between the different MIA subscales and VLT performance after six years follow-up adjusted for age, education and sex, baseline performance, and depressive symptoms

\begin{tabular}{|c|c|c|c|c|c|c|}
\hline & \multicolumn{3}{|c|}{ Immediate WLT recall } & \multicolumn{3}{|c|}{ Delayed VLT recall } \\
\hline & $\mathrm{R}^{2}$ change & Beta value & $p$ value & $\mathrm{R}^{2}$ change & Beta value & $p$ value \\
\hline \multicolumn{7}{|l|}{ Step1 } \\
\hline Age & & -0.18 & $<0.01$ & & -0.17 & $<0.01$ \\
\hline Education & & 0.10 & $<0.01$ & & 0.07 & 0.03 \\
\hline Sex & & 0.09 & 0.02 & & 0.06 & 0.08 \\
\hline Step 2 & $0.22^{* *}$ & & & $0.29 * *$ & & \\
\hline $\begin{array}{l}\text { WLT baseline } \\
\text { performance }\end{array}$ & & 0.50 & $<0.01$ & & 0.56 & $<0.01$ \\
\hline Step 3 & $0.02 * *$ & & & $0.01^{* *}$ & & \\
\hline SCL depression & & -0.12 & $<0.01$ & & -0.09 & $<0.01$ \\
\hline Step 4 & $0.005^{*}$ & & & $0.01^{* *}$ & & \\
\hline MSE total & & 0.07 & 0.04 & & 0.12 & $<0.01$ \\
\hline \multicolumn{7}{|l|}{ Overall } \\
\hline $\mathrm{R}^{2}$ overall model & 0.42 & & & 0.47 & & \\
\hline
\end{tabular}

WLT= Visual Verbal Learning Test $\mid \mathrm{MIA}=$ Metamemory in Adulthood questionnaire $\mid \mathrm{SCL}=$ Symptom Checklist questionnaire $* p<\left.0.05\right|^{* *} p<0.01$

In order to test the validity of this Change scale and see what this scale captures, some additional analyses were conducted. We examined whether the difference between the VVLT at 6 years and the VVLT at baseline would be able to predict MIA Change scores at 6 years follow-up. Results showed a significant relationship for the delayed VVLT recall score (Beta $=0.21, t=4.80$, p<0.01), with worse performance in the VVLT associated with more perceived changes in memory performance. The effect for the immediate VVLT recall score was not significant (Beta $=0.08, t=1.75, p=0.08$ ) (results not tabulated). 
The Change scale of the MIA was analyzed further, in order to examine whether individuals who acknowledged a subjective sense of change in memory functioning, differed in their pattern of performance with respect to memory consolidation across the three recall trials of the immediate VVLT recall score at six years follow-up. This analysis was conducted to directly address the hypothesis that individuals who, at baseline, perceived that their memory was getting worse would, over time, show a differential pattern of performance with respect to consolidation of verbal material from episodic memory, as measured by an increase in the words recalled across VVLT trials. Thus, two groups of individuals were isolated based on average Change subscale scores. More specifically, those who scored on average less than 3 on the MIA change subscore $(1=$ strongly agree, $2=$ agree my memory is getting worse, $N=46 ; M=1.77 ; S D=0.24)$ were contrasted with those who scored a 4 or 5 ( $4=$ disagree, $5=$ strongly disagree my memory is getting worse, $N=47 ; M=4.32 ; S D=0.29$ ).

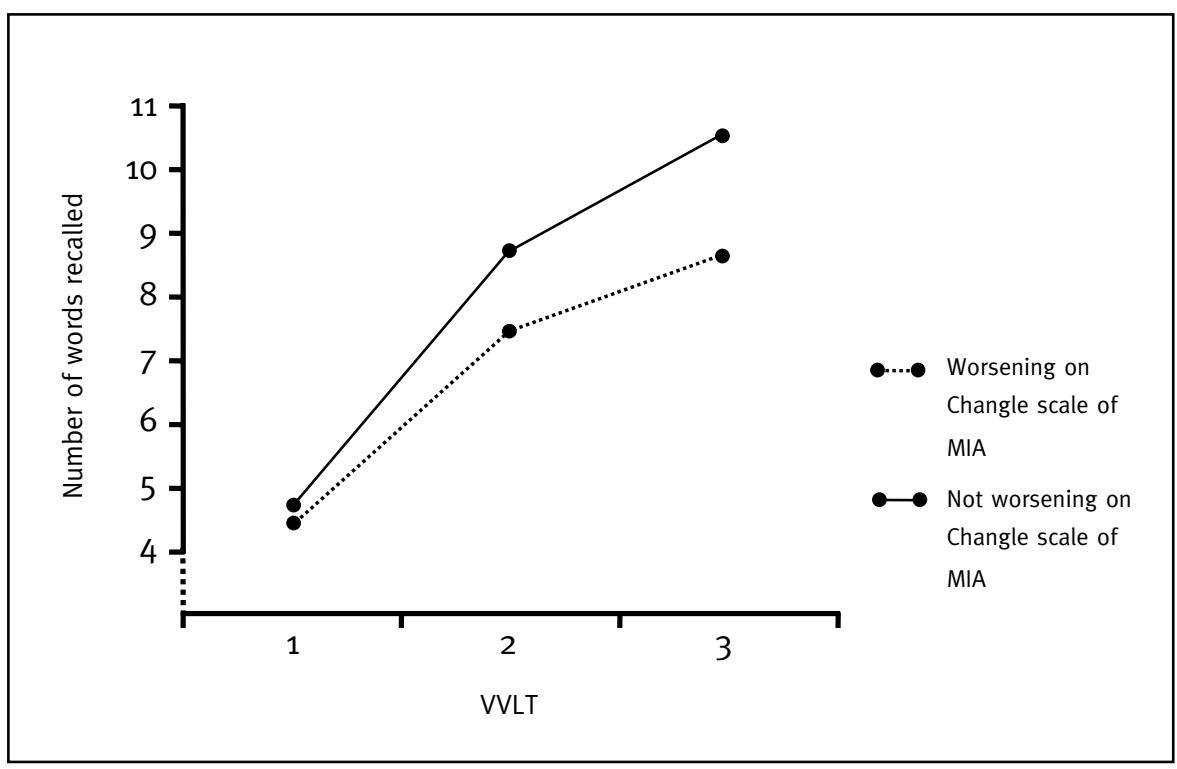

Figure 1. Word recall across three trials on the VLT for those who perceived their memory as worsening or not worsening over time

Those with an average score that was between 2.9 and 3.9 on this subscale, or who self-reported that they could discern whether their memory worsening or improving were not included in this subanalysis. A General Linear Model 
(GLM) repeated measures analysis of variance was used to assess group differences across the three recall trials of the VVLT at six years. Of interest in this regard was a significant group $x$ trial interaction $(F(1,87)=5.35$, $p=0.02, \quad \eta^{2}=0.57$ ), indicating that individuals who experienced more perceived decline at baseline, improved less across the three trials of the immediate VVLT recall score six years later. This contrast is highlighted in Figure 1 by a flatter word learning curve for those who had reported on the Change subscale that their memory was declining.

\section{Discussion}

The present study was designed to examine the relationship between memory self-efficacy (MSE) and objective memory performance at a follow-up interval of six years. The findings indicated that MSE, as measured by the MIA, was predictive of objective memory performance. Specifically, higher MSE scores were associated with better word learning performance. With respect to the different subscales that underlie the total MSE score, the present study found that the Change subscale was the best predictor of change in objective memory functioning after an interval of six years. Hertzog et al. (1989) postulated that the Capacity subscale should be the most defining feature of MSE from the MIA and, therefore the Capacity subscale was initially conceptualized as the focal measure of MSE. In several studies were MSE was defined as the MIA Capacity subscale, a relationship was found with objective memory performance e.g. (Cavanaugh \& Poon, 1989; Hertzog et al., 1990). These findings are consistent with a domain-specific explanation of a linkage between memory functioning at a static point in time and one's perceived capacity to perform an episodic memory task at that same time point. However, in this study, the Change subscale, as opposed to the Capacity subscale, had been highlighted as the most important of the MSE subscales with respect to predicting memory performance. This merits additional discussion. Because the Change subscale was the most salient predictor, it could be argued that when change in memory function is the outcome measure of interest, the better MSE predictor is one that emphasizes one's perceived sense that memory will worsen or improve with the passage of time. The finding that the MSE Change subscale was predictive of performance change in episodic memory 
represents an ideal test of the domain-specific hypothesis noted above; that is, a perceived sense of change (e.g., the perception of worsening or improving of one's memory capabilities) was associated with objective memory performance, not capacity or anxiety per se. In more concrete terms, accurately judging one's capacity after a six-year time interval would be difficult, if not impossible, for most older adults, in contrast to the perception that one's own memory is worsening. In order to test the validity of the MIA Change scale, we tested whether the difference between the VVLT at 6 years and the VVLT at baseline would be able to predict MIA Change scores at 6 years follow-up. Results support the notion that retrospectively monitored change (prior to inclusion in the MAAS) continues prospectively over the next 6-year period.

The data from this study suggest that a perceived sense of changes in memory could accurately predict objective memory performance at a future point in time. This point is further emphasized by an extreme groups analysis of the Change score, indicating that individuals who experienced more perceived decline at baseline, improved less across the three trials of the immediate VVLT recall score. Moreover, at follow-up, we did not find that the correlation of the VVLT with the MIA Change scale was stronger than with the other scales, suggesting that the advantage of the MIA Change scale is truly a lagged predictive effect and not an indirect manifestation of stronger relationships at follow-up.

Although retrospective, McDonald-Miszczak et al. (1995) also found a relationship between change in memory performance and perceptions of memory change, as measured with the MIA Change scale. The focus in this study, however, was on whether subjective feelings of change result from accurate monitoring of changes, or stem from an implicit theory about aging. The authors concluded that the latter explanation is most likely. However, in the McDonald-Miszczak study, as well as in a recent report from Lane and Zelinski (2003) at least some support for the accurate monitoring of change was found. Addressing the ongoing debate in the literature about whether subjective feelings of memory dysfunction are caused by an actual decline in objective memory or not, our results highlight the notion that individuals' perception of whether or not their memory is changing can be an accurate 
reflection of objective memory performance (Dik et al., 2001; Jonker, Geerlings, \& Schmand, 2000).

With respect to the theoretical foundation of the study, self-efficacy theory has been confirmed in mostly cross-sectional studies (Cavanaugh \& Poon, 1989; Floyd \& Scogin, 1997; Hertzog et al., 1990; Seeman et al., 1993). However, there are a few longitudinal studies that have also reported the predictive value of self-efficacy on cognitive performance, such as the MacArthur Studies of Successful Aging (Albert et al., 1995; Seeman et al., 1996). The findings of our study are consistent in that self-efficacy was predictive of cognition after a 6-year follow-up interval in a sample of older adults. However, the self-efficacy measure used in the MacArthur Studies of Successful Aging reflected only a generalized sense that one's actions could impact function on daily activities (e.g., arranging one's transportation). MSE could not be inferred from such a measure. In contrast, the present study utilized a highly specific metamemory questionnaire that was found to tap differential MSE domains in the cross sectional reports described earlier. Thus, employing the MIA, it was possible to pinpoint which MSE domain would predict episodic memory performance after a six year interval. Some other contrasts are also noteworthy, like the fact that in the study of Seeman et al. (1996) only a relation between self-efficacy and cognition was found in men. In the present study, when a domain-specific measure of MSE was utilized no gender effects were found. This highlights the fact that selfefficacy ratings of memory functioning may not be gender specific and, this were the case for the cross-sectional studies that utilized the MIA as the measure of MSE (Cavanaugh, 1996; Hertzog et al., 1990).

In order to determine whether the predictive value of memory selfefficacy on memory performance was altered by depressive symptoms, this variable was also added to the regression model. Although measures of memory self-efficacy and depressive symptoms are related to each other (Bandura, 1989), results indicated that memory self-efficacy remained a significant predictor of memory performance over time. An attempt was made to assess the extent that mood was related to MSE in this study, but because this was primarily a healthy sample and persons with depression were systematically excluded, it was not possible to definitively examine this individual difference variable. It might be expected that there are multiple 
variables that could be operating to bias efficacy ratings including chronic disorders of personality traits and mood. Future research on samples that are characterized by one or more individual difference variables could further elucidate the extent to which the accuracy of efficacy judgments are attenuated by different variables. 


\section{References}

Albert, M. S., Jones, K., Savage, C. R., Berkman, L., Seeman, T., Blazer, D., et al. (1995). Predictors of cognitive change in older persons: MacArthur studies of successful aging. Psychology and Aging, 10(4), 578-589.

Bandura, A. (1977). Self-efficacy: toward a unifying theory of behavioral change. Psychology Review, 84(2), 191-215.

Bandura, A. (1989). Regulation of cognitive processes through perceived self-efficacy. Developmental Psychology, 25(5), 729-735.

Bandura, A., Adams, N. E., Hardy, A. B., \& Howells, G. N. (1980). Tests of the generality of self-efficacy theory. Cognitive Therapy and Research, 4(1), 39-66.

Berry, J. M. (1999). Memory self-efficacy in its social cognitive context. In T. H. Hess \& F. Blanchard-Fields (Eds.), Social cognition and aging (pp. 70-96). San Diego: Academic Press.

Berry, J. M., \& West, R. L. (1993). Cognitive self-efficacy in relation to personal mastery and goal setting across the life span. International Journal of Behavioral Development, 16, 351-379.

Bosma, H., van Boxtel, M. P., Ponds, R. W., Houx, P. J., Burdorf, A., \& Jolles, J. (2003). Mental work demands protect against cognitive impairment: MAAS prospective cohort study. Experimental Aging Research, 29(1), 33-45.

Brand, N., \& Jolles, J. (1985). Learning and retrieval rate of words presented auditorily and visually. Journal of General Psychology, 112(2), 201-210.

Cavanaugh, J. C. (1996). Memory self-efficacy as a moderator of memory change. In F. Blanchard-Fields \& T. H. Hess (Eds.), Perspectives on Cognitive Change in Adulthood and Aging (pp. 488-507). New York: The McGraw-Hill Compagnies.

Cavanaugh, J. C., \& Poon, L. W. (1989). Metamemorial predictors of memory performance in young and older adults. Psycholohy and Aging, 4(3), 365-368.

Coyle, J. T. (2003). Use it or lose it--do effortful mental activities protect against dementia? New England Journal of Medicine, 348(25), 2489-2490.

De Bie, S. E. (1987). Standaardvragen 1987: Voorstellen voor uniformering van vraagstellingen naar achtergrondkenmerken en interviews [Standard questions 1987: Proposal for uniformization of questions regarding background variables and interviews] (2nd ed.). Leiden: Leiden University Press.

Derogatis, L. R. (1977). SCL-90: Administration, scoring and procedures manual-I for the R(evised) version. Baltimore: Johns Hopkins School of Medicine, Clinical Psychometrics Research Unit.

Dik, M. G., Jonker, C., Comijs, H. C., Bouter, L. M., Twisk, J. W., van Kamp, G. J., et al. (2001). Memory complaints and APOE-epsilon4 accelerate cognitive decline in cognitively normal elderly. Neurology, 57(12), 2217-2222.

Dixon, R. A., Hultsch, D. F., \& Hertzog, C. (1988). The metamemory in adulthood (MIA) questionnaire. Psychopharmacology Bulletin, 24(4), 671-688.

Fisk, J. E., \& Warr, P. (1996). Age-related impairment in associative learning: the role of anxiety, arousal and learning self-efficacy. Personality and Individual Differences, 21(5), 675-686.

Floyd, M., \& Scogin, F. (1997). Effects of memory training on the subjective memory functioning and mental health of older adults: a meta-analysis. Psychology and Aging, 12(1), 150-161.

Folstein, M. F., Folstein, S. E., \& McHugh, P. R. (1975). Mini-mental State: a practical method for grading the cognitive state of patients for the clinician. Journal of Psychiatric Research, 12, 189-198. 
Hertzog, C., Dixon, R. A., \& Hultsch, D. F. (1990). Relationships between metamemory, memory predictions, and memory task performance in adults. Psychology and Aging, 5(2), 215-227.

Hertzog, C., Hultsch, D. F., \& Dixon, R. A. (1989). Evidence for the convergent validity of two self-report metamemory questionnaires. Developmental Psychology, 25, 687-700.

Hultsch, D. F., Hertzog, C., Dixon, R. A., \& Davidson, H. (1988). Memory self-knowledge and self-efficacy in the aged. In N. L. Lowe \& C. J. Brainerd (Eds.), Cognitive development in adulthood: Progress in cognitive developmental research (pp. 65-92). New York: Springer-Verlag.

Hultsch, D. F., Hertzog, C., Small, B. J., \& Dixon, R. A. (1999). Use it or lose it: engaged lifestyle as a buffer of cognitive decline in aging? Psychology and Aging, 14(2), 245-263.

Jolles, J., Houx, P. J., van Boxtel, M. P. J., \& Ponds, R. W. H. M. (Eds.). (1995). Maastricht Aging Study: Determinants of cognitive aging. Maastricht: Neuropsych Publishers.

Jonker, C., Geerlings, M. I., \& Schmand, B. (2000). Are memory complaints predictive for dementia? A review of clinical and population-based studies. International Journal of Geriatric Psychiatry, 15(11), 983-991.

Lane, C. J., \& Zelinski, E. M. (2003). Longitudinal hierarchical linear models of the memory functioning questionnaire. Psychology and Aging, 18(1), 38-53.

Luszcz, M. A. (1993). When knowing is not enough: the role of memory beliefs in prose recall of older and younger adults. Australian Psychologist, 28, 16-20.

McDonald-Miszczak, L., Hertzog, C., \& Hultsch, D. F. (1995). Stability and accuracy of metamemory in adulthood and aging: a longitudinal analysis. Psychology and Aging, 10(4), 553-564.

Metsemakers, J. F. M., Höppener, P., Knottnerus, J. A., Kocken, R. J. J., \& Limonard, C. B. G. (1992). Computerized health information in the Netherlands: A registration network of family practices. British Journal of General Practice, 42, 102-106.

Ponds, R. W. H. M., \& Jolles, J. (1996). The abridged Dutch Metamemory in Adulthood (MIA) questionnaire: structure, and effects of age, sex, and education. Psychology and Aging, 11, 324-332.

Seeman, T., McAvay, G., Merrill, S., Albert, M., \& Rodin, J. (1996). Self-efficacy beliefs and change in cognitive performance: MacArthur Studies of Successful Aging. Psychology and Aging, 11(3), 538-551.

Seeman, T. E., Rodin, J., \& Albert, M. (1993). Self-Efficacy and Cognitive Performance in High-Functioning Older Persons. Journal of aging and health, 5(4), 455-474.

Van Boxtel, M. P. J., Buntinx, F., Houx, P. J., Metsemakers, J. F. M., Knottnerus, J. A., \& Jolles, J. (1998). The relation between morbidity and cognitive performance in a normal aging population. Journal of Gerontology, 53A(2), M146-M154.

Verghese, J., Lipton, R. B., Katz, M. J., Hall, C. B., Derby, C. A., Kuslansky, G., et al. (2003). Leisure activities and the risk of dementia in the elderly. New England Journal of Medicine, 348(25), 2508-2516.

Welch, D. C., \& West, R. L. (1995). Self-efficacy and mastery: Its application to issues of environmental control, cognition, and aging. Developmental Review, 15, 150-171. 
CHAPTER 2. MEMORY SELF-EFFICACY PREDICTS MEMORY PERFORMANCE 


\section{Abstract}

The objective of this study was to examine the longitudinal relationship between sensory functioning and a broad range of cognitive functions after 6-years follow-up, and to examine whether cataract surgery or first time hearing aid use affected cognition. Hierarchical regression procedures were employed to determine whether sensory functioning was predictive of cognitive performance. Participants were Dutch older adults $(50+)$ enrolled in the Maastricht Aging Study (MAAS) ( $N=418)$. The results indicated that a change in visual acuity was associated with change in most cognitive measures, including the total and recall scores of the Visual Verbal Learning Task (VVLT), the mean score of the first two cards of the Stroop Colour Word Test (SCWT), the mean score of the first two Concept Shifting Task cards (CST) and the Letter Digit Substitution Test (LDST). In addition, a change in auditory acuity predicted change in memory performance (VVLT total and recall scores) and auditory acuity measured at baseline predicted change in the mean score of the first two Stroop cards and the LDST. The findings support the notion of a strong connection between sensory acuity in auditory and visual domains and cognitive performance measures, both from a crosssectional and a longitudinal perspective. It also suggests that it is essential to screen older individuals in a clinical context for sensory functioning in order to avoid that changes in visual or auditory acuity are interpreted as changes in cognitive performance. 


\section{Introduction}

Visual and hearing impairments are common in old age. It has been suggested that at least 50 percent of individuals aged 75 years and older show some degree of measurable hearing loss and that best corrected visual acuity starts to decline after 45 years of age (Schneider \& Pichora-Fuller, 2000). Sensory impairment can dramatically affect a person's ability to socialize and his/her psychological or emotional functioning, functional status and thus quality of life (Horowitz, 1994; Keller, Morton, Thomas, \& Potter, 1999; Lee, Smith, \& Kington, 1999; Marsiske, Klumb, \& Baltes, 1997; Reuben, Mui, Damesyn, Moore, \& Greendale, 1999; Wallhagen, Strawbridge, Shema, Kurata, \& Kaplan, 2001). Moreover, in the literature on cognitive aging a strong connection has been found in cross-sectional studies between sensory functioning and cognition (Anstey, Lord, \& Williams, 1997; Lindenberger \& Baltes, 1994; Lindenberger, Scherer, \& Baltes, 2001; Stankov \& Anstey, 1997; van Boxtel, ten Tusscher, Metsemakers, Willems, \& Jolles, 2001). The purpose of this study is to examine the longitudinal co-variation of sensory function and cognitive functioning, independent of age, gender, and education.

However, the nature of this association is still ambiguous and several alternative explanatory hypotheses have been proposed. Although this study is not designed to test these different hypotheses, it is interesting to discuss the mechanisms that have been suggested. Currently, four theories specify different mechanisms that indicate a link between sensory functioning and cognition. Two theories hold that there is a direct causal association between sensory impairment and cognitive functioning. The second hypothesis states that sensory impaired individuals have to allocate more attentional resources in order to perceive and interpret sensory information. As a result, according to this 'resource allocation' hypothesis, there may be fewer resources left for other cognitively demanding tasks (Baltes \& Lindenberger, 1997). The third theory, the 'common cause' hypothesis, on the other hand, postulates that the association between sensory functioning and cognition is confounded by a third common factor. Sensory impairment and cognitive decline may both be the result of age-related changes in a shared factor, such as degeneration of central nervous structures (Anstey et al., 1997; Christensen, Mackinnon, Korten, \& Jorm, 2001; Lindenberger \& Baltes, 1994). An alternative, fourth 
hypothesis is that sensory impaired individuals are disadvantaged in their performance on psychometric tests as a direct result of difficulties in sensory perception. According to this notion, impaired performance on cognitive tasks is not a result of cognitive abilities per se, but a direct consequence of unclear and distorted perceptual information delivered to the cognitive system, thereby compromising the performance on neuropsychological tests (Lindenberger et al., 2001; Rabbitt, 1990; van Boxtel et al., 2001; Van Boxtel et al., 2000). Cognitive functioning is an important prerequisite for successful aging and independent living. Therefore, it is essential to identify variables associated with cognition that may predict future cognitive performance and which may be amenable to treatment. To date, few longitudinal studies have investigated the predictive value of sensory impairment on subsequent cognitive functioning (Sands \& Meredith, 1989). For example, Anstey et al. (Anstey, Luszcz, \& Sanchez, 2001) found that diminished visual acuity was associated with decline in memory functioning, but not with performance in other cognitive domains. In contrast, no association was found between diminished auditory functioning and decline in any of the cognitive domains. This dissociation between vision and hearing in relation to cognition has been used as an argument against a common cause explanation used in several cross-sectional studies, because vision, hearing, and cognition were apparently not affected at the same time by a fourth common factor (Anstey et al., 2001).

Because both the sensory deprivation and the resource reallocation theories imply that improvement of sensory functioning could result in improvement of cognition, in the present longitudinal study we investigated not only the relationship between sensory functioning and a broad range of cognitive functions after a 6-years follow-up, but also whether self-initiated treatments, such as cataract surgery or the use of a hearing aid would affect cognition. We used data obtained from relatively healthy older Dutch adults collected in the Maastricht Aging Study (MAAS), a longitudinal study of normal aging (Jolles, Houx, van Boxtel, \& Ponds, 1995; Van Boxtel et al., 1998). 


\section{Methods}

\section{Participants}

All participants were recruited from the Maastricht Aging Study (MAAS), a longitudinal study of the determinants and consequences of pathological and successful aging and cognitive functioning in particular. In the MAAS, a range of experimental and standardized instruments of health and psychological functioning were used to collect data at baseline and at two follow-up occasions, each separated by 3 years. Participants were selected from a register of 15 family practices in the South of the Netherlands (Metsemakers, Höppener, Knottnerus, Kocken, \& Limonard, 1992), were between 24 and 81 years old, and were at the moment of inclusion without medical conditions known to interfere with normal cognitive functioning (e.g. dementia, mental retardation, and cerebrovascular pathology). Overt visual or auditory handicaps (i.e. inability to read or understand spoken word with relative ease) also lead to baseline exclusion. The study population was stratified for age group, gender, and general ability. General ability was defined as the level of occupational achievement of individuals, which incorporates the degree of complexity of professional work, and the knowledge and experience required (Jolles et al., 1995).

All participants gave their informed consent. More study details can be found elsewhere (Bosma et al., 2003; Jolles et al., 1995; Van Boxtel et al., 1998). The current study uses the data for a smaller sample of 418 individuals (214 males; 204 females) aged 55 years or older at baseline, with a mean age of 65.9 years ( \pm 6.7 years, range 55 to 83 ). Of this group, 27 individuals received an intervention to improve vision (cataract surgery) or hearing (hearing aid use) during the six years of follow-up, and were analyzed separately. Mean level of education was $3.03( \pm 1.81)$ (comparable to 10 years of formal education), measured on a hierarchical scale of schooling available in the Dutch educational system. Level of education (1-8) was scored as follows: $1=$ primary education, $2=$ lower vocational education, $3=$ intermediate general secondary education, $4=$ intermediate vocational education, $5=$ higher general secondary education/ university preparatory education, $6=$ higher vocational preparatory education, $7=$ higher professional 
education, 8=university education (De Bie, 1987). Participants rated themselves as healthy (mean $3.69 \pm 0.64$ on a 1 to 5 rating of perceived health, $1=$ very poor health to $5=$ very good health) and had no serious cognitive problems (mean Mini-Mental Status Examination score of 27.8 ( \pm 1.82 ) (Folstein, Folstein, \& McHugh, 1975). In addition, we used a clinical interview to exclude individuals suffering from dementia from further participation.

\section{Measures}

\section{Cognitive Measures}

The Visual Verbal Learning Test (VVLT) (Brand \& Jolles, 1985) is a verbal memory task designed to measure the ability to learn new verbal information and to retrieve this information from memory. Fifteen low-associative words are visually presented in a booklet five times. The font size of the letters was large enough for all participants to perceive the words well. After each presentation the participant is asked to recall as many words as possible, with no restriction on the order of recall (immediate recall). The five trials provide a reliable estimate of learning and scores for each trial are summed to produce a total VVLT score. The maximum score after five successive trials is 75 . Twenty minutes after the last presentation, participants are again requested to recall as many correct words as possible (VVLTr).

The Stroop Color-Word Test (SCWT) is used as a measure of selective attention and speed of information processing and consists of three cards (Houx, Jolles, \& Vreeling, 1993; Stroop, 1935). On the first card color words (red, blue, yellow, and green) are printed in black ink and participants are asked to read the words as fast and accurately as possible. The second card displays color patches in the same four colors and participants are asked to name the colors of the patches as fast and accurately as possible. The third card displays color words that are printed in incongruously colored ink and participants are asked to name the color of the ink in which the words are printed. The variables of interest in this study are the mean scores of the total time needed to complete the first two cards as an indication of simple speed capacity (SCWT 1+2), and an interference score to measure inhibition of a habitual response (reading the word) (SCWT i). This latter interference 
score is computed by subtracting the mean score of the first and second cards from the time needed to complete the third card.

The Concept Shifting Task (CST) is a modified version of the Trail Making Test and is used as an instrument to measure simple speed and cognitive flexibility (Reitan, 1958; Vink \& Jolles, 1985). The test consists of three cards containing the stimulus material, which are 16 small circles grouped in a large circle. On the first card the smaller circles contain numbers in a fixed random order and participants are asked to cross out the numbers in the right order, as fast and accurately as possible. In the second part of the test, the circles contain letters, which have to be crossed out in alphabetical order. In the third part of the test, the card displays both numbers and letters, and participants are requested to alternate between numbers and letters. The scores correspond to the time needed to complete each card. The mean scores of the first two cards are used as a reflection of simple speed (CST A+B). The difference between the score for the last card and the mean score of the first two cards is considered to reflect the additional time needed to shift between two sets of stimuli (CST i).

The Verbal Fluency test is a subtask of the Groninger Intelligence Test (Lezak, 1995; Luteijn \& van der Ploeg, 1983) and measures the ability to recollect as many words as possible in a specific category (animals) from memory in an adequate and strategic manner. The outcome measure of interest is the total number of words produced in 90 seconds.

The Letter-Digit Substitution Test (LDST) is a modified version of the Symbol Digit Modalities Test and measures general information processing speed (Lezak, 1995; Smith, 1968). Participants are asked to fill in as many blank squares as possible, using a code supplied at the top of the page. In this code nine random letters of the alphabet correspond to nine different numbers. Participants have to copy the correct number in each box, indexed by a letter. The dependent variable is the total number of correctly filled in squares in 90 seconds.

\section{Sensory measures}

Best-corrected visual acuity was measured for both eyes using a Landolt-C optotype chart at a distance of 5 meters under standard luminescence and with corrected vision (Westheimer, 1987). Participants are requested to say in 
which direction the opening of black circles on a white background points (up, down, left, right). The outcome measure is the size of the last circle whose opening was correctly identified and is expressed as the ratio of 5 meters and the distance at which a reference group is able to encode the circle orientation (e.g. 1 is average for young individuals with normal visual acuity). Higher scores indicate better visual acuity.

Hearing acuity is expressed in $\mathrm{dB}$ and was measured with pure-tone auditory thresholds that were determined for both ears at different fixed frequencies at 1, 2, and $4 \mathrm{KHz}$ using a screening audiometer (Interacoustics AS7, Denmark). The overall hearing acuity, expressed as the average of the hearing thresholds for the better ear, was measured according to recommendations for the assessment of hearing handicap (Davis, 1995). Higher scores indicate worse auditory acuity.

\section{Procedure}

The outcome variables were obtained from a neuropsychological test battery that included the VVLT, the SCWT, the CST, the Verbal fluency task, and the LDST. On average, completion of a test session took 2.5 hours, with a rest period of 20 minutes. All participants were tested at the test laboratory of the University Hospital Maastricht. Trained assistants who were supervised by neuropsychologists and physicians of the project staff administered cognitive and sensory measures and comparable test protocols were used on all three measurement occasions.

\section{Statistical analysis}

For the cross-sectional data, zero-order correlations were computed between age, education, gender, and sensory and cognitive variables measured at baseline. Next, hierarchical linear regression analysis was employed to examine the relationship between baseline sensory functioning and baseline cognitive functioning.

Hierarchical linear regression analysis was used also to examine the association between sensory functioning and change in cognitive performance after 6 years. In this regression analysis, three blocks of predictors were constructed; age, gender, and education were entered first, 
followed by baseline cognitive performance at the second step, and change in vision or hearing and baseline vision or hearing at the third step.

With respect to the longitudinal analyses, a change in vision or hearing was computed as the regression coefficient B (slope) of the individual regression line that was fitted based on the three available measurements of sensory function (baseline, 3 years follow-up, 6 years follow-up). Baseline vision and hearing scores were expressed as the intercept of this regression line. All statistical analyses were performed using SPSS for Macintosh, version 10 (SPSS-Inc., Chicago).

\section{Results}

Descriptive data at baseline and six years follow-up of individuals who did not undergo any interventions during the six years follow-up are given in Table 1. At baseline, 240 individuals had reading glasses for far-sightedness, $(N=231), 189$ people used eye glasses to correct near-sightedness $(N=181)$, 30 people used one hearing aid and 14 subjects used a hearing aid for both ears (main reason was presbyacusia, $\mathrm{N}=23$ ). Furthermore, male participants had better visual acuity than women at baseline $(F(1,389)=9.139$, pro.01), at three years follow-up $(F(1,366)=10.327$, pro.01), and at six years follow-up $(F 1,366)=8.054, p=0.01)$. Women had better hearing acuity than men, but only at the six years follow-up measurement $(F(1,358)=3.990, p=0.05)$ (results not tabulated).

In addition, results indicated that of this group of individuals, at baseline there were $30(7.7 \%)$ individuals who could be regarded as auditory impaired since their average pure-tone auditory threshold at the best ear was $35 \mathrm{~dB}$ or more measured at 1,2 and $4 \mathrm{KHz}$ (Davis, 1995). At six years follow-up this group consisted of 128 (32.7 \%) individuals. With respect to vision, at baseline $36(9.2 \%)$ of the participants had a mean visual acuity of 0.5 or less, an often used clinical cut-off point to determine impaired vision e.g.(van Boxtel et al., 2001). Six years later there were 42 (11.4\%) participants who had a mean visual acuity of 0.5 or less (see Table 2). 
CHAPTER 3. CHANGE IN SENSORY FUNCTIONING PREDICTS CHANGE IN COGNITIVE FUNCTIONING

Table 1. Descriptive data of participants at baseline and six years follow-up ( $N=391)$

\begin{tabular}{lll}
\hline & Baseline & Six years follow-up \\
& Mean $( \pm$ standard deviation) $($ range) & Mean $( \pm$ standard deviation) (range) \\
\hline Age & $65.1(6.6)$ & - \\
Education & $3.1(1.8)$ & - \\
Gender (percentage women) & 48.6 & - \\
Marital status (percentage & 79.5 & - \\
married/living together) & & \\
\hline MMSE * & $27.9( \pm 1.8)$ & $28.1( \pm 1.9)$ \\
WLT total $*$ & $42.6( \pm 9.2)(14-68)$ & $46( \pm 10.3)(12-7)$ \\
WLT r ${ }^{*}$ & $8.8( \pm 2.8)(1-15)$ & $9.5( \pm 3.3)(0-15)$ \\
SCWT $1+2 * *$ & $55.3( \pm 9.4)(36.9-100.5)$ \\
SCWT ${ }^{* *}$ & $53.2( \pm 8.6)(34.5-88.6)$ & $61.6( \pm 33.6)(15.3-281.6)$ \\
CST A+B ** & $52.8( \pm 19.9)(19-148.7)$ & $29.4( \pm 8.2)(15.2-73.6)$ \\
CST $i * *$ & $26.8( \pm 6.5)(14.8-54.8)$ & $18.9( \pm 16.1)(-9.4-148.4)$ \\
Fluency * & $14.1( \pm 11.6)(-2-93.9)$ & $20.9( \pm 5.7)(7-40)$ \\
LDST ** & $22.4( \pm 5.9)(6-4)$ & $43.1( \pm 10.8)(13-77)$ \\
Visual acuity & $42.6( \pm 9.6)(17-7)$ & $1( \pm 0.4)(0.1-3)$ \\
Auditory acuity & $1( \pm 0.3)(0.3-2)$ & $29.2( \pm 14.9)(1.7-8)$ \\
\hline
\end{tabular}

MMSE $=$ Mini-Mental State Examination $\mid$ WLT $=$ Visual Verbal Learning Test $\mid$ SCWT $=$ Stroop Color Word Test $\mid$ CST $=$ Concept Shifting Task | LDST = Letter Digit Substitution Task

* Higher sores indicate better neuropsychological test performance, ${ }^{* *}$ Lower scores indicate better neuropsychological test performance

The zero-order correlations among the sensory variables (visual acuity and auditory acuity), the cognitive variables, and the demographic variables are summarized in Table 3. These scores were highly intercorrelated, with zeroorder correlations ranging from 0.11 to 0.83 , all $p$-values $<0.05$.

Based on the cross-sectional data, a hierarchical regression analysis was used to examine whether visual and hearing acuity measured at baseline was predictive of the different cognitive variables. Results indicated that after controlling for age, educational attainment, and gender, baseline visual acuity was predictive of scores on the SCWT $1+2(B=-2.75 ; t=-1.98 ; p=0.05)$, 
the CST $A+B(B=-2.49 ; t=-2.54 ; p=0.01)$, and the LDST $(B=3.47 ; t=-2.57$; $p=0.01$ ). No associations were found with the remaining cognitive variables. Auditory acuity was not significantly associated with any of the cognitive variables investigated (not tabulated).

Table 2. Descriptive data of participants at baseline and six years follow-up with impaired vision or hearing $(\mathrm{N}=391)$

\begin{tabular}{lll}
\hline & $\begin{array}{l}\text { Baseline } \\
\text { Number (percentage) }\end{array}$ & $\begin{array}{l}\text { Six years follow-up } \\
\text { Number (percentage) }\end{array}$ \\
\hline $\begin{array}{l}\text { Individuals with impaired } \\
\text { vision }\end{array}$ & $36(9.2)$ & $42(11.4)$ \\
$\begin{array}{l}\text { Individuals with impaired } \\
\text { hearing }\end{array}$ & $30(7.7)$ & $128(32.7)$ \\
\hline
\end{tabular}

The second set of planned regression analyses was employed to examine whether visual and hearing acuity at baseline and a change in vision and hearing was predictive of change in cognitive performance in 6 years. The results of these analyses revealed that, after controlling for the demographic variables and baseline cognitive performance, change in visual acuity predicted change in the VVLT total score $(B=5.47 ; t=2.47 ; p=0.01)$, the recall score of the VVLT $(B=2.04 ; t=2.75 ; p=0.01)$, the SCWT 1+2 $(B=-5.25 ; t=-3.09$; $p$ <0.01), the CST $A+B(B=-3.63 ; t=-2.20 ; p=0.03)$, and the LDST $(B=4.74$; $t=2.80 ; p=0.01$ ). All effects indicated that deterioration of visual acuity was associated with worse cognitive performance. No effects were found for the SCWT $\mathrm{i}$ and the CST i scores and for the Verbal Fluency task. Furthermore, baseline visual acuity was not associated with change in cognitive performance.

With respect to hearing, a 6-year change in auditory acuity predicted change in the total score of the $\operatorname{VVLT}(B=-0.24 ; t=-2.37 ; p=0.02)$, and the recall score of the $\operatorname{VVLT}(B=-0.07 ; t=-2.04 ; p=0.04)$. Baseline auditory acuity was predictive of change in SCWT $1+2(B=6.79 ; t=2.30 ; p=0.02)$ and LDST $(B=-0.06 ; t=-2.21, p=0.03)$ scores. All associations indicated that a decline in auditory acuity, or worse hearing at baseline was associated with worse cognitive performance (see Table 5). 


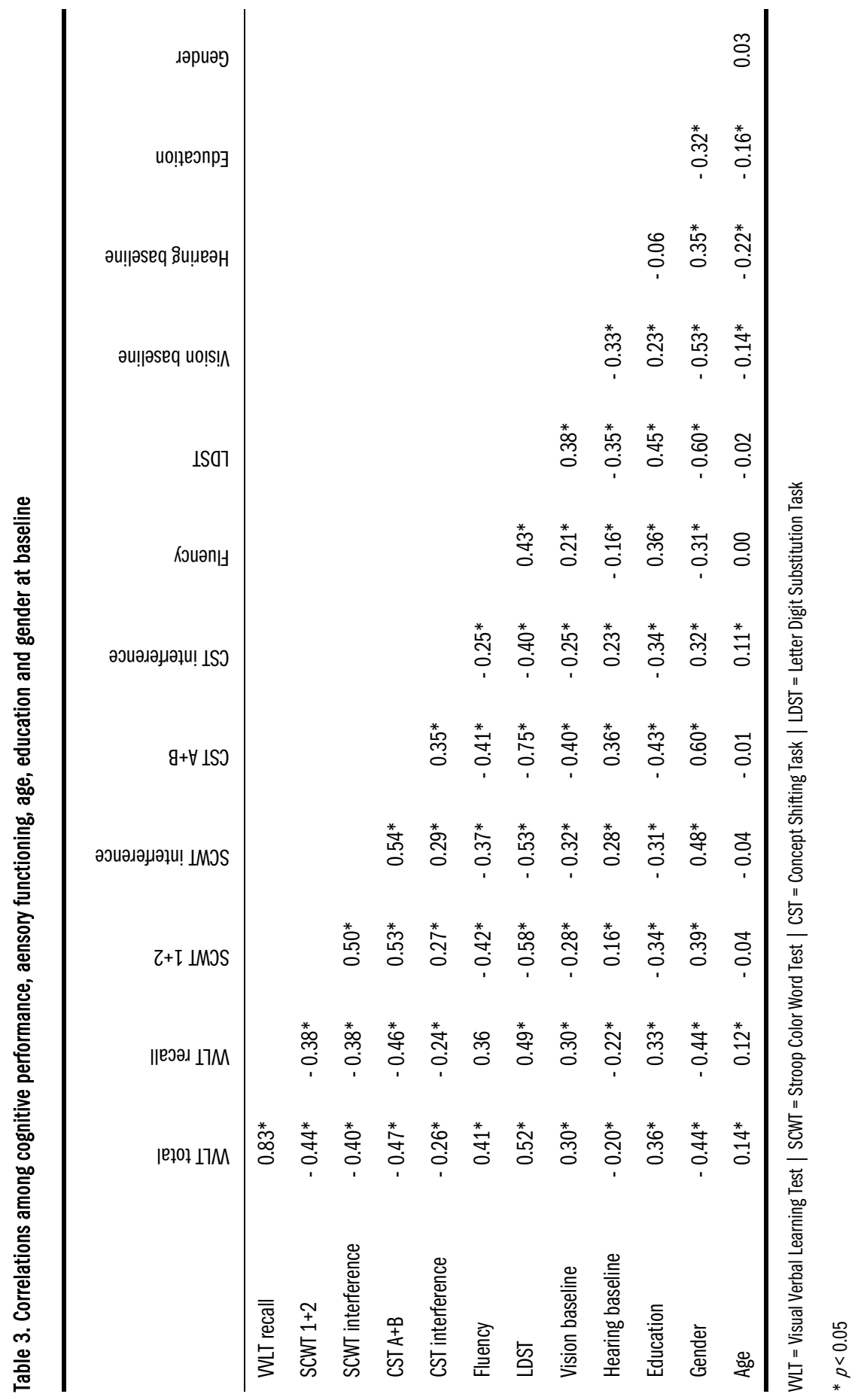


Table 4. The association between visual functioning and cognitive performance after 6 years follow-up adjusted for baseline performance, age, education, and gender

\begin{tabular}{|c|c|c|c|c|c|c|c|c|}
\hline & $\begin{array}{l}\text { WLT } \\
\text { total }\end{array}$ & WLT r & $\begin{array}{c}\text { SCWT } \\
1+2\end{array}$ & SCWT i & CST $A+B$ & CST i & Fluency & LDST \\
\hline & $B$ value & $B$ value & $B$ value & $B$ value & $B$ value & $B$ value & $B$ value & $B$ value \\
\hline \multicolumn{9}{|l|}{ VISION } \\
\hline \multicolumn{9}{|l|}{ Step 1} \\
\hline Age & $-0.25^{* *}$ & $-0.06 * *$ & $0.24 * *$ & $0.65^{* *}$ & $0.24^{* *}$ & $0.54^{* *}$ & $-0.12^{* *}$ & $-0.23^{* *}$ \\
\hline Education & $0.82^{* *}$ & $0.21^{* *}$ & -0.17 & -0.09 & $-0.41^{*}$ & $-1.35^{* *}$ & 0.14 & $0.39 *$ \\
\hline Gender & 1.06 & 0.14 & -0.99 & -2.57 & 0.14 & 1.40 & 0.35 & -0.59 \\
\hline$\Delta \mathrm{R}^{2}$ & $0.22^{* *}$ & $0.16^{* *}$ & $0.18^{* *}$ & $0.12^{* *}$ & $0.25^{* *}$ & $0.13^{* *}$ & $0.13^{* *}$ & $0.34^{* *}$ \\
\hline \multicolumn{9}{|l|}{ Step 2} \\
\hline $\begin{array}{r}\text { Baseline } \\
\text { performance }\end{array}$ & $0.63^{* *}$ & $0.68^{* *}$ & $0.77^{* *}$ & $0.96 * *$ & $0.78^{* *}$ & $0.29 * *$ & $0.57^{* *}$ & $0.83^{* *}$ \\
\hline$\Delta R^{2}$ & $0.27^{* *}$ & $0.29 * *$ & $0.47^{* *}$ & $0.35^{* *}$ & $0.33^{* *}$ & $0.04^{* *}$ & $0.31^{* *}$ & $0.40^{* *}$ \\
\hline \multicolumn{9}{|l|}{ Step 3} \\
\hline $\begin{array}{r}\text { Baseline } \\
\text { vision }\end{array}$ & 1.46 & 0.60 & -2.24 & -2.27 & -0.96 & -3.12 & 1.40 & 1.18 \\
\hline$\Delta \mathrm{R}^{2}$ & $<0.01$ & $<0.01$ & $<0.01$ & $<0.01$ & $<0.01$ & $<0.01$ & $<0.01$ & $<0.01$ \\
\hline \multicolumn{9}{|l|}{ Step 4} \\
\hline $\begin{array}{r}\text { Change in } \\
\text { vision }\end{array}$ & $5.47^{*}$ & $2.04^{* *}$ & $-5.25^{* *}$ & -6.17 & $-3.63^{*}$ & -8.50 & 0.87 & $4.74^{* *}$ \\
\hline$\Delta \mathrm{R}^{2}$ & $0.01^{* *}$ & $0.01^{* *}$ & $0.01^{* *}$ & $<0.01$ & $0.01^{*}$ & 0.01 & $<0.01$ & $0.01^{* *}$ \\
\hline \multicolumn{9}{|l|}{ Overall } \\
\hline $\begin{array}{r}\mathrm{R}^{2} \text { overall } \\
\text { model }\end{array}$ & 0.50 & 0.46 & 0.65 & 0.48 & 0.59 & 0.17 & 0.44 & 0.74 \\
\hline
\end{tabular}

WLT $=$ Visual Verbal Learning Test $\mid$ SCWT $=$ Stroop Color Word Test $\mid$ CST $=$ Concept Shifting Task $\mid$ LDST $=$ Letter Digit Substitution Task

$* p<\left.0.05\right|^{* *} p<0.01$

Additional analyses were done to examine the effect of self-initiated treatments to improve vision or hearing on cognitive performance after six years follow-up. In total, 22 individuals underwent cataract surgery during the MAAS study (mean age $=72.7$ years, mean visual acuity at baseline $=$ $0.83( \pm 0.26)$ and mean visual acuity after 6 years $=0.85( \pm 0.39))$ and seven 
CHAPTER 3. CHANGE IN SENSORY FUNCTIONING PREDICTS CHANGE IN COGNITIVE FUNCTIONING

people were fitted with a hearing aid (mean age $=69.6$ years, mean hearing acuity at baseline $=30.95( \pm 9.07)$ and mean hearing acuity at 6 years $=$ $56.11( \pm 3.90)$ ). Hierarchical analyses with a dummy variable (intervention, yes/no) as an additional step did not indicate that the intervention had a significant effect on the different cognitive measures (results not shown).

Table 5. The association between auditory functioning and cognitive performance after 6 years follow-up adjusted for baseline performance, age, education, and gender

\begin{tabular}{|c|c|c|c|c|c|c|c|c|}
\hline & $\begin{array}{l}\text { WLT } \\
\text { total }\end{array}$ & WLT $r$ & $\begin{array}{c}\text { SCWT } \\
1+2\end{array}$ & SCWT i & CST A+B & CST i & Fluency & LDST \\
\hline & $B$ value & $B$ value & $B$ value & $B$ value & $B$ value & $B$ value & $B$ value & $B$ value \\
\hline \multicolumn{9}{|l|}{ HEARING } \\
\hline \multicolumn{9}{|l|}{ Step1 } \\
\hline Age & $-0.24^{* *}$ & $-0.07^{* *}$ & $0.29 * *$ & $0.87^{* *}$ & $0.25^{* *}$ & $0.43^{* *}$ & $-0.10^{* *}$ & $-0.20^{* *}$ \\
\hline Education & $0.78^{* *}$ & $0.18^{*}$ & -0.29 & -0.30 & $-0.49 * *$ & $-1.75^{* *}$ & 0.25 & $0.52^{* *}$ \\
\hline Gender & 0.50 & -0.04 & -0.71 & -2.49 & 0.01 & 2.41 & 0.16 & -0.91 \\
\hline$\Delta R^{2}$ & $0.22^{* *}$ & $0.15^{* *}$ & $0.19 * *$ & $0.14^{* *}$ & $0.27^{* *}$ & $0.13^{* *}$ & $0.13^{* *}$ & $0.37^{* *}$ \\
\hline \multicolumn{9}{|l|}{ Step 2} \\
\hline $\begin{array}{r}\text { Baseline } \\
\text { performance }\end{array}$ & $0.63^{* *}$ & $0.68^{* *}$ & $0.77^{* *}$ & $0.97 * *$ & $0.77^{* *}$ & $0.28 * *$ & $0.56 * *$ & $0.82^{* *}$ \\
\hline$\Delta R^{2}$ & $0.27 * *$ & $0.28^{* *}$ & $0.44^{* *}$ & $0.34^{* *}$ & $0.30^{* *}$ & $0.03^{* *}$ & $0.31^{* *}$ & $0.38^{* *}$ \\
\hline \multicolumn{9}{|l|}{ Step 3} \\
\hline $\begin{array}{r}\text { Baseline } \\
\text { hearing }\end{array}$ & -0.04 & -0.01 & $0.07^{*}$ & -0.21 & $<-0.01$ & -0.02 & -0.02 & $-0.06 *$ \\
\hline$\Delta \mathrm{R}^{2}$ & $<0.01$ & $<0.01$ & $0.01 *$ & 0.01 & $<0.01$ & $<0.01$ & $<0.01$ & $<0.01^{*}$ \\
\hline \multicolumn{9}{|l|}{ Step 4} \\
\hline $\begin{array}{r}\text { Change in } \\
\text { hearing }\end{array}$ & $-0.24^{*}$ & $-0.07^{*}$ & 0.02 & 0.15 & 0.06 & 0.36 & -0.05 & -0.09 \\
\hline$\Delta R^{2}$ & $0.01^{* *}$ & $0.01^{*}$ & $<0.01$ & $<0.01$ & $<0.01$ & 0.01 & $<0.01$ & $<0.01$ \\
\hline \multicolumn{9}{|l|}{ Overall } \\
\hline $\begin{array}{r}R^{2} \text { overall } \\
\text { model }\end{array}$ & 0.49 & 0.44 & 0.64 & 0.49 & 0.57 & 0.17 & 0.44 & 0.75 \\
\hline
\end{tabular}

WLT $=$ Visual Verbal Learning Test $\mid$ SCWT $=$ Stroop Color Word Test $\mid$ CST $=$ Concept Shifting Task $\mid$ LDST $=$ Letter Digit Substitution Task

${ }^{*} p<0.05 \mid * * p<0.01$ 


\section{Discussion}

The objective of this study was to determine whether (change in) visual and auditory acuity are predictive of change in cognitive performance after a 6year follow-up. The results indicated that, with respect to vision, a change in visual acuity was associated with change in most cognitive measures, including the total and recall scores of the VVLT, the mean score of the first two SCWT cards, the mean score of the first two CST cards and the LDST test. However, no effects were found on the interference scores of the SCWT and the CST test and on the Verbal Fluency task. With regard to hearing, change in auditory acuity was found to be associated with change in memory performance (VVLT total and recall scores) and acuity measured at baseline predicted change in the mean score of the first two SCWT cards and the LDST. Although we found an association between a change in hearing and memory performance, the predictive value of a change in visual acuity was more consistent and pronounced. These results confirm earlier longitudinal data derived from the Australian Longitudinal Study of Aging, where a decline in vision, but not in hearing was associated with a decline in memory performance after a 2-year follow-up (Anstey et al., 2001). In contrast, Sands and colleagues (Sands \& Meredith, 1989) found that only auditory acuity was associated with change in intellectual performance.

With respect to our cross-sectional findings, the results of the present study corroborate earlier findings in that the association between sensory impairment and cognition was shown to be dynamic over a longer period of time, i.e. change in visual acuity predicted change in cognition after 6 years follow-up.

In order to elucidate the relationship between sensory functioning and cognition several alternative hypotheses are postulated. Although the results of this longitudinal study may help to gain more insight in nature of the relationship, the current study was not specifically designed to single out the best explanatory model(s). Because in this study we found a robust and consistent relationship between sensory functioning and cognition only for visual acuity, it seems unlikely that an age-related common factor affects both sensory functioning and cognition. However, in this study, sensory function was measured peripherally. Since the 'common-cause' hypothesis refers to sensory impairments that are caused by neuronal deficits that are 
not easily rehabilitated at the level of the end organ, a 'common' factor may still operate on a central level of information processing. Therefore the common cause hypothesis cannot be precluded.

Change in visual acuity was not predictive for performance on all cognitive tests. In fact, no association was found with the SCWT and CST interference scores and a verbal fluency task score. It is possible that this is due to the fact that these particular tasks tap on different cognitive domains, and are reflections of executive functioning, which may have a different relationship with sensory impairment than other domains, including memory or simple speed. However, it seems more plausible that the lack of associations is the mere consequence of the fact that these tasks do not draw heavily on an intact visual input system. This is consistent with the notion put forward by the information degradation hypothesis, which assumes that the association between sensory and cognitive functioning is the result not of impaired cognitive performance but of difficulties in the sensory phase of perception, which may compromise performance on neuropsychological tests. Although the results of some authors (e.g. (Lindenberger et al., 2001) ) do not support this theory, those of others studies do (van Boxtel et al., 2001; Van Boxtel et al., 2000).

The sensory deprivation hypothesis and the resource allocation hypothesis were postulated to explain the direct causal relationship between sensory impairment and cognitive performance. In the present investigation, cataract surgery or hearing aid use did not affect, i.e. ameliorate cognitive performance, suggesting that there is no long-term beneficial effect of improvement of sensory function on cognitive variables. However, several methodological considerations must be taken into account. First, the group of participants that received a hearing prosthesis in the MAAS period was very small and consisted of only seven participants, which reduces the statistical power of our test. Second, with respect to the individuals that underwent cataract surgery, it is difficult to draw conclusions as to whether the operation was successful or not in terms of the objective gain in visual acuity. In fact, when the mean baseline visual acuity scores of this group were compared to their scores six years later, no overall improvement in the visual acuity measure was detected, although it may be possible that this method was not sensitive enough to measure visual improvements that may 
be apparent in daily life, since visual acuity was measured binocularly. Thus, it is possible that other factors may have affected visual function in this group, e.g. a progression of cataract on one (or even both) eyes, inadequate correction of nearby vision at the moment of testing, or even insufficient improvement of vision after surgery. Unfortunately, no information was available with regard to the status of the operation, whether one or two eye lenses were replaced, if the optical correction was optimal, or whether additional treatment was required (e.g. laser therapy). Therefore, no firm conclusions can be drawn from the evaluation of cognitive effects of selfinitiated intervention in this study.

A methodological issue of the current study involves the sample of participants in this study, which consists of healthy individuals that volunteered to participate in the MAAS and have been doing so for over 6 years. Inevitably, this selection of participants may have caused a bias in our results. However, it was previously shown that although individuals who discontinue participation in MAAS are more likely to be older and have lower scores on cognitive tasks, this selection of dropouts did not substantially affect estimates of cognitive change (Van Beijsterveldt et al., 2002). Moreover, a tendency towards a 'restriction of range' in terms of cognitive variables due to dropout may result in less variability in performance measures. In this situation the reported effect sizes may even reflect an underestimation of true associations.

In summary, although effect sizes were relatively small, our findings support the notion of a strong connection between sensory acuity in auditory and visual domains and cognitive performance measures, both from a crosssectional and a longitudinal perspective. No convincing evidence was found for a time lag between reduced sensory function and cognitive ability, which ultimately supports the hypothesis that this connection is primarily based on a reduced ability to process stimuli of neuropsychological test material efficiently. From a practical point of view, this implies that it is therefore essential to screen aged 55 years and older individuals in a clinical context for sensory functioning in order to avoid that changes in visual or auditory acuity are interpreted as changes in cognitive performance. Adequate acknowledgement of vision and hearing impairments in older individuals therefore seems warranted. In order to draw conclusions about the causal 
CHAPTER 3. CHANGE IN SENSORY FUNCTIONING PREDICTS CHANGE IN COGNITIVE FUNCTIONING

relationship between sensory functioning and cognition in the future, we suggest that controlled experiments to test the effect of interventions aimed at improving visual or auditory acuity, are required. 


\section{References}

Anstey, K. J., Lord, S. R., \& Williams, P. (1997). Strength in the lower limbs, visual contrast sensitivity, and simple reaction time predict cognition in older women. Psychology and Aging, 12(1), 137-144.

Anstey, K. J., Luszcz, M. A., \& Sanchez, L. (2001). Two-year decline in vision but not hearing is associated with memory decline in very old adults in a population-based sample. Gerontology, 47(5), 289-293.

Baltes, P. B., \& Lindenberger, U. (1997). Emergence of a powerful connection between sensory and cognitive functions across the adult life span: a new window to the study of cognitive aging? Psychology and Aging, 12(1), $12-21$.

Bosma, H., van Boxtel, M. P., Ponds, R. W., Houx, P. J., Burdorf, A., \& Jolles, J. (2003). Mental work demands protect against cognitive impairment: MAAS prospective cohort study. Experimental Aging Research, 29(1), 33-45.

Brand, N., \& Jolles, J. (1985). Learning and retrieval rate of words presented auditorily and visually. Journal of General Psychology, 112(2), 201-210.

Christensen, H., Mackinnon, A. J., Korten, A., \& Jorm, A. F. (2001). The "common cause hypothesis" of cognitive aging: evidence for not only a common factor but also specific associations of age with vision and grip strength in a cross-sectional analysis. Psychology and Aging, 16(4), 588-599.

Davis, A. (1995). Hearing in adults. Nottingham: Whurr Publishers.

De Bie, S. E. (1987). Standaardvragen 1987: Voorstellen voor uniformering van vraagstellingen naar achtergrondkenmerken en interviews [Standard questions 1987: Proposal for uniformization of questions regarding background variables and interviews] (2nd ed.). Leiden: Leiden University Press.

Folstein, M. F., Folstein, S. E., \& McHugh, P. R. (1975). Mini-mental State: a practical method for grading the cognitive state of patients for the clinician. Journal of Psychiatric Research, 12, 189-198.

Horowitz, A. (1994). Vision Impairment and Functional Disability Among Nursing Home Residents. The Gerontological Society of America, 34(3), 316-323.

Houx, P. J., Jolles, J., \& Vreeling, F. W. (1993). Stroop interference: aging effects assessed with the Stroop Color-Word Test. Experimental Aging Research, 19(3), 209-224.

Jolles, J., Houx, P. J., van Boxtel, M. P. J., \& Ponds, R. W. H. M. (Eds.). (1995). Maastricht Aging Study: Determinants of cognitive aging. Maastricht: Neuropsych Publishers.

Keller, B. K., Morton, J. L., Thomas, V. S., \& Potter, J. F. (1999). The effect of visual and hearing impairments on functional status. Journal of the American Geriatrics Society, 47(11), 1319-1325.

Lee, P., Smith, J. P., \& Kington, R. (1999). The Relationship of Self-rated Vision and Hearing to Functional Status and Well-being Among Seniors 70 Years and Older. American Journal of Ophthalmology, 127, 447-452.

Lezak, M. D. (1995). Neuropsychological Assessment (3rd ed.). New York: Oxford University Press.

Lindenberger, U., \& Baltes, P. B. (1994). Sensory functioning and intelligence in old age: a strong connection. Psychology and Aging, 9(3), 339-355.

Lindenberger, U., Scherer, H., \& Baltes, P. B. (2001). The strong connection between sensory and cognitive performance in old age: not due to sensory acuity reductions operating during cognitive assessment. Psychology and Aging, 16(2), 196-205.

Luteijn, F., \& van der Ploeg, F. A. E. (1983). Handleiding Groninger Intelligentietest (GIT) [Manual Groningen Intelligence Test]. Lisse, The Netherlands: Swets and Zeitlinger. 


\section{CHAPTER 3. CHANGE IN SENSORY FUNCTIONING PREDICTS CHANGE IN COGNITIVE FUNCTIONING}

Marsiske, M., Klumb, P., \& Baltes, M. M. (1997). Everyday activity patterns and sensory functioning in old age. Psychology and Aging, 12(3), 444-457.

Metsemakers, J. F. M., Höppener, P., Knottnerus, J. A., Kocken, R. J. J., \& Limonard, C. B. G. (1992). Computerized health information in the Netherlands: A registration network of family practices. British Journal of General Practice, 42, 102-106.

Rabbitt, P. (1990). Mild hearing loss can cause apparent memory failures which increase with age and reduce with IQ. Acta Otolaryngol Suppl Stockh, 476(167), 167-175.

Reitan, R. M. (1958). Validity of the Trail Making Test as an indication of organic brain damage. Perceptual and Motor Skills, 8, 271-276.

Reuben, D. B., Mui, S., Damesyn, M., Moore, A. A., \& Greendale, G. A. (1999). The prognostic value of sensory impairment in older persons. Journal of the American Geriatrics Society, 47(8), 930-935.

Sands, L. P., \& Meredith, W. (1989). Effects of sensory and motor functioning on adult intellectual performance. Journal of Gerontology, 44(2), 56-58.

Schneider, B. A., \& Pichora-Fuller, M. K. (2000). Implications of perceptual deterioration for cognitive aging research. In F. I. Craik \& T. A. Salthouse (Eds.), The handbook of aging and cognition (pp. 155-219). Mahwah, NJ: Erlbaum.

Smith, A. (1968). The Symbol Digit Modalities Test: A neuropsychological test for economic screening of learning and other cerebral disorders. Learning Disorders, 36, 83-91.

Stankov, L., \& Anstey, K. (1997). Health and cognitive aging: the emerging role of sensorimotor abilities. Australian Journal on Aging, 16(1), 34-39.

Stroop, J. R. (1935). Studies of interference in serial verbal reactions. Journal of Experimental Psychology, 18, 643662.

Van Beijsterveldt, C. E., van Boxtel, M. P., Bosma, H., Houx, P. J., Buntinx, F., \& Jolles, J. (2002). Predictors of attrition in a longitudinal cognitive aging study: the Maastricht Aging Study (MAAS). Journal of Clinical Epidemiology, 55(3), 216-223.

Van Boxtel, M. P., ten Tusscher, M. P., Metsemakers, J. F., Willems, B., \& Jolles, J. (2001). Visual determinants of reduced performance on the Stroop color-word test in normal aging individuals. Journal of Clinical and Experimental Neuropsychology, 23(5), 620-627.

Van Boxtel, M. P. J., Buntinx, F., Houx, P. J., Metsemakers, J. F. M., Knottnerus, J. A., \& Jolles, J. (1998). The relation between morbidity and cognitive performance in a normal aging population. Journal of Gerontology, 53A(2), M146-M154.

Van Boxtel, M. P. J., van Beijsterveldt, T., Houx, P. J., Anteunis, L. J. C., Metsemakers, J. F. M., \& Jolles, J. (2000). Mild hearing impairment can reduce verbal memory performance in a healthy adult population. Journal of Clinical and Experimental Neuropsychology, 22(1), 147-154.

Vink, M., \& Jolles, J. (1985). A new version of the Trail-Making Test as an information processing task. Journal of Clinical Neuropsychology, 7, 162.

Wallhagen, M. I., Strawbridge, W. J., Shema, S. J., Kurata, J., \& Kaplan, G. A. (2001). Comparative impact of hearing and vision impairment on subsequent functioning. Journal of the American Geriatrics Society, 49(8), 1086-1092. 
Westheimer, G. (1987). Visual Acuity. In R. A. Moses \& W. M. J. Hart (Eds.), Adler's Physiology of the Eye: Clinical Application. St. Louis: Mosby. 
CHAPTER 3. CHANGE IN SENSORY FUNCTIONING PREDICTS CHANGE IN COGNITIVE FUNCTIONING 

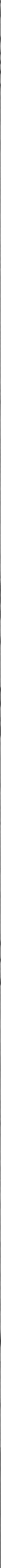

Robert D. Hill, Susanne A.M. Valentijn, Susan A.H. van Hooren, Jelle Jolles and Martin P. J. van Boxtel. 


\section{Abstract}

This study examined the SF-36 Physical Functioning (PF) scale score as a measure of Functional Independence in a representative sample of older Dutch adults. Hierarchical logistic regression procedures were employed to determine whether the PF scale score could be used to predict the emergence of an expressed need for assistance on activities of daily living $(A D L / I A D L)$ after an interval of three years. Participants were enrolees in the Maastricht Aging Study (MAAS). They were 50 years and older and were screened for health and cognitive deficits. Results indicated that the SF-36 PF scale score predicted change in assistance need for daily activities three years later. Lower SF-36 PF scores were associated with the emergence of an assistance need on daily activities. The SF-36 PF scale, which assesses restriction in functioning on activities of daily living may be a suitable measure of change in the explicit acknowledgement of ADL/IADL assistance need with the passage of time. 


\section{Introduction}

Functional Independence $(\mathrm{FI})$ is a generic term that has been used to describe an individual's capability to negotiate self-care and domestic tasks essential in everyday living particularly among older adults who are at risk for functional impairment including chronically ill, frail older, and disabled individuals (MacNeill \& Lichtenberg, 1998). The characterization of $\mathrm{FI}$ in normal aging has been elusive given that a generally accepted standard of $\mathrm{FI}$ in normal aging has been the presence of an acknowledged need of help (or assistance) from another person to successfully negotiate activities of daily living (Brorsson \& Asberg, 1984; Fillenbaum, 1984). However, measures of independent functioning that discriminate only on the basis of those who explicitly express the need for assistance in performing activities of daily living tasks from those who do not need assistance are not sufficiently sensitive to detect the small but precursory changes in one's capability to perform an everyday living task that could identify one's risk for functional dependency at a much earlier point in the disablement process (Mor, Murphy, \& Masterson-Allen, 1989; Reuben, Valle, Hays, \& Siu, 1995).

In spite of this challenge, several large-scale population-based studies have examined $\mathrm{FI}$ in normal aging employing traditional measures of Activities of Daily Living (or ADL) and/or Instrumental Activities of Daily Living (IADL) as the criterion of FI (Stessman, Hammerman-Rozenberg, Maaravi, \& Cohen, 2002; Strauss, Aguero-Torres, Kareholt, Winblad, \& Fratiglioni, 2003). In the form of paper-and-pencil surveys, ADL/IADL checklists are ubiquitous in the extant clinical literature with the majority designed to assess one's ability to accomplish self-care (or instrumental) tasks with or without the provision of help from another person. For example, the Katz (Katz, Ford, Moskowitz, Jackson, \& Jaffe, 1963), a widely used ADL checklist, constrains functional independence to six self-care activities; namely, bathing, grooming, dressing, toileting, transferring, and feeding oneself. For these tasks, the respondent (or a proxy) is required to report whether the identified patient is able to perform each criterion task: (1) without help, (2) with help, or (3) cannot perform the task even with assistance.

As a quantifiable marker of demand that the deterioration of a person's functional status places upon the support environment, accurately gauging one's ability to perform activities of daily living has important public 
health implications, especially among those older adults who are already functionally limited (Morris, Sherwood, \& Mor, 1984). However, little can be gained from these measures as to whether an older adult, who is functioning independently with respect to activities of daily living, is at risk of becoming functionally dependent in the future. Thus, for those older adults who are in relatively good health and living independently, markers of functionality that are more sensitive to the subtle changes that occur in one's functional capacity are needed (Kempen, Miedema, Ormel, \& Molenaar, 1996; Verbrugge \& Jette, 1994). Such markers can be used to identify individuals 'at risk' for loosing their independence in the near future. From a pragmatic viewpoint, in the everyday world, people range in their ability to independently negotiate daily living tasks including those who can perform them with ease and efficiency to others who can only just meet the minimum criteria for successful independent performance. In both of these instances scores on traditional $A D L$ and IADL measures would not distinguish these persons although in the latter case the likelihood of functional dependence in the future would be relatively high.

To address this issue, several contemporary measures of Fl have been developed and employed to discriminate groups of older adults with respect to $\mathrm{Fl}$ using metrics that depend on multiple indicators of functional capability, in addition to the expressed need for assistance (or help) from another person. In a study of 70-year old persons in Denmark, a measure that incorporated a broad range of daily living tasks (e.g., laundry, shopping, gardening, etc.) with additional performance indicators including tiredness, slower speed, as well as the need for help, was used to assess older adults who varied with respect to IADL-activities (Avlund, Schultz-Larsen, \& Kreiner, 1993). A similar instrument, the Groningen Activity Restriction Scale, employed a measure of "activity restriction" as a marker of functional ability in old age. It should be noted that both instruments are highly specific with respect to their content domain and they have not been prospectively examined as predictors of $\mathrm{Fl}$ (Kempen et al., 1996).

The SF-36 (Ware \& Sherbourne, 1992; Ware, Snow, Kosinski, \& Gandek, 1993), a widely used measure of subjective physical and mental health, includes in its item base both ADL and IADL tasks. Further, the SF-36 not only assesses one's general sense of health, but also whether one's 
health influences functionality operationalized as grocery shopping, bathing and/or dressing, transfer (in the form of walking), and engaging in goalrelated behavior (such as climbing a flight of stairs). Specifically, the SF-36 inquires not whether one can (or cannot) perform a specific daily living task without assistance, but whether one 'feels' limited in performing activities of daily living due to changes in one's physical or mental health condition (Ware \& Sherbourne, 1992). Further, SF-36 has been administered to older adult samples including diseased (Wiener, Hanley, Clark, \& VanNostrand, 1990) and healthy (von Strauss, Aguero-Torres, Kareholt, Winblad, \& Fratiglioni, 2003) individuals across a variety of culturally-diverse groups (Sabbah, Drouby, Sabbah, Retel-Rude, \& Mercier, 2003). Unlike ADL/IADL checklists, the SF-36 has not been specifically used to measure $\mathrm{Fl}$ in older adults, however, its nature and content, as well as its previous use in older adult groups makes it a potential candidate for such a purpose.

The goal of this study was to examine whether the SF-36, or it's component scale scores, could predict change in the acknowledgment of assistance need on activities representative of ADL and IADL tasks in a sample of older Dutch adults from the Maastricht Aging Study (MAAS) who, by definition, were aging normally and whose baseline rate of affirming $A D L / I A D L$ assistance need was relatively low.

\section{Method}

\section{Sample}

The Maastricht Aging Study (MAAS) is a longitudinal investigation of Dutch adults from the Limburg Province of the Netherlands (the southern-most geographical region). The MAAS was initiated in 1993 to examine the cognitive and physiological consequences of normal aging. To this end, it has employed a range of experimental and standardized instruments of health and psychological functioning at a baseline interval and across two follow-up occasions, each separated by three years. The details of the MAAS, its overall scope and design, can be found in several published reports (Jolles et al., 2001; Van Beijsterveldt et al., 2002; Van Boxtel et al., 1998). The focus of this study, however, was on a subgroup of 838 older MAAS 
participants, 50+ years, who were re-assessed at the first follow-up interval, denoted as Wave 2, when the SF-36 was systematically administered to all participants. Of these persons, $85 \%$ or 710 persons were also successfully reassessed at a second follow-up, denoted as Wave 3. Thus, this group represented those MAAS enrolees who had completed the SF-36 Health Survey as well as the activities of daily living items from the MAAS Health and Family History Questionnaire at both follow-up occasions; namely, Waves 2 and 3. Noteworthy, 14 persons with Mini-Mental State Examination (MMSE) (Folstein, Folstein, \& McHugh, 1975) scores indicative of cognitive dysfunction (a score $<=23$ ) at Wave 2 who were excluded in order to maximize the trustworthiness of SF-36 and the activities of daily living selfreport data. This resulted in a target sample of 696 persons who were identified for analysis. A small number of these participants had missing SF36 items $(n=10)$ and when this occurred, imputed data were employed to replace missing values based on standard procedures described for the replacement of missing SF-36 data (Ware \& Sherbourne, 1992). Missing information was also identified in approximately $12 \%$ of individual daily activity tasks and, where this occurred, data were imputed using a decision rule based on the pattern of existing data (e.g., if 3 or more activities were rated as "needing help" the missing item values were coded as "needing help"). However, when this was not possible, random replacement data was imputed.

\section{Measures}

\section{Daily Activity Tasks}

The questions that assessed adaptive functioning included a listing of specific daily living tasks that were representative of ADL/IADL functioning across five functional domains; namely, (1) shopping, (2) housework, (3) personal hygiene, (4) dressing, and (5) preparing meals. Although two of these, personal hygiene and dressing, have been construed as ADL behaviors, they have also been employed in several IADL scales as well (Kempen et al., 1996) and, for this reason, the designers of the MAAS assessment battery chose not to distinguish these as either IADL or ADL behaviors per se. For each daily living task respondents indicated whether 
they could perform the task with or without help. A dichotomous score was subsequently generated with (o) indicating that no assistance was needed on any of the five daily activity tasks and a (1) indicating that assistance was needed on at least one of the five daily activity tasks.

\section{Affective Symptomatology}

Depressive and anxiety symptomatology was measured using the depression and anxiety subscales of a Dutch language translation of the Symptom Check List-90 (SCL-90) (Arrindell \& Ettema, 1986). As a widely used standardized self-report inventory of psychiatric symptomatology, the SCL-9o is rated on a 5-point scale and has been employed to measure mental health status in non-clinical older adult samples (Derogatis, 1977).

\section{Subjective Health}

A Dutch translation of the MOS 36-item Short-Form Health Survey (SF-36) (Zee, Xanderman, \& Heyink, 1993) was administered to all participants at Waves 2 and 3 . This widely used 36-item paper-and-pencil measure of perceived health is composed of eight scale scores conceptually linked to healthy functioning; namely, physical functioning (PF), role functioning (RP), Emotional Role (RE), Bodily Pain (BP), General Health (GH), Vitality (VT), Social Functioning (SF), and Mental Health (MH). With respect to individual items within each scale score, the PF Scale contains several items that are also reflective of activities of daily living referencing leisure/sport activities, grocery shopping, dressing, and bathing. In each case, however, the item content is based on the extent to which a respondent believes that the performance of these tasks is restricted (or limited) due to one's health. The remaining seven SF-36 scale scores; namely the RP, RE, BP, GH, VT, SF, MH scales, do not contain items that make specific reference to daily activities, but focus on multiple issues that impact health (e.g., pain). The SF-36 response format is standardized based on predetermined procedures described in the SF-36 user's manual with each scale score ranging from o to 100. Higher scores indicate better health within each scale score domain. 


\section{Procedure}

Demographics, as well as the $A D L$ and IADL self-report items were administered as part of a packet of health questions that were mailed to all MAAS participants who agreed to be re-assessed at Wave 2 and then subsequently at Wave 3. With respect to the mailing procedures, participants received a 24-page questionnaire booklet labelled the MAAS Medical and Family History Survey that was composed of several self-report instruments including Dutch language translations of the SF-36 and the SCL-90 respectively. Also contained in this questionnaire were general questions about physical and cognitive functioning that included the five activity of daily living tasks. Participants who received the mailing were instructed to complete the questionnaire and asked to return it in the provided enclosed self-addressed, stamped envelope. When the questionnaire was returned by mail, a member of the MAAS project staff contacted the respondent and scheduled a return visit. It was at this return visit that the MMSE was administered to the participant by a trained psychometric technician.

\section{Results}

Table 1 summarizes the selected demographic characteristics of the 696 MAAS participants including age, sex, and educational attainment. The SCL90 depression and anxiety scale scores at the six-year follow-up interval (Wave 3) are also summarized, as well as the eight SF-36 scale scores obtained at Wave 2 and at Wave 3. At Wave 2, there was a significant difference between groups in age, sex, and education with respect to assistance need (ps<0.05) with those who were older, female, and with less education needing more often assistance. Group differences were also found for MMSE, depressive and anxiety symptomatology favouring those MAAS enrolees who reported no assistance needs (ps<0.01). All SF-36 scale scores were significant, ps<0.001, with those reporting assistance need scoring lower in each instance. With respect to Wave 3, there were group differences for the MMSE and the SCL-9o anxiety and depression scores favouring those who had no assistance needs (ps<0.01). The same was the case across all SF36 scale scores with those reporting assistance needs scoring lower than those who reported no assistance need (ps<0.01). 
Table 1. Baseline demographics, SCL-90, and SF-36 data among MAAS participants at wave 2 and wave 3

\begin{tabular}{|c|c|c|c|c|c|c|}
\hline & Wave 2 & & & Wave 3 & & \\
\hline & $\begin{array}{l}\text { ADL present } \\
(\mathrm{N}=150)\end{array}$ & $\begin{array}{l}\text { ADL absent } \\
(\mathrm{N}=546)\end{array}$ & $p$ value & $\begin{array}{l}\text { ADL present } \\
(\mathrm{N}=199)\end{array}$ & $\begin{array}{l}\text { ADL absent } \\
(\mathrm{N}=497)\end{array}$ & $p$ value \\
\hline Age (years) & $67.02(9.15)$ & $60.81(8.13)$ & $<0.01$ & - & - & - \\
\hline $\begin{array}{l}\text { Sex } \\
\text { (\% female) }\end{array}$ & 70.7 & 42.5 & $<0.01$ & - & - & - \\
\hline Education & $2.95(1.63)$ & $3.29(1.80)$ & $<0.05$ & - & - & - \\
\hline $\begin{array}{l}\text { Depressive } \\
\text { symptoms }\end{array}$ & $24.21(8.30)$ & $21.14(6.18)$ & $<0.05$ & $22.81(6.61)$ & $21.40(4.06)$ & $<0.01$ \\
\hline $\begin{array}{l}\text { Anxiety } \\
\text { symptoms }\end{array}$ & $14.26(5.18)$ & $12.52(3.63)$ & $<0.05$ & $13.36(4.39)$ & $12.71(4.06)$ & $<0.01$ \\
\hline MMSE & $28.11(1.66)$ & $28.51(1.44)$ & $<0.01$ & $28.12(1.92)$ & $28.58(1.36)$ & $<0.01$ \\
\hline $\begin{array}{l}\text { Physical } \\
\text { functioning }\end{array}$ & $54.18(23.45)$ & 83.44 (15.81) & $<0.01$ & $54.86(24.35)$ & $81.63(16.73)$ & $<0.01$ \\
\hline $\begin{array}{l}\text { Role } \\
\text { physical }\end{array}$ & $52.42(42.75)$ & $85.38(30.06)$ & $<0.01$ & $53.50(40.04)$ & 83. 29 (30.42) & $<0.01$ \\
\hline $\begin{array}{l}\text { Role } \\
\text { emotional }\end{array}$ & $70.82(41.20)$ & 89.38 (26.21) & $<0.01$ & 73.78 (37.35) & $87.05(28.30)$ & $<0.01$ \\
\hline $\begin{array}{l}\text { Social } \\
\text { functioning }\end{array}$ & $73.00(24.32)$ & $87.90(16.55)$ & $<0.01$ & $72.14(23.53)$ & $87.00(17.14)$ & $<0.01$ \\
\hline $\begin{array}{l}\text { Mental } \\
\text { health }\end{array}$ & 71.61 (17.32) & $78.64(14.10)$ & $<0.01$ & 72.60 (15.39) & 78.30 (14.11) & $<0.01$ \\
\hline Vitality & $57.82(20.36)$ & $70.36(15.26)$ & $<0.01$ & $58.66(17.67)$ & $69.69(14.89)$ & $<0.01$ \\
\hline Bodily pain & $65.12(23.21)$ & $82.41(18.83)$ & $<0.01$ & $65.11(23.39)$ & $83.06(19.21)$ & $<0.01$ \\
\hline $\begin{array}{l}\text { General } \\
\text { health }\end{array}$ & $55.69(17.75)$ & $68.53(14.59)$ & $<0.01$ & $54.16(17.92)$ & $66.58(14.86)$ & $<0.01$ \\
\hline
\end{tabular}

MMSE $=$ Mini Mental State Examination

To examine the impact of the demographic variables, SCL-9o subscales, and SF-36 scale scores on change in assistance need (from Wave 2 to Wave 3), an hierarchical logistic regression was employed with assistance need at Wave 3 as the dichotomous outcome variable (e.g., no help with daily activity tasks = 0; an acknowledged "assistance need" on one or more daily activity tasks $=1$ ). Variable entry was: Assistance need at Wave 2 entered first (step 1) followed by the entry of four additional variable blocks; namely, demographics (age, education, sex; step 2), the MMSE (step 3), affective symptomatology (the SCL-9o depression and anxiety subscales; step 4), and 
CHAPTER 4. THE SF-36 AS A PRECURSORY MEASURE OF ADAPTIVE FUNCTIONING IN NORMAL AGING

the final variable block that included the eight SF-36 scale scores obtained at Wave 2 (PF, RP, RE, BP, GH, VT, MH, and SF; step 5).

Table 2. Regression analysis with ADL need at wave 3 as the dependent variable

\begin{tabular}{|c|c|c|c|c|c|c|}
\hline & & $\chi^{2}$ & $B$ value & $\begin{array}{l}\text { Standard } \\
\text { Error }\end{array}$ & $p$ value & OR $(95 \% \mathrm{Cl})$ \\
\hline Step 1 & & $231.52^{* *}$ & & & & \\
\hline & ADL Need (at wave 2) & & 2.47 & 0.29 & $<0.01$ & $11.90(6.80-20.83)$ \\
\hline \multirow[t]{4}{*}{ Step 2} & & $42.74^{* *}$ & & & & \\
\hline & Age & & 0.07 & 0.01 & $<0.01$ & $1.08(1.05-1.11)$ \\
\hline & Sex & & -0.36 & 0.23 & 0.13 & $0.70(0.44-1.11)$ \\
\hline & Education & & -0.03 & 0.07 & 0.65 & $0.97(0.85-1.11)$ \\
\hline \multirow[t]{2}{*}{ Step 3} & & 0.33 & & & & \\
\hline & MMSE & & 0.44 & 0.08 & 0.58 & $1.05(0.89-1.23)$ \\
\hline Step 4 & & 1.22 & & & & \\
\hline & Depressive symptoms & & -0.00 & 0.03 & 0.95 & $1.00(0.94-1.07)$ \\
\hline & Anxiety symptoms & & -0.06 & 0.04 & 0.15 & $0.94(0.86-1.02)$ \\
\hline Step 5 & & $17.87^{*}$ & & & & \\
\hline & Physical functioning & & -0.18 & 0.01 & 0.02 & $0.98(0.97-1.00)$ \\
\hline & Role physical & & -0.00 & 0.00 & 0.69 & $1.00(0.99-1.01)$ \\
\hline & Role emotional & & -0.00 & 0.00 & 0.45 & $1.00(0.99-1.00)$ \\
\hline & Social functioning & & -0.00 & 0.01 & 0.63 & $1.00(0.98-1.01)$ \\
\hline & Mental health & & -0.01 & 0.01 & 0.38 & $1.00(0.96-1.01)$ \\
\hline & Vitality & & -0.02 & 0.01 & 0.14 & $1.02(0.99-1.04)$ \\
\hline & Bodily pain & & -0.01 & 0.01 & 0.36 & $0.99(0.98-1.01)$ \\
\hline & General health & & -0.00 & 0.01 & 0.80 & $1.00(0.98-1.02)$ \\
\hline \multicolumn{7}{|l|}{ Overall } \\
\hline & Overall model fit & 293.67 & & & & \\
\hline
\end{tabular}

MMSE $=$ Mini Mental State Examination,

$* p<0.05 \mid * * p<0.01$

As summarized in Table 2, assistance need at Wave 2 was predictive of assistance need at Wave 3 (odds ratio 11.90, 95\%, Cl: 6.80-20.83). Age was the only significant demographic variable (odds ratio $1.08,95 \%, \mathrm{Cl}: 1.05-1.11$ ) 
with older participants more likely to report the emergence of an assistance need from Wave 2 to Wave 3. When entered last, the PF scale score of SF-36 at Wave 2 was the only significant predictor (odds ratio 0.98, 95\%, Cl: 0.971.0) with a lower score indicating an increased propensity for assistance need.

To determine the discriminatory accuracy of the SF-36 PF subscale for detecting assistance need on daily activities prior to its overt acknowledgement, a receiver operating characteristic (ROC) curve was computed. The area under the ROC curve of $0.81 \quad(\mathrm{SE}=0.007)$ indicated moderate to good discrimination based on generally accepted of standards of clinical estimation (Hsiao, Bartko, \& Potter, 1989).

\section{Discussion}

The primary objective of this study was to examine the extent to which specific subscales of the SF-36 could predict assistance need on tasks of daily living in a sample of older adults who were, for the most part, nondiseased and community-dwelling. Daily activities were assessed by the selfreported acknowledgement of whether assistance from another person was needed to negotiate one of the five daily living tasks representative of typical ADL/IADL behaviors. In this study the percentage of individuals who reported that they needed assistance in order to perform one or more of these tasks were relatively low - $22 \%$ at wave 2 and $29 \%$ at wave 3 - which underscores the healthy nature of this sample. As expected, SF-36 scores were reflective of the endorsement of assistance need at Wave 2 and at Wave 3; that is, those who reported assistance need scored lower across all SF-36 subscales. This finding was anticipated given that the SF-36 content overlaps with many of the activities of daily living measured in this study. Of specific interest, however was the finding that the SF-36 physical function scale score was predictive of conversion to a need for assistance on daily living tasks from Wave 2 to Wave 3; that is, those who developed an activity assistance need from Wave 2 to Wave 3 follow-up could be reliably identified by the SF-36 physical function (PF) score. 
For the purpose of obtaining a more sensitive metric of functionality with respect to daily living tasks the SF-36 PF scale score identified the emergence of an assistance need in ADL/IADL behaviors over time in healthy older adults who did not acknowledge such a need at Wave 2. Thus, the SF36 PF scale score may have utility as an early marker of risk for loss of $\mathrm{Fl}$ in old age. Several researchers (Verbrugge \& Jette, 1994) have cogently argued that new measures of functionality are needed (beyond traditional ADL and IADL checklists) in order to produce more continuous versus ordinal criterion scores capable of gauging Fl. This argument makes strong intuitive sense, since continuous scores could be very useful in developing more comprehensive and sensitive prediction models of $\mathrm{Fl}$ in normal aging.

As future studies employ the SF-36 PF scale score as a measure of functionality this could have important practical implications for long-term care, particularly if an SF-36 functionality index could be used to identify individuals at risk for becoming functionally dependent even though they may not, at the time of measurement, explicitly report that their functional limitations are so great as to need assistance in negotiating self-care or instrumental tasks essential for daily living. Information about disablement at the earliest possible point in the process (e.g., before objective changes have occurred in one's overt functioning) could create a window of opportunity for preventive planning to more effectively address the needs of individuals at high risk from becoming functionally impaired in the future.

The fact that the SF-36 is a highly regarded reliable and valid measure of health quality makes it an ideal instrument that could easily be incorporated in longitudinal studies designed to address the epidemiology of functional dependence in older adults. Future research could employ this measure to assess functional disability specific to activities of daily living such as the Groningen Activity Restriction Scale (Kempen et al., 1996) to pinpoint the extent to which such content-specific measures of functionality can be used to gauge the disablement process in older adults who are, for the most part, aging normally. 


\section{References}

Arrindell, W. A., \& Ettema, J. H. M. (1986). SCL-90. Een multidimensionele psychopathologie indicator (The SCL-90. A multidimensional instrument for the assessment of psychopathology). Lisse, The Netherlands: Swets \& Zeitlinger.

Avlund, K., Schultz-Larsen, K., \& Kreiner, S. (1993). The measurement of instrumental ADL: Content validity and construct validity. Aging, Clinical and Experimental Research, 5(1-13).

Brorsson, B., \& Asberg, K. H. (1984). Katz index of independence in ADL: Reliability and validity in short-term care. Scandinavian Journal of Rehabilitative Medicine, 16, 125-132.

Derogatis, L. R. (1977). SCL-90: Administration, scoring and procedures manual-I for the R(evised) version. Baltimore: Johns Hopkins School of Medicine, Clinical Psychometrics Research Unit.

Fillenbaum, G. G. (1984). The well-being of the elderly. Approaches to multidimensional assessment. Geneva: World Health Organization.

Folstein, M. F., Folstein, S. E., \& McHugh, P. R. (1975). Mini-mental State: a practical method for grading the cognitive state of patients for the clinician. Journal of Psychiatric Research, 12, 189-198.

Hsiao, J. K., Bartko, J. J., \& Potter, W. Z. (1989). Diagnosing diagnoses receiver operacting characteristic methods and psychiatry. Archives of General Psychiatry, 46(664-667).

Jolles, J., Commissaris, C. J. A. M., Bosma, H., van Boxtel, M. P. J., Ponds, R. W. H. M., Metsemakers, J. F. M., et al. (2001). De Maastricht Aging Study en het longitudinale perspectief van cognitieve veroudering. In A. H. Schene, F. Boer, T. J. Heeren, H. W. J. Henselmans, R. W. Trijsburg, W. Vandereycken \& K. van der Velden (Eds.), Jaarboek voor Psychiatrie en Psychotherapie (Vol. 7, pp. 175-193). Houten/Giegem: Bohn Stafleu Van Loghum.

Katz, S., Ford, A. B., Moskowitz, R. W., Jackson, B. A., \& Jaffe, M. W. (1963). Studies of illness in the aged. Journal of the American Medical Association, 185(12), 914-919.

Kempen, G. I. J. M., Miedema, I., Ormel, J., \& Molenaar, W. (1996). The assessment of disability with the Groningen Activity Restriction Scale. Conceptual framework and psychometric properties. Social Science Medicine, 43(11), 1602-1996.

MacNeill, S. E., \& Lichtenberg, P. A. (1998). Predictors for functional outcome in older rehabilitation patients. Rehabilitation Psychology, 1998 Fal Vol 43(3) 246-257, 246-257.

Mor, V., Murphy, J., \& Masterson-Allen, S. (1989). Risk of functional decline among well elders. Journal of Clinical Epidemiology, 42, 895-904.

Morris, J. N., Sherwood, S., \& Mor, V. (1984). An assessment tool for use in identifying functionally vulnerable persons living in the community. Gerontologist, 24(373-380).

Reuben, D. B., Valle, L. A., Hays, R. D., \& Siu, A. L. (1995). Measuring physical function in community-dwelling older persons: A comparison of self-administered, interviewer-administered, and performance-based measures. Journal of the American Geriatrics Society, 43(17-23).

Sabbah, I., Drouby, N., Sabbah, S., Retel-Rude, N., \& Mercier, M. (2003). Quality of life in rural and urban populations in Lebanon using SF-36 Health Survey. Health and Quality of Life Outcomes, 1, 30.

Stessman, J., Hammerman-Rozenberg, R., Maaravi, Y., \& Cohen, A. (2002). Effect of exercise on ease in performing activities of daily living and instrumental activities of daily living from age 70 to 77 : the Jerusalem Longitudinal Study. Journal of the American Geriatrics Society, 50(12), 1934. 
Strauss, E. v., Aguero-Torres, H., Kareholt, l., Winblad, B., \& Fratiglioni, L. (2003). Women are more disabled in basic activities of daily living than men only in very advanced ages: A study on disability, morbidiety, and mortality from the Kungsholmen Project. Journal of Clinical Epidemiology, 56, 2003.

Van Beijsterveldt, C. E., van Boxtel, M. P., Bosma, H., Houx, P. J., Buntinx, F., \& Jolles, J. (2002). Predictors of attrition in a longitudinal cognitive aging study: the Maastricht Aging Study (MAAS). Journal of Clinical Epidemiology, 55(3), 216-223.

Van Boxtel, M. P. J., Buntinx, F., Houx, P. J., Metsemakers, J. F. M., Knottnerus, A., \& Jolles, J. (1998). The Maastricht Aging Study The relation between morbidity and cognitive performance in a normal aging population. Journals of Gerontology: Medical Sciences, 53A, 147-154.

Verbrugge, L. M., \& Jette, A. M. (1994). The disablement process. Social Science \& Medicine, 38(1), 1-14.

Von Strauss, E., Aguero-Torres, H., Kareholt, I., Winblad, B., \& Fratiglioni, L. (2003). Women are more disabled in basic activities of dialy living than men only in very advanced ages: A study on disability, morbidity, and mortality from the Kngsholmen Project. Journal of Clinical Epidemiology, 56, 669-677.

Ware, J., J. E., \& Sherbourne, C. D. (1992). The MOS 36-item short-form health survey (SF-36): I. conceptual framework and item selection. Medical Care, 30(6), 473-483.

Ware, J. E., Snow, K. K., Kosinski, M., \& Gandek, B. (1993). SF-36 health survey manual and interpretation guide. Boston, MA: New England Medical Center, The health institute.

Wiener, J. M., Hanley, R. J., Clark, R., \& VanNostrand, R. F. (1990). Measuring the activities of daily living: Compatrison across national sruveys. Journals of Gerontology: Social Sciences, 45, 229.

Zee, K. I. v. d., Xanderman, R., \& Heyink, J. (1993). Psychometrische kwaliteiten van de MOS 36-item Short Form Health Survey (SF-36) in een Nederlandse populatie. Tijdschrift voor Sociale Gezondheidzorg, 71, 183-191. 


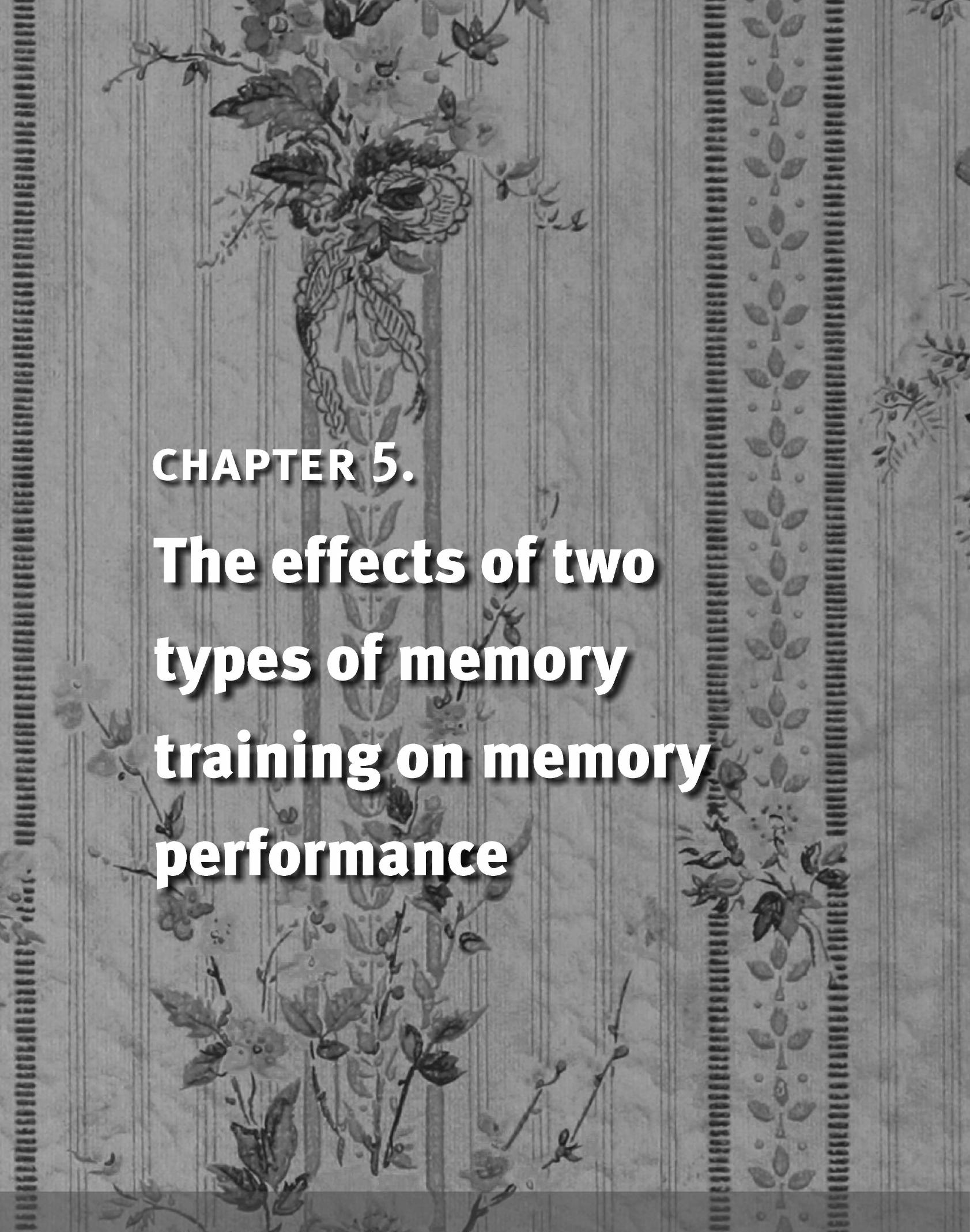

Patient Education and Counseling. In press.

Susanne A.M. Valentijn, Susan A.H. van Hooren, Hans Bosma, Dory M. Touw, Jelle Jolles, Martin P.J. van Boxtel and Rudolf W.H.M. Ponds. 


\section{Abstract}

The objective of the study was to examine the effectiveness of two types of memory training (collective and individual), compared to control (waitinglist), on memory performance. Participants were 139 community-dwelling older individuals recruited through media advertisements asking for people with subjective memory complaints to participate in a study. Data were collected at baseline, and at 1 week and 4 months after the intervention. Training effects were assessed using measures of subjective and objective memory performance. After the intervention, participants in the collective training group reported more stability in memory functioning and had fewer feelings of anxiety and stress about memory functioning. In addition, positive effects were found on objective memory functioning. Compared with the other two groups, the collective training group participants had an improved recall of a previously learned word list. Compared to controls, participants in the individual training group reported fewer feelings of anxiety and stress in relation to memory functioning. 


\section{Introduction}

Elderly individuals often complain about their memory and are concerned that this perceived memory loss might lead to degenerative disorders such as Alzheimer's Disease (Cutler \& Grams, 1988; R. W. H. M. Ponds, 1998). A decline in memory functioning in old age might explain in part subjective memory complaints (Dik et al., 2001; Jonker, Geerlings, \& Schmand, 2000; Jorm, Christensen, Korten, Jacomb, \& Henderson, 2001). However, this explanation is not adequate because complaints of memory loss are not always associated with an actual decline in objective memory function (Birren \& Schaie, 1996; Bolla, Lindgren, Bonaccorsy, \& Bleecker, 1991; Comijs, Deeg, Dik, Twisk, \& Jonker, 2002; Commissaris, Ponds, \& Jolles, 1998; Derouesne, Lacomblez, Thibault, \& LePoncin, 1999). Research shows that memory complaints are determined by several other factors besides objective memory performance (Clarnette, Almeida, Forstl, Paton, \& Martins, 2001; Stevens, Kaplan, Ponds, \& Jolles, 2001). The knowledge, beliefs, and perceptions people have about their own memory functioning and the memory system in general, termed 'metamemory', are considered an important factor (Dixon, 1989; Jolles, van Boxtel, Ponds, Metsemakers, \& Houx, 1998; Levy-Cushman \& Abeles, 1998; Ponds, 1998). Metamemory covers several dimensions that are relevant to everyday memory functioning. One of these dimensions, 'Memory Self-Efficacy' (MSE), can be defined as the level of confidence a person has in the effectiveness of his or her own memory in different situations (Cavanaugh, 1996). MSE is considered an important moderator of changes in memory functioning and can have affect memory performance through cognitive, affective and motivational processes (Berry \& West, 1993; Lovelace, 1990). For example, low expectations of successful memory functioning could lower motivation to achieve a good performance or could even cause avoidance of situations that call on memory. This negative influence could lead to a poorer memory performance and in turn reinforces the negative memory beliefs elderly have (Ponds \& Jolles, 1996b).

We designed a training program to improve objective memory and MSE. This program emphasizes how MSE works in relation to everyday memory performance. Participants are asked to actively register memory failures and successes in a dairy, to help them to gain insight into their memory functioning and to analyze their everyday memory problems. In 
addition, memory skills are trained by teaching the participants internal (repeating, visualization, making associations) and external (habits, agenda, people around you) memory strategies. Another important aspect of this training program is education on how the memory works in old age. Educating elderly people on how memory works and about the difference between normal and pathological aging are indispensable aspects of memory training. Other important aspects essential to optimal memory functioning, such as time, attention, concentration, good vision and hearing are also discussed in depth (Commissaris, 1993).

To our knowledge, there have been few studies evaluating intervention programs focused on influencing and adjusting maladaptive beliefs about memory performance, combined with memory skills training (Floyd \& Scogin, 1997). Furthermore, most studies evaluated group-training programs. Group sessions are known to have a comforting and motivating effect because people can share problems with a relevant peer group (Verhaeghen, Marcoen, \& Goossens, 1992). However, self-taught memory training programs are also an effective form of memory intervention (Andrewes, Kinsella, \& Murphy, 1996; Scogin, Prohaska, \& Weeks, 1998; Woolverton, Scogin, Shackelford, Black, \& Duke, 2001), and are advantageous in that a large group of subjects can be reached in a fairly inexpensive way. Moreover, self-taught memory training programs have some practical advantages, such as the fact that participants do not have to go to the training at fixed times and have the opportunity to study at their own speed. Therefore, we offered the intervention as a collective training program and as an individual self-taught training program, based on a handbook about memory functioning in daily life, and which contained the essentials of the collective training intervention.

The aim of the present study was to examine the effectiveness of these two forms of our memory-training program in comparison with control, in improving memory performance in a large group of community-dwelling older individuals. 


\section{Methods}

\section{Participants}

All participants were older people recruited through media advertisements asking for people with subjective memory complaints to participate in a study. Participants were included in the study if they were 55 years or older, had a good comprehension of the Dutch language, were mobile enough to travel independently to the research center, were not using psychotropic medication on a daily basis, and had not previously participated in a neuropsychological research program. Exclusion criteria were a score below 24 on the Mini-Mental State Examination (MMSE) (Folstein, Folstein, \& McHugh, 1975), a diagnosis of central nervous system pathology, or a major psychiatric disorder.

The Medical Ethics Committee of the University Hospital Maastricht approved the protocol and all participants gave informed consent.

\section{Intervention}

\section{Collective training}

The memory training program was developed by (Ponds \& Bouwens, 1997) and taught by experienced teachers of the service center of the home care organization Groene Kruis Heuvelland in Maastricht, the Netherlands. The program was developed to increase knowledge of normal memory functioning and normal memory decline with aging, and to promote insight into one's memory functioning. The maximum number of participants per group was twelve, to ensure that the training group could function optimally, and for logistic reasons. The training was administered in eight 2-hour sessions, one session a week. Each session was structured: homework and last week's theme were discussed first and then the new theme or topic was introduced. All themes were illustrated with practical assignments. The themes involved were: short -and long-term memory, storage and retrieval of information, age-related decline in memory functioning, differences between normal memory functioning and dementia, memory self-efficacy, the relation between memory functioning and physical and psychological health, and 
internal and external memory strategies. All topics were discussed briefly in the last session. All participants received a reader.

\section{Individual training}

The Dutch book 'Geheugensteun' ('Memory support') (Ponds \& Verhey, 2000) covers the same content in the same order as the above described memory training program. All themes discussed in the collective memory training sessions are also extensively described in the book. The memory training book differed from the collective training program in that there were fewer practical assignments and homework and subjects had to study on their own. To facilitate and motivate this self-study, all subjects were given a study schedule, and after 4 weeks they were telephoned to ask them if they were on schedule with their reading and if they had any questions about the book.

\section{Measures}

The outcome variables were obtained from a test battery that included subjective and objective memory tests to measure memory functioning before and immediately after the intervention and 4 months later. All measures were administered by trained assistants who were not involved in the memory training.

\section{Objective Memory Tests}

The Visual Verbal Learning Test (VVLT) (Brand \& Jolles, 1985) is a verbal memory task to measure the ability to learn new verbal information and retrieve information from memory. Fifteen low-associative words are presented to the subject five times. After each presentation the subject is asked to recall as many words as possible, with no restriction concerning the order of recall (immediate recall). The maximum score that can be obtained after five successive trails is 75 . Twenty minutes after the last presentation the subject is again requested to recall as many correct words as possible (delayed recall). Parallel versions of the memory task were used for each assessment. 
The Short Story test (Bouma, Lindenboom, \& van Houte, 1990; Niehof, 1995) is a Dutch memory task to measure storage of logical information. Participants are handed out a page of carefully constructed prose. After reading the story out aloud, the subjects are given 3 minutes to study the story and then they are asked to tell as much as possible about the story in their own words (immediate recall) and again 15 minutes later (delayed recall). The maximum score is 38 . Parallel versions of the story were used for each assessment.

\section{Subjective Memory Tests}

Three scales of the abridged Metamemory in Adulthood questionnaire (MIA) (Ponds \& Jolles, 1996a) were used to evaluate subjective memory functioning. Participants are asked to rate statements on a 5-point Likert scale (strongly agree, agree, undecided, disagree, strongly disagree). The Capacity scale consists of 12 items and higher scores indicate more perceived memory capacity (e.g. 'I am good at remembering birthdays'). The Change scale has 10 items and a higher score indicates less perceived decline or more stability in memory functioning (e.g. 'I am less efficient at remembering things now than I used to be'). The Anxiety scale includes12 items and a higher score reflects more feelings of anxiety and stress in relation to memory functioning (e.g. 'I get anxious when I am asked to remember something'). The three scales Capacity, Change and Anxiety together form the factor 'Memory Self-Efficacy' and higher scores indicate a higher MSE level.

The Cognitive Failure Questionnaire (CFO) (Broadbent, Cooper, FitzGerald, \& Parkes, 1982) is validated for and adapted to the Dutch population (Merckelbach, Muris, Nijman, \& de Jong, 1996; Ponds, 1998). The questionnaire consists of 25 items measuring the frequency of everyday cognitive 'failures' in the area of memory, attention, perception and action. Participants are asked to indicate on a 5-point scale how often they usually experience each particular cognitive failure (never, very rarely, occasionally, quite often, and very often). A higher score on the CFQ indicates more cognitive failure. 


\section{Other variables}

Four subtasks of the Groningen Intelligence Test (GIT) (Luteijn \& van der Ploeg, 1983) were used to make a reliable estimation of IQ. The four subtasks involved were: the correct completion of as many addition sums as possible in 1 minute, indicating which of five alternative words is exactly synonymous with a given word, indicating which two-dimensional shapes from a larger set are needed to exactly fill up a given space, and indicating which of five alternatives is related in the same way to a given word as two words in an example.

The Mini-Mental State Examination (MMSE) (Folstein et al., 1975) was used as a screening instrument for dementia, and consists of the subscales orientation, registration, recall, attention, language, and construction. A maximum score of 30 can be obtained.

Level of education (1-8) was scored as follows: $1=$ primary education, $2=$ lower vocational education, $3=$ intermediate general secondary education, $4=$ intermediate vocational education, $5=$ higher general secondary education/ university preparatory education, $6=$ higher vocational preparatory education, $7=$ higher professional education, $8=$ university education (De Bie, 1987).

\section{Procedure}

The design was a randomized controlled trial with two follow-up measurements. All groups were neuropsychologically tested four times; two pre-test assessments (double baseline, with 1 week in between), a post-test (at 9 weeks, 1 week after completion of the intervention program) and a follow-up assessment ( 4 months after the intervention). The main reason for using a double baseline was to administer the VVLT two times, in order to minimize learning and procedure-learning effects. Therefore, all the statistical analyses were performed using data for the second baseline assessment and the two subsequent follow-up measurements. The same test battery and questionnaires were administered before treatment (second baseline), at the 1-week follow-up and at the 4-month follow-up. All neuropsychological tests were administered in the same order on all test occasions.

Participants were randomly assigned to a collective memory-training program, an individual memory-training program, or a control group. The 
method of randomization was a block design with block size three, and with stratification for sex. The investigators responsible for randomization were not involved in the training procedures. To avoid contamination, couples were always assigned to the same condition.

\section{Statistical analysis}

All statistical analyses were performed using SPSS for Macintosh, version 10 (SPSS-Inc., Chicago). Although individuals were randomly assigned to the three conditions, differences in baseline characteristics between the three groups were examined. Separate One-way Analyses of Variance (ANOVA) were performed for age, educational level, intelligence and MMSE scores. A Chi-square test was used to analyze the variables sex and marital status (married or cohabiting versus others).

General Linear Model (GLM) repeated measures analysis of variance was carried out to examine the effect of the interventions on memory performance. Analyses were performed with group as the between-subjects variable and memory performance on the first and second follow-up phase as the within-subjects factor. Contrasts were defined to compare performance of the three groups over time.

In these analyses, age, sex, educational level and baseline scores were treated as covariates. Baseline scores were treated as covariates in this model to control for baseline group differences, which were present in one of the outcome variables. Because comparisons were made between more than two groups, estimated effects sizes were defined with partial Eta-squared values $\left(\eta^{2}\right)$. Consistent with the rules for clinical trials, all analyses were based on the groups as randomized, according to the principle of 'intentionto-treat' (Altman, 1991). In addition, results of analyses with data for subjects who actually completed the intervention are also reported.

\section{Results}

\section{Recruitment}

One hundred forty-nine individuals were willing to participate. Ten participants did not meet the inclusion criteria and were excluded from 
participation; seven participants with a MMSE score below 24, and three participants who previously participated in a neuropsychological research program.

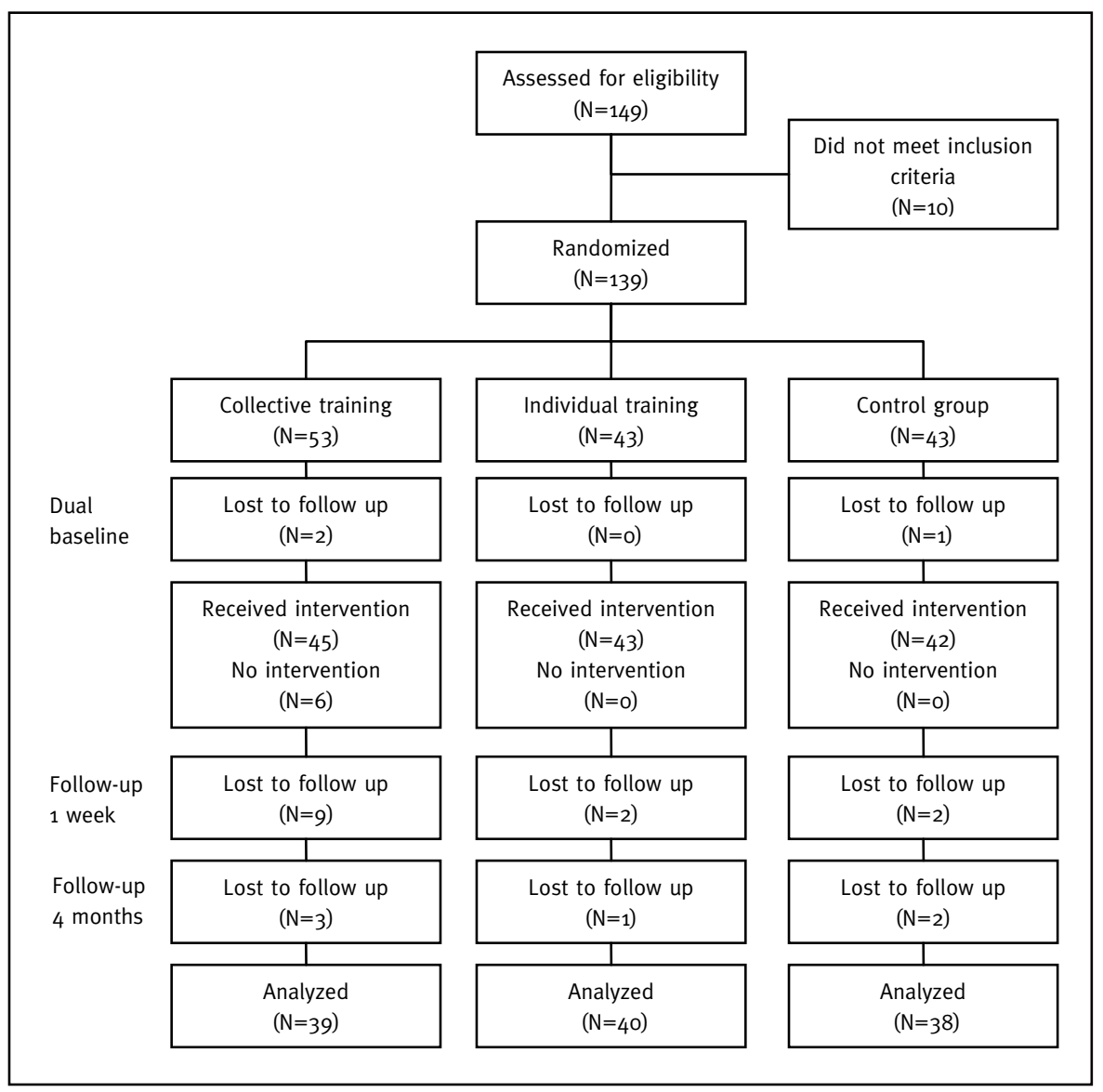

Figure 1. Results of recruitment

The 139 elderly individuals who met the inclusion criteria were randomly assigned to one of three groups: a collective training group $(\mathrm{N}=53)$, an individual training group $(\mathrm{N}=43)$ or a control group $(\mathrm{N}=43)$. In total 136 (97.8\%) people completed the assessment before the intervention, 123 (88.5\%) persons completed the 1-week follow-up and 117 (84.2\%) participants completed the whole study. Twenty-two people dropped out the study, 14 of them were originally assigned to the collective training group, 3 
to the individual training group and 5 to the control group. The number of dropouts was significantly higher in the collective training group $(p=0.02)$. Results of recruitment and randomization are given in Figure 1.

\section{Baseline background characteristics}

There were no significant differences between the three groups in age, marital status, intelligence, education, and MMSE-score. Demographic characteristics and mean MMSE and IQ scores are summarized in Table 1.

Table 1. Means and standard deviations for demographic variables in each study group (total $\mathrm{N}=139$ )

\begin{tabular}{lllll}
\hline & $\begin{array}{l}\text { Collective } \\
\text { training } \\
(\mathrm{N}=53)\end{array}$ & $\begin{array}{l}\text { Individual } \\
\text { training } \\
(\mathrm{N}=43)\end{array}$ & $\begin{array}{l}\text { Control group } \\
(\mathrm{N}=43)\end{array}$ & $\begin{array}{l}p \\
\text { value }\end{array}$ \\
\hline Age & $69.32(7.77)$ & $68.07(6.58)$ & $68.30(8.03)$ & 0.68 \\
Marital status (\% married/living together) & $60 \%$ & $53 \%$ & $72 \%$ & 0.49 \\
Gender (\% women) & $70 \%$ & $63 \%$ & $63 \%$ & 0.70 \\
Education & $3.83(1.96)$ & $3.74(1.84)$ & $3.86(2.24)$ & 0.96 \\
IQ & $118.88(13.37)$ & $122.51(11.62)$ & $122.40(11.46)$ & 0.26 \\
MMSE & $28.72(1.26)$ & $28.77(1.48)$ & $28.49(1.74)$ & 0.65 \\
\hline
\end{tabular}

MMSE $=$ Mini Mental State Examination

In addition, the three groups were compared with respect to the number of self-reported life events, the number of illnesses reported on a morbidity checklist, whether or not participants ever suffered from concussion, or had been under general anaesthesia, and their levels of depressive and anxiety symptoms, measured with the subscales Depression and Anxiety of the Symptom Checklist-9o (SCL-90) (Derogatis, 1977). No differences were found between the three groups on any of these variables (not tabulated). 
CHAPTER 5. THE EFFECT OF TWO TYPES OF MEMORY TRAINING ON MEMORY PERFORMANCE

Table 2. Means, standard deviations and group differences in objective memory

\begin{tabular}{|c|c|c|c|c|c|}
\hline & $\begin{array}{l}\text { Collective } \\
\text { training (1) }\end{array}$ & $\begin{array}{l}\text { Individual } \\
\text { training (2) }\end{array}$ & $\begin{array}{l}\text { Control group } \\
\text { (3) }\end{array}$ & $\begin{array}{l}\text { Main } \\
\text { effect } \\
p \text {-value }\end{array}$ & Contrasts \\
\hline WLT total score & $\mathrm{N}=38$ & $\mathrm{~N}=40$ & $\mathrm{~N}=38$ & 0.16 & \\
\hline Baseline & $49.40(9.57)^{\dagger}$ & $49.75(8.94)^{\dagger}$ & $52.42(8.03)^{\dagger}$ & & \\
\hline 1-week follow-up & $53.26(7.34)^{\dagger}$ & $52.35(10.21)^{\dagger}$ & $53.24(8.42)^{\dagger}$ & & \\
\hline 4-month follow-up & $55.76(8.98)^{\dagger}$ & $53.70(9.370)^{\dagger}$ & $55.22(8.69)^{\dagger}$ & & \\
\hline 1-week follow-up & $54.00(1.06)^{\ddagger}$ & $52.82(1.03)^{\ddagger}$ & $52.01(1.06)^{\ddagger}$ & & \\
\hline 4-month follow-up & $56.73(1.10)^{\ddagger}$ & $54.07(1.06)^{\ddagger}$ & $53.86(1.10)^{\ddagger}$ & & \\
\hline WLT recall & $\mathrm{N}=38$ & $\mathrm{~N}=40$ & $\mathrm{~N}=38$ & 0.001 & $\begin{array}{l}1>2^{* *} \\
1>3^{* *}\end{array}$ \\
\hline Baseline & $9.76(3.48)^{\dagger}$ & $9.90(3.25)^{\dagger}$ & $10.32(2.79)^{\dagger}$ & & \\
\hline 1-week follow-up & $11.76(2.42)^{\dagger}$ & $10.85(3.22)^{\dagger}$ & $10.95(2.57)^{\dagger}$ & & \\
\hline 4-month follow-up & $11.95(2.58)^{\dagger}$ & $10.50(3.11)^{\dagger}$ & $11.11(2.89)^{\dagger}$ & & \\
\hline 1-week follow-up & $11.93(0.32)^{\ddagger}$ & $10.90(0.31)^{\ddagger}$ & $10.73(0.32)^{\ddagger}$ & & \\
\hline 4-month follow-up & $12.12(0.32)^{\ddagger}$ & $10.55(0.31)^{\ddagger}$ & $10.88(0.32)^{\ddagger}$ & & \\
\hline $\begin{array}{l}\text { Short story immediate } \\
\text { recall }\end{array}$ & $\mathrm{N}=36$ & $\mathrm{~N}=40$ & $\mathrm{~N}=38$ & 0.33 & \\
\hline Baseline & $13.67(4.78)^{\dagger}$ & $16.98(4.23)^{\dagger}$ & $15.00(4.84)^{\dagger}$ & & \\
\hline 1-week follow-up & $15.17(4.12)^{\dagger}$ & $16.30(5.81)^{\dagger}$ & $15.74(5.31)^{\dagger}$ & & \\
\hline 4-moths follow-up & $16.22(3.78)^{\dagger}$ & $15.55(3.99)^{\dagger}$ & $15.42(3.29)^{\dagger}$ & & \\
\hline 1-week follow-up & $16.14(0.73)^{\ddagger}$ & $15.43(0.70)^{\ddagger}$ & $15.74(0.70)^{\ddagger}$ & & \\
\hline 4-month follow-up & $16.64(0.57)^{\ddagger}$ & $15.15(0.54)^{\ddagger}$ & $15.45(0.54)^{\ddagger}$ & & \\
\hline Short story delayed recall & $\mathrm{N}=35$ & $\mathrm{~N}=40$ & $\mathrm{~N}=38$ & 0.15 & \\
\hline Baseline & $17.09(4.82)^{\dagger}$ & $19.95(6.01)^{\dagger}$ & $18.74(5.55)^{\dagger}$ & & \\
\hline 1-week follow-up & $17.71(5.37)^{\dagger}$ & $18.30(6.70)^{\dagger}$ & $18.26(6.52)^{\dagger}$ & & \\
\hline 4-month follow-up & $17.97(4.89)^{\dagger}$ & $18.38(6.58)^{\dagger}$ & $18.00(4.79)^{\dagger}$ & & \\
\hline 1-week follow-up & $18.94(0.75)^{\ddagger}$ & $17.33(0.70)^{\ddagger}$ & $18.16(0.71)^{\ddagger}$ & & \\
\hline 4-month follow-up & $19.15(0.65)^{\ddagger}$ & $17.50(0.60)^{\ddagger}$ & $17.84(0.61)^{\ddagger}$ & & \\
\hline
\end{tabular}

WLT $=$ Visual Verbal Learning Test $\mid p$ values are interpreted as the results of comparison between the different groups $\mid{ }^{* *} p<$ $\left.0.01\right|^{\dagger}$ Unadjusted mean scores and standard deviations | ${ }^{\ddagger}$ Mean scores and standard errors adjusted for age, gender, educational level and baseline scores 


\section{Objective memory performance}

The collective training group had better performance scores than the individual training group or the control group on the delayed recall task of the VVLT $(F(2,109)=7.584, p=0.001)$. Significant contrasts were found between the group training condition and the other two groups, indicating that over time, the subjects who received the collective training intervention were better able to remember a previously learned word list. The estimated effect size $\left(\eta^{2}\right)$ was 0.122 . No interactions were found, suggesting that no change in intervention effect took place from 1 week to 4 months follow-up. This was confirmed using univariate Analyses of Variance on the second follow-up, where a significant effect was found for group training condition ( $F$ $(2,109)=6.634, p=0.002)$. Main effects of group membership on the other objective outcome variables were not statistically significant (see Table 2).

\section{Subjective memory performance}

A significant main effect was found for group membership on the MIA scale Change $(F(2,98)=3.089, p=0.050)$, estimated effect size $\left(\eta^{2}\right)$ was 0.059 , with a significant contrast between the collective training group and the control group (see Table 3). After the intervention the collective training group reported more feelings of stability concerning memory functioning, as compared to the control group. In addition, a main effect of group membership was found on the Anxiety scale of the $\operatorname{MIA}(F(2,98)=3.986$, $p=0.022)$. The estimated effect size $\left(\eta^{2}\right)$ was 0.075 . Significant contrasts were found between the collective training group and the control group, and between the individual training group and the control group, indicating that over time both intervention groups showed a consistent decrease in stress and anxiety in memory related situations, as compared to the control group. Main effects of group membership on the other subjective outcome variables were not statistically significant.

Data were analyzed separately for participants who completed the intervention. In the collective training group, non-compliance was defined as attendance of 5 or fewer sessions. 
CHAPTER 5. THE EFFECT OF TWO TYPES OF MEMORY TRAINING ON MEMORY PERFORMANCE

Table 3. Means, standard deviations and group differences in subjective memory

\begin{tabular}{|c|c|c|c|c|c|}
\hline & $\begin{array}{l}\text { Collective } \\
\text { training (1) }\end{array}$ & $\begin{array}{l}\text { Individual } \\
\text { training (2) }\end{array}$ & $\begin{array}{l}\text { Control group } \\
\text { (3) }\end{array}$ & $\begin{array}{l}\text { Main } \\
\text { effect } \\
p \text {-value }\end{array}$ & Contrasts \\
\hline Memory Self -Efficacy & $\mathrm{N}=38$ & $\mathrm{~N}=40$ & $\mathrm{~N}=38$ & 0.09 & \\
\hline Baseline & $2.76(0.54)^{\dagger}$ & $2.72(0.40)^{\dagger}$ & $2.88(0.54)^{\dagger}$ & & \\
\hline 1-week follow-up & $2.89(0.51)^{\dagger}$ & $2.82(0.42)^{\dagger}$ & $2.83(0.56)^{\dagger}$ & & \\
\hline 4-month follow-up & $2.87(0.54)^{\dagger}$ & $2.82(0.44)^{\dagger}$ & $2.88(0.53)^{\dagger}$ & & \\
\hline 1-week follow-up & $2.92(0.05)^{\ddagger}$ & $2.86(0.05)^{\ddagger}$ & $2.76(0.05)^{\ddagger}$ & & \\
\hline 4-month follow-up & $2.91(0.05)^{\ddagger}$ & $2.87(0.05)^{\ddagger}$ & $2.80(0.05)^{\ddagger}$ & & \\
\hline Mia Capacity & $\mathrm{N}=38$ & $\mathrm{~N}=40$ & $\mathrm{~N}=38$ & 0.97 & \\
\hline Baseline & $2.79(0.52)^{\dagger}$ & $2.67(0.39)^{\dagger}$ & $2.83(0.66)^{\dagger}$ & & \\
\hline 1-week follow-up & $2.85(0.57)^{\dagger}$ & $2.71(0.38)^{\dagger}$ & $2.85(0.63)^{\dagger}$ & & \\
\hline 4-month follow-up & $2.78(0.50)^{\dagger}$ & $2.75(0.31)^{\dagger}$ & $2.83(0.55)^{\dagger}$ & & \\
\hline 1-week follow-up & $2.83(0.07)^{\ddagger}$ & $2.76(0.07)^{\ddagger}$ & $2.81(0.07)^{\ddagger}$ & & \\
\hline 4-month follow-up & $2.77(0.06)^{\ddagger}$ & $2.80(0.06)^{\ddagger}$ & $2.79(0.06)^{\ddagger}$ & & \\
\hline Mia Change & $\mathrm{N}=36$ & $\mathrm{~N}=40$ & $\mathrm{~N}=38$ & 0.05 & $1>3 *$ \\
\hline Baseline & $2.49(0.71)^{\dagger}$ & $2.50(0.48)^{\dagger}$ & $2.64(0.68)^{\dagger}$ & & \\
\hline 1-week follow-up & $2.76(0.62)^{\dagger}$ & $2.63(0.53)^{\dagger}$ & $2.59(0.69)^{\dagger}$ & & \\
\hline 4-month follow-up & $2.74(0.74)^{\dagger}$ & $2.59(0.49)^{\dagger}$ & $2.72(0.73)^{\dagger}$ & & \\
\hline 1-week follow-up & $2.81(0.07)^{\ddagger}$ & $2.65(0.07)^{\ddagger}$ & $2.51(0.07)^{\ddagger}$ & & \\
\hline 4-month follow-up & $2.80(0.08)^{\ddagger}$ & $2.61(0.08)^{\ddagger}$ & $2.64(0.08)^{\ddagger}$ & & \\
\hline Mia Anxiety & $\mathrm{N}=35$ & $\mathrm{~N}=40$ & $\mathrm{~N}=38$ & 0.02 & $1>3^{*}, 2>3^{* *}$ \\
\hline Baseline & $3.00(0.73)^{\dagger}$ & $3.02(0.69)^{\dagger}$ & $2.85(0.64)^{\dagger}$ & & \\
\hline 1-week follow-up & $2.92(0.70)^{\dagger}$ & $2.89(0.65)^{\dagger}$ & $2.94(0.69)^{\dagger}$ & & \\
\hline 4-month follow-up & $2.90(0.69)^{\dagger}$ & $2.87(0.74)^{\dagger}$ & $2.90(0.64)^{\dagger}$ & & \\
\hline 1-week follow-up & $2.87(0.06)^{\ddagger}$ & $2.84(0.06)^{\ddagger}$ & $3.03(0.06)^{\ddagger}$ & & \\
\hline 4-month follow-up & $2.85(0.06)^{\ddagger}$ & $2.82(0.06)^{\ddagger}$ & $3.00(0.06)^{\ddagger}$ & & \\
\hline CFQ total score & & & & 0.79 & \\
\hline Baseline & $36.83(12.16)^{\dagger}$ & $37.24(11.48)^{\dagger}$ & $36.95(12.58)^{\dagger}$ & & \\
\hline 1-week follow-up & $35.85(12.42)^{\dagger}$ & $36.54(12.92)^{\dagger}$ & $37.40(11.43)^{\dagger}$ & & \\
\hline 4-month follow-up & $34.78(10.85)^{\dagger}$ & $35.66(11.49)^{\dagger}$ & $36.00(13.69)^{\dagger}$ & & \\
\hline 1-week follow-up & $36.03(1.37)^{\ddagger}$ & $36.50(1.34)^{\ddagger}$ & $37.26(1.36)^{\ddagger}$ & & \\
\hline 4-month follow-up & $34.89(1.39)^{\ddagger}$ & $35.53(1.36)^{\ddagger}$ & $36.02(1.38)^{\ddagger}$ & & \\
\hline
\end{tabular}


$\mathrm{Mia}=$ Metamemory In Adulthood questionnaire $\mid \mathrm{CFQ}=$ Cognitive Failure Questionnaire $\mid p$ values are interpreted as the results of comparison between the different groups $\left.\right|^{*} p<\left.0.05\right|^{* *} p<\left.0.01\right|^{\dagger}$ Unadjusted mean scores and standard deviations $\left.\right|^{\ddagger}$ Mean scores and standard errors, adjusted for age, gender, educational level and baseline scores

In the individual training group, non-compliance was defined as the inability to answer correctly 7 of 11 statements (true or false) about the content of the book and the inability to name at least three memory strategies, discussed in the book. In the collective training group, six people decided not to start with the intervention, but stayed in the study and provided follow-up data. Nine participants discontinued the intervention and were lost to follow-up, but they had already been excluded from analyses. In the individual training group three participants were considered non-compliant, but did provide follow-up data. Main reasons for not completing the training course or not reading the book were being too busy with other activities or work, having no transport to the training center, health-related problems, or family circumstances.

When the analyses were restricted to compliant participants only, the results were similar, except that effects became more robust. For example, an additional small effect on the total score of the $\operatorname{VVLT}(F(2,100)=2.639$, $p=0.076$ ) was found with a significant contrast between the collective training group and the control group.

\section{Discussion}

The main objective of this study was to compare the effect of two types of memory training interventions, relative to a waiting-list control. Outcome variables were both subjective and objective memory functioning. After the intervention, participants in the collective memory-training group reported more stability in memory functioning and had fewer feelings of anxiety and stress in relation to memory functioning. In addition, positive effects were found in objective memory functioning. Compared with the other two groups, the collective training group had an improved recall of a previously learned word list. However, no effects were found on the logical memory test. A possible explanation for the absence of intervention effects on the latter test is differences in test reliability (Lezak, 1995). In contrast, a positive effect of the intervention in the individual training group was only found on the Anxiety scale of the MIA. This contrasts with reports of the effectiveness of 
self-taught training in improving memory performance and memory knowledge (Woolverton et al., 2001) and with reports that individual training is as effective as group training (Rasmusson, Rebok, Bylsma, \& Brandt, 1999; Scogin et al., 1998). However, our findings are consistent with other studies showing that the gain of an intervention is maximal when participants can benefit from the comforting and motivating effect of sharing their concerns about memory with others (Flynn \& Storandt, 1990; Verhaeghen et al., 1992). Since the elderly participants in the individual training program received the same information as those in the collective memory-training group, this group effect is apparently considerable. Bandura (1989) also pointed out that vicarious observation and social influences or persuasions are important sources of self-efficacy, and these sources are provided by group participation. A second important difference is that in the collective training program all themes that were discussed were illustrated with practical examples, so participants had the opportunity to practice the new information.

Attrition and compliance appeared to be selective in this study, in that most of the dropouts were originally assigned to the collective training group. This indicates that motivational factors contribute significantly to a successful intervention. This conclusion is supported by the observation that when the analyses were restricted to compliant participants, effects became more robust, even when as a result of this procedure the power of the overall test was reduced. Participants in this study already had an above average performance on memory tests at baseline, and were intelligent, healthy and particularly interested in memory functioning. We compared the performance on the VVLT of the participants in this study with the performance of elderly subjects who participated in the Maastricht Aging Study (MAAS), a longitudinal study on normal cognitive aging (Dijkstra, Van Boxtel, Houx, \& Jolles, 1998; Jolles, Houx, van Boxtel, \& Ponds, 1995; van Boxtel et al., 1998). Participants in our study outperformed elderly subjects who were enrolled in the MAAS study in terms of the total score and the recall score of the VVLT, after matching for sex, age, and education. However, compared with elderly people in the MAAS, the participants in the current study were less confident about the effectiveness of their own memory, reported more perceived decline, and had more feelings of anxiety and stress 
in relation to memory functioning (Ponds, 1998). This indicates that the participants of our study may belong to a sub-population of elderly people, with a relatively normal functioning but who do have complaints and who are willing to invest time and effort in an intervention. This may be an important finding because it suggests that there are elderly who would like to participate in an intervention, possibly in the expectation that training may help prevent an incipient decline of cognitive functioning. A follow-up study is warranted to learn more about the characteristics of this group of elderly individuals and the determinants of success of the training. These findings also have implications for the maximal results that can be obtained with the training program. Because our participants were already functioning at a relatively high level at baseline, intervention gains could possibly be more difficult to detect. However, previous studies have found that individuals who tend to benefit the most from interventions are the ones who are younger and have better cognitive functions at baseline (Hill, Yesavage, Seikh, \& Friedman, 1989; Kliegl, Smith, \& Baltes, 1990; Verhaeghen et al., 1992), although others did not confirm these findings (Brooks, Friedman, Pearman, Gray, \& Yesavage, 1999; Cavallini, Pagnin, \& Vecchi, 2003; Mohs et al., 1998; Rasmusson et al., 1999).

Although effects were relatively small and were not found for all outcome variables, the overall pattern of results suggests that the collective variant of this training program is effective in improving subjective and objective memory performance. Taking into account the time, effort and costs associated with the intervention, we consider the program a valuable contribution to public health interventions for older adults. Our conclusions were based on between-group comparisons. In individual cases there may be even more substantial intervention effects. This makes it potentially important to find out whether particular variables can predict maximal treatment outcome. Results suggest that the program is most likely to be effective in people who have the time, the opportunity and the motivation to participate in a memory-training program. It is conceivable that the intervention would have more beneficial effects in more selected groups of participants, such as elderly individuals with more pronounced memory 
CHAPTER 5. THE EFFECT OF TWO TYPES OF MEMORY TRAINING ON MEMORY PERFORMANCE

complaints, or patients who have been referred to a memory clinic. A followup study is being planned to test this notion in more detail. 


\section{References}

Altman, D. G. (1991). Practical statistics for medical research (1st ed.). London: Chapman \& Hall.

Andrewes, D. G., Kinsella, G., \& Murphy, M. (1996). Using a memory handbook to improve everyday memory in community-based older adults with memory complaints. Experimental Aging Research, 22, 305-322.

Bandura, A. (1989). Regulation of cognitive processes through perceived self-efficacy. Developmental Psychology, 25(5), 729-735.

Berry, J. M., \& West, R. L. (1993). Cognitive self-efficacy in relation to personal mastery and goal setting across the life span. International Journal of Behavioral Development, 16, 351-379.

Birren, J. E., \& Schaie, K. W. E. (1996). Handbook of the psychology of aging (4 ed.). San Diego: Academic Press.

Bolla, K. I., Lindgren, K. N., Bonaccorsy, C., \& Bleecker, M. L. (1991). Memory complaints in older adults. Fact or fiction? Archives of Neurology, 48, 61-64.

Bouma, J. M., Lindenboom, J., \& van Houte, L. (1990). Klinische neuropsychologische assesment: een handleiding voor de praktijk. Amsterdam.

Brand, N., \& Jolles, J. (1985). Learning and retrieval rate of words presented auditorily and visually. Journal of General Psychology, 112(2), 201-210.

Broadbent, D. E., Cooper, P. F., FitzGerald, P., \& Parkes, K. R. (1982). The Cognitive Failure Questionnaire (CFQ) and its correlates. British Journal of Clinical Psychology, 21, 1-16.

Brooks, J. 0., 3rd, Friedman, L., Pearman, A. M., Gray, C., \& Yesavage, J. A. (1999). Mnemonic training in older adults: effects of age, length of training, and type of cognitive pretraining. International Psychogeriatrics, 11(1), 75-84.

Cavallini, E., Pagnin, A., \& Vecchi, T. (2003). Aging and everyday memory: the beneficial effect of memory training. Arch Gerontol Geriatr, 37(3), 241-257.

Cavanaugh, J. C. (1996). Memory self-efficacy as a moderator of memory change. In F. Blanchard-Fields \& T. H. Hess (Eds.), Perspectives on Cognitive Change in Adulthood and Aging (pp. 488-507). New York: The McGraw-Hill Compagnies.

Clarnette, R. M., Almeida, O. P., Forstl, H., Paton, A., \& Martins, R. N. (2001). Clinical characteristics of individuals with subjective memory loss in Western Australia: results from a cross-sectional survey. International Journal of Geriatric Psychiatry, 16(2), 168-174.

Comijs, H. C., Deeg, D. J., Dik, M. G., Twisk, J. W., \& Jonker, C. (2002). Memory complaints; the association with psycho-affective and health problems and the role of personality characteristics. A 6-year follow-up study. Journal of Affective Disorders, 72(2), 157-165.

Commissaris, C. J. A. M., Ponds, R. W. H. M., \& Jolles, J. (1998). Subjective forgetfulness in a normal Dutch population: possibilities for health education and other interventions. Patient Education and Counseling, 34, 2532.

Commissaris, C. J. A. M. (1993). Voorlichting over geheugenproblemen en dementie [Education about memory problems and dementia] (Thesis). Maastricht University.

Cutler, S. J., \& Grams, A. E. (1988). Correlates of self-reported everyday memory problems. Journal of Gerontology: Social Sciences, 43(3), 82-90. 


\section{CHAPTER 5. THE EFFECT OF TWO TYPES OF MEMORY TRAINING ON MEMORY PERFORMANCE}

De Bie, S. E. (1987). Standaardvragen 1987: Voorstellen voor uniformering van vraagstellingen naar achtergrondkenmerken en interviews [Standard questions 1987: Proposal for uniformization of questions regarding background variables and interviews] (2nd ed.). Leiden: Leiden University Press.

Derogatis, L. R. (1977). SCL-90: Administration, scoring and procedures manual-I for the R(evised) version. Baltimore: Johns Hopkins School of Medicine, Clinical Psychometrics Research Unit.

Derouesne, C., Lacomblez, L., Thibault, S., \& LePoncin, M. (1999). Memory complaints in young and elderly subjects. International Journal of Geriatric Psychiatry, 14(4), 291-301.

Dijkstra, J. B., Van Boxtel, M. P., Houx, P. J., \& Jolles, J. (1998). An operation under general anesthesia as a risk factor for age-related cognitive decline: results from a large cross-sectional population study. Journal of the American Geriatric Society, 46(10), 1258-1265.

Dik, M. G., Jonker, C., Comijs, H. C., Bouter, L. M., Twisk, J. W., van Kamp, G. J., et al. (2001). Memory complaints and APOE-epsilon4 accelerate cognitive decline in cognitively normal elderly. Neurology, 57(12), 2217-2222.

Dixon, R. A. (1989). Questionnaire research on metamemory and aging: issues of structure and function. In L. W. Poon, D. C. Rubin \& B. A. Wilson (Eds.), Everyday cognition in adulthood and late life (pp. 394-415). Cambridge: Cambridge University Press.

Floyd, M., \& Scogin, F. (1997). Effects of memory training on the subjective memory functioning and mental health of older adults: a meta-analysis. Psychology and Aging, 12(1), 150-161.

Flynn, T. M., \& Storandt, M. (1990). Supplemental group discussions in memory training for older adults. Psychology and Aging, 5(2), 178-181.

Folstein, M. F., Folstein, S. E., \& McHugh, P. R. (1975). Mini-mental State: a practical method for grading the cognitive state of patients for the clinician. Journal of Psychiatric Research, 12, 189-198.

Hill, R. D., Yesavage, J. A., Seikh, J., \& Friedman, L. (1989). Mental status as a predictor of response to memory training in older adults. Educational Gerontology, 15, 633-639.

Jolles, J., Houx, P. J., van Boxtel, M. P. J., \& Ponds, R. W. H. M. (Eds.). (1995). Maastricht Aging Study: Determinants of cognitive aging. Maastricht: Neuropsych Publishers.

Jolles, J., van Boxtel, M. P., Ponds, R. W., Metsemakers, J. F., \& Houx, P. J. (1998). [The Maastricht aging study (MAAS). The longitudinal perspective of cognitive aging. Tijdschift voor Gerontologie en Geriatrie, 29(3), 120129.

Jonker, C., Geerlings, M. I., \& Schmand, B. (2000). Are memory complaints predictive for dementia? A review of clinical and population-based studies. International Journal of Geriatric Psychiatry, 15(11), 983-991.

Jorm, A. F., Christensen, H., Korten, A. E., Jacomb, P. A., \& Henderson, A. S. (2001). Memory complaints as a precursor of memory impairment in older people: a longitudinal analysis over 7-8 years. Psychological Medicine, 31(3), 441-449.

Kliegl, R., Smith, J., \& Baltes, P. B. (1990). On the locus and process of magnification of age differences during mnemonic training. Developmental Psychology, 6, 894-904.

Levy-Cushman, J., \& Abeles, N. (1998). Memory complaints in the able elderly. Clinical Gerontologist, 19, 3-24.

Lezak, M. D. (1995). Neuropsychological Assessment (3rd ed.). New York: Oxford University Press. 
Lovelace, E. A. (1990). Aging and metacognitions concerning memory function. In E. A. Lovelace (Ed.), Aging and cognition: mental processes, self awareness and interventions (pp. 157-188). Amsterdam, the Netherlands: Elsevier Science.

Luteijn, F., \& van der Ploeg, F. A. E. (1983). Handleiding Groninger Intelligentietest (GIT) [Manual Groningen Intelligence Test]. Lisse, The Netherlands: Swets and Zeitlinger.

Merckelbach, H., Muris, P., Nijman, H., \& de Jong, P. (1996). Self-reported cognitive failures and neurotic symptomatology. Personality and Individual Differences, 20, 715-724.

Mohs, R. C., Ashman, T. A., Jantzen, K., Albert, M., Brandt, J., Gordon, B., et al. (1998). A study of the efficacy of a comprehensive memory enhancement program in healthy elderly persons. Psychiatry Research, 77(3), 183-195.

Niehof, J. (1995). Validering van een zestal logical memory taken.Unpublished manuscript, Groningen.

Ponds, R., \& Verhey, F. (2000). geheugensteun. Utrecht/Antwerpen: Kosmos-Z\&K Uitgevers.

Ponds, R. W. H. M. (1998). Forgetfulness and cognitive aging: Prevalence, characteristics, and determinants (Thesis). Maastricht University.

Ponds, R. W. H. M., \& Bouwens, M. R. J. (1997). Geheugencursus voor ouderen. Den Bosch: Gezondheid Service Nederland.

Ponds, R. W. H. M., \& Jolles, J. (1996a). The abridged Dutch Metamemory in Adulthood (MIA) questionnaire: structure, and effects of age, sex, and education. Psychology and Aging, 11, 324-332.

Ponds, R. W. H. M., \& Jolles, J. (1996b). Memory complaints in elderly people: the role of memory abilities, metamemory, depression, and personality. Educational Gerontology, 22, 341-357.

Rasmusson, D. X., Rebok, G. W., Bylsma, F. W., \& Brandt, J. (1999). Effects of three types of memory training in normal elderly. Aging, Neuropsychology, and Cognition, 6, 56-66.

Scogin, F., Prohaska, M., \& Weeks, E. (1998). The comparative efficacy of self-taught and group memory training for older adults. Journal of Clinical Geropsychology, 4(4), 301-314.

Stevens, F. C. J., Kaplan, C. D., Ponds, R. W. H. M., \& Jolles, J. (2001). The importance of active lifestyles for memory performance and memory self-knowledge. Basic and applied social psychology, 23(2), 137-145.

Van Boxtel, M. P., Gaillard, C., Houx, P. J., Buntinx, F., de Leeuw, P. W., \& Jolles, J. (1998). Is nondipping in $24 \mathrm{~h}$ ambulatory blood pressure related to cognitive dysfunction? Journal of Hypertension, 16(10), 1425-1432.

Verhaeghen, P., Marcoen, A., \& Goossens, L. (1992). Improving memory performance in the aged through mnemonic training: a meta-analytic study. Psychology and Aging, 7(2), 242-251.

Woolverton, M., Scogin, F., Shackelford, J., Black, S., \& Duke, L. (2001). Problem-targeted memory training for older adults. Aging Neuropsychology and cognition, 8(4), 241-255. 
CHAPTER 5. THE EFFECT OF TWO TYPES OF MEMORY TRAINING ON MEMORY PERFORMANCE 


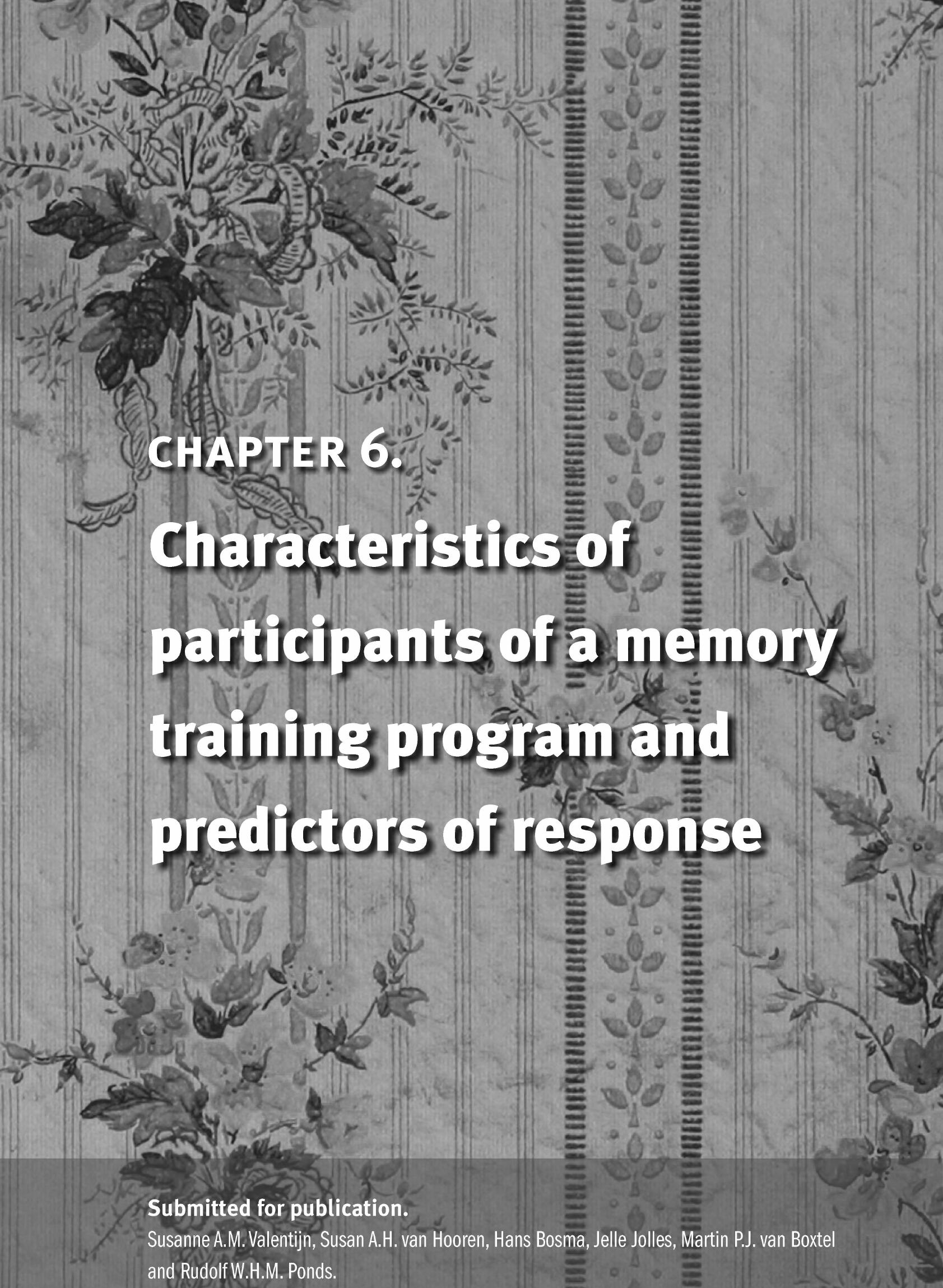




\section{Abstract}

In order to learn more about the characteristics of elderly individuals who participate in a memory-training program, these individuals were compared with healthy older individuals enrolled in the Maastricht Aging Study (MAAS), a longitudinal study of normal cognitive aging. The results indicated that the memory-training program participants had more depressive symptoms and higher levels of neuroticism than did the control subjects. Moreover, it was investigated whether outcome was not associated with neuroticism or anxiety and depression. The overall pattern of interaction effects indicated that these variables are not associated with treatment outcome. Thus, the intervention was equally effective for individuals with high and low levels of neuroticism and for individuals with and without anxiety. However, dropout was higher among elderly individuals who were more neurotic and anxious, which suggests that personality traits can influence the commitment to complete a chosen course of action, such as a memory training program. 


\section{Introduction}

Elderly individuals often complain of problems with memory (Commissaris, Ponds, \& Jolles, 1998; R. W. H. M. Ponds, 1998), and memory-training programs are a popular method to treat these problems. Cognitive restructuring techniques, combined with memory skills training, appear to be most effective in improving memory performance and beliefs about memory efficacy (Best, Hamlett, \& Davis, 1992; Caprio-Prevette \& Fry, 1996; Floyd \& Scogin, 1997; Lachman, Weaver, Bandura, Elliott, \& Lewkowicz, 1992). We designed a training program with emphasis on the modification of negative beliefs and attitudes about memory, combined with memory skills training. Previously we found that the training program was effective in improving subjective and objective memory performance, although attrition was substantial in the intervention group (Valentijn et al., 2004). However, these conclusions are made on a group comparison level and in individual cases there may be even more substantial intervention effects. From a clinical point of view, this makes it potentially important to know which individuals participate in a memory-training program and whether there are variables that can predict maximal treatment outcome, in selecting older adults with memory complaints to participate in a memory training intervention. Data about this are inconsistent, with some studies finding that individuals who tend to benefit most from interventions are the ones that are younger and that have a better cognitive function at baseline (Hill, Yesavage, Seikh, \& Friedman, 1989; Kliegl, Smith, \& Baltes, 1990; Verhaeghen, Marcoen, \& Goossens, 1992), whereas other more recent studies do not confirm these findings (Floyd \& Scogin, 1997; Mohs et al., 1998; Rasmusson, Rebok, Bylsma, \& Brandt, 1999).

Variables such as personality (e.g., neuroticism) and mood (e.g., anxiety, depression) however, are considered important mediators of agerelated change in memory functioning (Comijs, Deeg, Dik, Twisk, \& Jonker, 2002; Jorm, Christensen, Korten, Jacomb, \& Henderson, 2001; Ponds \& Jolles, 1996b; Stevens, Kaplan, Ponds, \& Jolles, 2001), but little is known about how these variables affect the ability to benefit from a memory training program. Given the fact that our memory program focuses on changing negative beliefs, increasing self-efficacy, and reducing worries, it could be argued that this program may be of greater benefit to older individuals who are anxious 
or neurotic than to people who are less anxious or neurotic. On the other hand, anxiety and neuroticism might prevent participants from participating fully in such programs and thus make them less likely to experience benefit. Indeed, according to the processing efficiency theory, anxiety can reduce the storage and processing capacity of the working memory system (Eysenck \& Calvo, 1992; Kizilbash, Vanderploeg, \& Curtiss, 2002; Szymura \& Wodniecka, 2003).

The aim of the present study was twofold. First, individuals who participated in our memory-training program were compared with normal healthy older individuals enrolled in the Maastricht Aging Study (MAAS), a longitudinal study of normal cognitive aging (Jolles, Houx, van Boxtel, \& Ponds, 1995; Van Boxtel et al., 1998). Previously we reported that participants in the intervention study outperformed MAAS participants on the total score and the recall score of a verbal learning test, after matching for sex, age, and education. This indicates that the participants in the memory training study may belong to a sub-population of elderly people, who are functioning relatively normal and have no major complaints, but who are willing to invest time and effort in an intervention (Valentijn et al., 2004). In order to learn more about the characteristics of this group and the determinants of success of the training, we examined if memory-training participants differ from healthy participants of the MAAS study with regard to personality (neuroticism) and mood (anxiety, depression). Second, it was investigated whether these variables can predict which individuals benefit most from the memory intervention program.

\section{Method}

\section{Participants}

Participants of the memory training study were 139 older people $\left(55^{+}\right)$with subjective memory complaints. Briefly, all participants were randomly assigned to one of three conditions: a collective training group ( $\mathrm{N}=53$ ), an individual training group ( $\mathrm{N}=43)$, or a control group $(\mathrm{N}=43)$ (Valentijn et al., 2004). These subjects were compared with subjects recruited from the MAAS, who were selected from a register of 15 family practices in the south of the Netherlands (Metsemakers, Höppener, Knottnerus, Kocken, \& Limonard, 
1992) and were at the moment of inclusion without medical conditions known to interfere with normal cognitive functioning (e.g., dementia, mental retardation, and cerebrovascular pathology). More details can be found elsewhere (Bosma et al., 2003; Jolles et al., 1995; Van Boxtel et al., 1998). The Medical Ethics Committee of the University Hospital Maastricht approved the protocol and all participants gave informed consent.

\section{Intervention protocol}

\section{Collective training}

The memory-training program was developed by Ponds and Bouwens (Ponds \& Bouwens, 1997) and was taught by experienced teachers from the home care organization Groene kruis Heuvelland in Maastricht, the Netherlands. The program was developed to increase knowledge of normal memory functioning and normal memory decline with aging, and to promote insight into own memory functioning. The maximum number of participants per group was twelve, to ensure that the training group could function optimally, and for logistic reasons. The training was given in eight 2-hour sessions, one session a week. Each session was structured: homework and last week's theme were discussed first and then a new theme or topic was introduced. All themes were illustrated with practical assignments. The themes covered were: short- and long-term memory, storage and retrieval of information, age-related decline in memory functioning, differences between normal memory functioning and dementia, memory self-efficacy, the relation between memory functioning and physical and psychological health, and internal and external memory strategies. All topics were discussed briefly in the last session. All participants received a reader.

\section{Individual training}

The Dutch commercially available book 'Geheugensteun' ('Memory support') (Ponds \& Verhey, 2000) covers the same content in the same order as the above described memory-training program. All themes discussed in the collective memory training sessions are also extensively described in the book. The memory-training book differs from the collective training program in that there are fewer practical assignments and homework and subjects 
have to study on their own. To facilitate and motivate this self-study, all subjects were given a study schedule, and after 4 weeks they were telephoned to ask them if they were on schedule with their reading and if they had any questions about the book.

\section{Measures}

The outcome variables were obtained from a test battery that included subjective and objective memory tests to measure memory functioning before, immediately after, and 4 months after completion of the training program. Objective memory tests included the Visual Verbal Learning Test (VVLT) (Brand \& Jolles, 1985), a verbal memory task to measure the ability to learn new verbal information and to retrieve information from memory, and the Short Story, a Dutch memory task to measure storage of logical information (Bouma, Lindenboom, \& van Houte, 1990; Niehof, 1995). The Memory Self-Efficacy subscale of the abridged Metamemory in Adulthood questionnaire (MIA) (R. W. H. M. Ponds \& Jolles, 1996a) and the Cognitive Failure Questionnaire (CFQ) were used as an index of subjective memory function (Broadbent, Cooper, FitzGerald, \& Parkes, 1982; Merckelbach, Muris, Nijman, \& de Jong, 1996).

\section{Psychosocial variables}

The subscales Depression and Anxiety of the Symptom Checklist-9o (SCL-90) were used to measure feelings of depression and anxiety, respectively. Because the two scales are highly correlated, scores can be combined into one distress score (Arrindell \& Ettema, 1986; Derogatis, 1977). Neuroticism was measured with the Neuroticism scale of the Eysenck Personality Questionnaire Revised (EPQ-R) (Eysenck, Eysenck, \& Barrett, 1985).

\section{Procedure}

The design was a randomized controlled trial with two follow-up measurements. All participants were tested neuropsychologically four times; two pre-test assessments (double baseline, with 1 week in between to avoid procedural learning effects), a post-test assessment (at 9 weeks, 1 week after completion of the intervention program), and a follow-up assessment (4 months after completion of the intervention). 


\section{Statistical analysis}

In order to assess group differences between the memory training participants and participants in the MAAS study, One-way Analyses of Variance (ANOVA) were performed for symptoms of depression and anxiety and for level of neuroticism. All participants were matched for sex, age, and education. Because attrition was substantial in the intervention group, group differences between compliant and non-compliant participants in the memory training study were also tested with an ANOVA. Because the non-compliant sample was relatively small, compared to the other groups, analyses were adjusted if variances were not equal.

The differential effectiveness of the memory-training program was examined by including multiplicative interactions between group condition (collective training, individual training, and controls) and level of neuroticism, and between group condition and level of distress (depression and anxiety) in a linear regression model predicting memory functioning at the two followup phases. In these analyses, age, sex, educational level, baseline memory scores, main effects of neuroticism, mental distress, and group condition, and time between measurements were treated as covariates. There were two dummy variables for collective and individual training, respectively; change in memory performance in these two groups was compared with that of the control group (reference group). In order to illustrate the intervention effects for participants with low and high scores on level of mental distress and neuroticism on the various outcome variables, high and low levels were computed as the mean score \pm the standard deviation. In compliance with general rules for analysis of data from clinical trails, all analyses were performed on an 'intention-to-treat' basis (Altman, 1991). All statistical analyses were performed using the SPSS for Macintosh program series, version 10 (SPSS-Inc., Chicago).

\section{Results}

\section{Comparison with MAAS participants}

Depression and anxiety scores on the SCL-90 of the memory training program participants were compared with data for older individuals who participated 
in the MAAS as a population based reference group. The memory training program participants reported significantly more depressive symptoms ( $F$ $(1,272)=8.94, p=0.03)$ on the SCL-90 than the reference population did. Moreover, level of neuroticism was significantly higher for memory training participants than for individuals who were enrolled in the MAAS study ( $F$ $(1,269)=4.61 p=0.03)$. Levels of anxiety symptoms did not differ between the two groups $(\mathrm{F}(1,273)=3.01, \mathrm{p}=0.08)($ Table 1$)$.

Table 1. Means and standard deviations for mood and personality variables and results of comparisons with MAAS participants and between compliant and non-compliant participants

\begin{tabular}{llllll}
\hline & $\begin{array}{l}\text { MAAS } \\
\text { participants }\end{array}$ & $\begin{array}{l}\text { Memory } \\
\text { intervention } \\
\text { participants }\end{array}$ & $\begin{array}{l}\text { Non-compliant } \\
\text { participants }\end{array}$ & $\begin{array}{l}\text { Compliant } \\
\text { participants }\end{array}$ & $\begin{array}{l}\text { Significant } \\
\text { contrasts }\end{array}$ \\
& $\begin{array}{l}(\mathrm{N}=139) \\
(1)\end{array}$ & $\begin{array}{l}(\mathrm{N}=12) \\
(3)\end{array}$ & $\begin{array}{l}(\mathrm{N}=76) \\
(4)\end{array}$ & \\
\hline $\begin{array}{l}\text { SCL } \\
\text { depression }\end{array}$ & $21.96(8.28)$ & $24.81(7.24)$ & $29.85(7.19)$ & $23.84(7.19)$ & $1<2,3>4$ \\
SCL anxiety & $13.35(5.34)$ & $14.47(5.39)$ & $20.00(9.61)$ & $13.91(4.22)$ & $3>4$ \\
$\begin{array}{l}\text { EPQ } \\
\text { neuroticism }\end{array}$ & $3.07(3.04)$ & $3.89(3.22)$ & $5.60(3.24)$ & $3.36(3.10)$ & $1<2,3>4$ \\
\hline
\end{tabular}

SCL= Symptom Checklist-90 |EPQ= Eysenck Personality Questionnaire

\section{Treatment outcome}

The intervention effects for participants with low and high scores on level of mental distress and neuroticism on the various outcome variables are given in table 2 and 3 for short-term and long-term intervention effects, respectively. The results were very similar for the depression and the anxiety scale of the SCL questionnaire, therefore, only the results of the combined subscale, the distress score, is tabulated.

For instance, Table 2 shows that participants of the collective training program with low levels of neuroticism were able to recall 1.84 more words than participants of the control group, whereas participants of the collective training program with high levels of neuroticism were able to recall 2.29 more words than participants in the control group. Overall, anxiety and neuroticism did not have a consistent significant effect on the effectiveness 
of the training program, regardless of how the training was delivered (collectively or individually) or when performance was measured (1 week or 4 months after completion of the training program). There was a significant interaction between level of distress and the total score of the VVLT $(p=0.05)$, but this was probably due to chance.

Table 2. Effect of intervention on treatment outcome and the p values of the interaction terms, 1 week after the intervention ${ }^{\dagger}$

\begin{tabular}{|c|c|c|c|c|c|c|}
\hline & \multicolumn{3}{|c|}{ Level of neuroticism } & \multicolumn{3}{|c|}{ Level of distress } \\
\hline & Low & High & $p$-value & Low & High & $p$-value \\
\hline WLT total score & & & 0.92 & & & 0.05 \\
\hline Collective Course & 1.84 & 2.29 & & -1.61 & 6.03 & \\
\hline Individual Book & -0.12 & 1.04 & & -1.56 & 2.55 & \\
\hline WLT recall score & & & 0.97 & & & 0.44 \\
\hline Collective Course & 1.18 & 1.24 & & 0.61 & 1.78 & \\
\hline Individual Book & 0.19 & 0.04 & & 0.03 & 0.17 & \\
\hline Logical Memory Immediate recall & & & 0.12 & & & 0.35 \\
\hline Collective Course & -1.29 & 2.20 & & -0.91 & 1.07 & \\
\hline Individual Book & -2.38 & 1.30 & & -6.54 & 0.83 & \\
\hline Logical Memory Delayed recall & & & 0.21 & & & 0.62 \\
\hline Collective Course & 1.36 & 3.09 & & 0.59 & 2.06 & \\
\hline Individual Book & 0.30 & -1.53 & & -0.67 & -1.10 & \\
\hline Memory self-efficacy & & & 0.86 & & & 0.32 \\
\hline Collective Course & 4.77 & 5.31 & & 2.33 & 7.24 & \\
\hline Individual Book & 5.61 & 3.67 & & 1.45 & 8.52 & \\
\hline Cognitive Failure Questionnaire & & & 0.42 & & & 0.71 \\
\hline Collective Course & -3.23 & 2.27 & & 0.34 & -0.42 & \\
\hline Individual Book & -1.90 & 0.00 & & 7.88 & -2.33 & \\
\hline
\end{tabular}

WLT $=$ Visual Verbal Learning Test

${ }^{\dagger}$ The control group is the reference group against which treatment outcome in the group training condition and the individual training condition are contrasted. 
CHAPTER 6. CHARACTERISTICS OF PARTICIPANTS OF A MEMORY TRAINING PROGRAM AND PREDICTORS OF RESPONSE

Table 3. Effect of intervention on treatment outcome and the $p$ values of the interaction terms, 4 months after the intervention $^{\dagger}$

\begin{tabular}{|c|c|c|c|c|c|c|}
\hline & \multicolumn{3}{|c|}{ Level of neuroticism } & \multicolumn{3}{|c|}{ Level of distress } \\
\hline & Low & High & $p$-value & Low & High & $p$-value \\
\hline WLT total score & & & 0.93 & & & 0.06 \\
\hline Collective Course & 3.18 & 1.79 & & -0.71 & 6.12 & \\
\hline Individual Book & 0.45 & -0.20 & & -3.17 & 3.54 & \\
\hline WLT recall score & & & 0.53 & & & 0.72 \\
\hline Collective Course & 1.57 & 0.49 & & 0.92 & 1.43 & \\
\hline Individual Book & -0.25 & -0.56 & & -0.79 & -0.07 & \\
\hline \multicolumn{7}{|l|}{ Logical Memory } \\
\hline Immediate recall & & & 0.80 & & & 0.16 \\
\hline Collective Course & 0.83 & 1.70 & & -0.18 & 3.15 & \\
\hline Individual Book & -0.75 & 0.18 & & -0.93 & 0.36 & \\
\hline \multicolumn{7}{|l|}{ Logical Memory } \\
\hline Delayed recall & & & 0.25 & & & 0.09 \\
\hline Collective Course & 0.88 & 1.99 & & 0.07 & 2.82 & \\
\hline Individual Book & 0.50 & -1.43 & & 0.15 & -1.14 & \\
\hline Memory self-efficacy & & & 0.53 & & & 0.43 \\
\hline Collective Course & 2.91 & 0.98 & & 1.93 & 0.11 & \\
\hline Individual Book & 3.74 & -1.14 & & 3.92 & -1.67 & \\
\hline \multicolumn{7}{|l|}{ Cognitive Failure } \\
\hline Questionnaire & & & 0.40 & & & 0.34 \\
\hline Collective Course & -2.86 & 0.68 & & 2.05 & -3.27 & \\
\hline Individual Book & -2.54 & 2.23 & & 0.12 & -0.05 & \\
\hline
\end{tabular}

WLT = Visual Verbal Learning Test

${ }^{\dagger}$ The control group is the reference group against which treatment outcome in the group training condition and the individual training condition are contrasted.

\section{Compliance}

Nine people stopped participation in the collective training program and were lost to follow-up. Three participants of the individual training program were considered non-compliant. Main reasons for non-compliance were being too busy with other activities or work, no transportation to the training center, 
health-related problems, or family circumstances. Overall, participants who were non-compliant had significantly higher levels of neuroticism $(F(1,84)=$ 4.59, $p=0.04)$ and had higher levels of depression $(F(1,85)=7.23, p=0.01)$ and anxiety $(F(1,86)=4.67, p=0.05)$ than the participants who were compliant (Table 1).

\section{Discussion}

The aim of this study was to determine whether participation in a memorytraining program was associated with specific behavioural characteristics. To this end, we compared memory-training program participants with normal healthy elderly individuals enrolled in the MAAS. Participants of the memorytraining program reported significantly more depressive symptoms and had higher levels of neuroticism than the control population. Although the training program participants performed memory tasks better than the normal control population of the MAAS (Valentijn et al., 2004), apparently good memory function does not prevent individuals from worrying about their memory. Personality traits, such as depression and neuroticism, may make individuals more prone to worry about their memory functioning and to be concerned about degenerative disorders such as Alzheimer's disease (Ponds, 1998).

We also investigated whether personality (neuroticism) and mood (anxiety, depression) can predict which individuals will benefit most from a memory-training program. Outcome variables were subjective and objective indicators of memory functioning. We did not find level of neuroticism and distress to affect treatment outcome, showing that the intervention is equally effective for persons with and without mental distress and neuroticism. However, when non-compliant participants were compared with those who were compliant to the intervention, results indicated that participants who discontinued the intervention had higher levels of neuroticism, and had more depressive and anxiety symptoms. Elderly individuals who are more neurotic, or who have more depressive and anxiety symptoms were less compliant to memory training and more prone to drop out the training program. Although there were no significant interaction effects predicting treatment outcome, these results indicate that levels of neuroticism and distress are indeed important variables with respect to memory training programs. This 
implicates that it is advisable to take precautionary measures in order to prevent dropping out of such participants in the future. Moreover, this finding has also consequences for the results in this study, considering the fact that there were no follow-up data available for individuals with the highest levels of mental distress symptoms and neuroticism. It is possible that interaction effects may have been significant if more participants had completed the study.

In conclusion, individuals who participate in a memory training intervention have more depressive symptoms and higher levels of neuroticism than a control population. However, the overall pattern of interaction effects indicates that there is no direct evidence that these variables are associated with treatment outcome. Thus, the intervention is equally effective for individuals with high and low levels of neuroticism and for individuals with and without mental distress. However, levels of neuroticism and distress may be important variables because elderly individuals who were neurotic and anxious were more likely to drop out and thus may be less committed to completing such programs. 


\section{References}

Altman, D. G. (1991). Practical statistics for medical research (1st ed.). London: Chapman \& Hall.

Arrindell, W. A., \& Ettema, J. H. M. (1986). SCL-90. Een multidimensionele psychopathologie indicator (The SCL-90. A multidimensional instrument for the assessment of psychopathology). Lisse, The Netherlands: Swets \& Zeitlinger.

Best, D. L., Hamlett, K. W., \& Davis, S. W. (1992). Memory complaint and memory performance in the elderly: The effects of memory-skills training and expectancy change. Applied Cognitive Psychology, 6, 405-416.

Bosma, H., van Boxtel, M. P., Ponds, R. W., Houx, P. J., Burdorf, A., \& Jolles, J. (2003). Mental work demands protect against cognitive impairment: MAAS prospective cohort study. Experimental Aging Research, 29(1), 33-45.

Bouma, J. M., Lindenboom, J., \& van Houte, L. (1990). Klinische neuropsychologische assesment: een handleiding voor de praktijk. Amsterdam.

Brand, N., \& Jolles, J. (1985). Learning and retrieval rate of words presented auditorily and visually. Journal of General Psychology, 112(2), 201-210.

Broadbent, D. E., Cooper, P. F., FitzGerald, P., \& Parkes, K. R. (1982). The Cognitive Failure Questionnaire (CFQ) and its correlates. British Journal of Clinical Psychology, 21, 1-16.

Caprio-Prevette, M. D., \& Fry, P. S. (1996). Memory enhancement program for community-based older adults: Development and evaluation. Experimental Aging Research, 22, 281-303.

Comijs, H. C., Deeg, D. J., Dik, M. G., Twisk, J. W., \& Jonker, C. (2002). Memory complaints; the association with psycho-affective and health problems and the role of personality characteristics. A 6-year follow-up study. Journal of Affective Disorders, 72(2), 157-165.

Commissaris, C. J. A. M., Ponds, R. W. H. M., \& Jolles, J. (1998). Subjective forgetfulness in a normal Dutch population: possibilities for health education and other interventions. Patient Education and Counseling, 34, 2532.

Derogatis, L. R. (1977). SCL-90: Administration, scoring and procedures manual-I for the R(evised) version. Baltimore: Johns Hopkins School of Medicine, Clinical Psychometrics Research Unit.

Eysenck, M. W., \& Calvo, M. G. (1992). Anxiety and performance: the processing efficiency theory. Cognition and Emotion, 6(6), 409-434.

Eysenck, S. B. G., Eysenck, H. J., \& Barrett, P. (1985). A revised version of the psychoticism scale. Personality and Individual differences, 6(1), 21-29.

Floyd, M., \& Scogin, F. (1997). Effects of memory training on the subjective memory functioning and mental health of older adults: a meta-analysis. Psychology and Aging, 12(1), 150-161.

Hill, R. D., Yesavage, J. A., Seikh, J., \& Friedman, L. (1989). Mental status as a predictor of response to memory training in older adults. Educational Gerontology, 15, 633-639.

Jolles, J., Houx, P. J., van Boxtel, M. P. J., \& Ponds, R. W. H. M. (Eds.). (1995). Maastricht Aging Study: Determinants of cognitive aging. Maastricht: Neuropsych Publishers.

Jorm, A. F., Christensen, H., Korten, A. E., Jacomb, P. A., \& Henderson, A. S. (2001). Memory complaints as a precursor of memory impairment in older people: a longitudinal analysis over 7-8 years. Psychological Medicine, 31(3), 441-449.

Kizilbash, A. H., Vanderploeg, R. D., \& Curtiss, G. (2002). The effects of depression and anxiety on memory performance. Archives of clinical neuropsychology, 17, 57-67. 
Kliegl, R., Smith, J., \& Baltes, P. B. (1990). On the locus and process of magnification of age differences during mnemonic training. Developmental Psychology, 6, 894-904.

Lachman, M. E., Weaver, S. L., Bandura, M., Elliott, E., \& Lewkowicz, C. J. (1992). Improving memory and control beliefs through cognitive restructuring and self-generated strategies. Journal of Gerontology, 47(5), 293-299.

Merckelbach, H., Muris, P., Nijman, H., \& de Jong, P. (1996). Self-reported cognitive failures and neurotic symptomatology. Personality and Individual Differences, 20, 715-724.

Metsemakers, J. F. M., Höppener, P., Knottnerus, J. A., Kocken, R. J. J., \& Limonard, C. B. G. (1992). Computerized health information in the Netherlands: A registration network of family practices. British Journal of General Practice, 42, 102-106.

Mohs, R. C., Ashman, T. A., Jantzen, K., Albert, M., Brandt, J., Gordon, B., et al. (1998). A study of the efficacy of a comprehensive memory enhancement program in healthy elderly persons. Psychiatry Research, 77(3), 183-195.

Niehof, J. (1995). Validering van een zestal logical memory taken.Unpublished manuscript, Groningen.

Ponds, R., \& Verhey, F. (2000). geheugensteun. Utrecht/Antwerpen: Kosmos-Z\&K Uitgevers.

Ponds, R. W. H. M. (1998). Forgetfulness and cognitive aging: Prevalence, characteristics, and determinants (Thesis). Maastricht University.

Ponds, R. W. H. M., \& Bouwens, M. R. J. (1997). Geheugencursus voor ouderen. Den Bosch: Gezondheid Service Nederland.

Ponds, R. W. H. M., \& Jolles, J. (1996a). The abridged Dutch Metamemory in Adulthood (MIA) questionnaire: structure, and effects of age, sex, and education. Psychology and Aging, 11, 324-332.

Ponds, R. W. H. M., \& Jolles, J. (1996b). Memory complaints in elderly people: the role of memory abilities, metamemory, depression, and personality. Educational Gerontology, 22, 341-357.

Rasmusson, D. X., Rebok, G. W., Bylsma, F. W., \& Brandt, J. (1999). Effects of three types of memory training in normal elderly. Aging, Neuropsychology, and Cognition, 6, 56-66.

Stevens, F. C. J., Kaplan, C. D., Ponds, R. W. H. M., \& Jolles, J. (2001). The importance of active lifestyles for memory performance and memory self-knowledge. Basic and applied social psychology, 23(2), 137-145.

Szymura, B., \& Wodniecka, Z. (2003). What really bothers neurotics? In search for factors impairing attentional performance. Personality and Individual Differences, 34, 109-126.

Van Boxtel, M. P. J., Buntinx, F., Houx, P. J., Metsemakers, J. F. M., Knottnerus, J. A., \& Jolles, J. (1998). The relation between morbidity and cognitive performance in a normal aging population. Journal of Gerontology, 53A(2), M146-M154.

Valentijn, S.A.M., van Hooren, S.A.H., Bosma, H., Touw, D.M., Jolles, J., Van Boxtel, M.P.J., \& Ponds, R.W.H.M. (2004). The effect of two types of memory training on subjective and objective memory performance in healthy individuals aged 55 years and older: A randomized controlled trial. Patient, Education and Counseling, In press.

Verhaeghen, P., Marcoen, A., \& Goossens, L. (1992). Improving memory performance in the aged through mnemonic training: a meta-analytic study. Psychology and Aging, 7(2), 242-251. 


\section{Abstract}

One of the most common visual problems in old age is senile cataract. In the present study, the direct effects of an intervention aimed at re-establishing visual function (cataract surgery) on cognitive performance were examined in 146 cataract patients. We compared two groups of individuals, namely, older patients who underwent cataract surgery (intervention group), and cataract patients in a waiting list control group. Results indicated that compared to controls, in addition to improving visual acuity, cataract surgery also improved verbal memory function and the ability to inhibit a habitual response in the intervention group. These results confirm that visual function can have significant consequences for cognitive test performance and must therefore be taken into consideration when interpreting neuropsychological tests results. 


\section{Introduction}

As individuals grow older, visual functioning decreases (Fozard, 1990). One of the most frequent visual problems in old age is senile cataract, an eye disease that is characterized by opacification and swelling of the lens, thereby obstructing penetration of light to the retina. This causes double or blurred vision, changes in colour perception and a decrease in visual acuity, ultimately resulting in blindness if the condition is not treated (Steinberg et al., 1994). Cataract is usually a gradual process that affects both eyes, but seldom at the same pace. The only treatment is to surgically remove the opaque lens and replace it with an artificial implant lens. It is generally agreed that cataract surgery is a highly effective treatment with a very low incidence rate of surgical complications (Powe et al., 1994).

Visual functioning plays an important role in cognitive aging and may be a profound determinant of inter-individual differences in cognitive test performance (Lindenberger \& Baltes, 1994). Several cross-sectional as well as longitudinal studies have found a strong negative association between sensory functioning and cognition (Anstey, Lord, \& Williams, 1997; Anstey, Luszcz, \& Sanchez, 2001; Lindenberger \& Baltes, 1994; Lindenberger, Scherer, \& Baltes, 2001; Stankov \& Anstey, 1997; van Boxtel, ten Tusscher, Metsemakers, Willems, \& Jolles, 2001). This evidence that there is a powerful connection between perceptual and cognitive factors in aging calls for a model that explains the nature of this connection. Up until now several explanatory hypotheses have been formulated. The 'common cause' hypothesis postulates that the association between sensory functioning and cognition is mediated by a common third factor, e.g. a mechanism related to degeneration in the central nervous system (Christensen, Mackinnon, Korten, \& Jorm, 2001; Lindenberger \& Baltes, 1994). On the other hand, other hypotheses suggest that there is a direct causal association between sensory impairment and cognitive functioning, such as the 'sensory deprivation' hypothesis that states that a prolonged reduction sensory input will reduce opportunities for cognitively stimulating exchanges with the environment and result in cognitive deterioration due to neuronal atrophy (Lindenberger \& Baltes, 1994; Sekuler \& Blake, 1987), and the 'resource allocation' hypothesis that predicts that sensory impaired individuals need to allocate more attentional resources to the perception and interpretation of sensory 
information, leaving fewer resources available for higher order processes involved in the execution of complex tasks (Baltes \& Lindenberger, 1997; Rabbitt, 1990). A final related hypothesis that has been coined is that impaired performance on cognitive tasks is not a result of cognitive abilities per se, but is a direct consequence of unclear and distorted perceptual information delivered to the cognitive system, for examples, see (Lindenberger et al., 2001; van Boxtel et al., 2001; Van Boxtel et al., 2000). The nature of the relationship, however, is still quite speculative because controlled experiments that may address the causal mechanisms underlying these hypotheses are lacking. Ideally, in such studies one would restore sensory function in older adults to the optimum level and then examine the long-term effects on cognitive abilities. In the present study, the direct effects of an intervention aimed at reestablishment of visual functioning on cognitive performance in older adults were examined using a controlled design. This experiment offers the unique opportunity to study whether changes in perceptual functioning are related to changes in a broad range of cognitive abilities by comparing two groups of individuals, namely older patients who underwent cataract surgery, and cataract patients in a waiting list control group.

\section{Methods}

\section{Participants}

Participants were older individuals recruited through the department of Ophthalmology of the University Hospital Maastricht, and were treated at the University Hospital Maastricht, the Medical Centre Maastricht Annadal, and the Atrium Medical Centre Heerlen, all located in the Netherlands. All patients were diagnosed with senile cataract and were qualified for treatment with first-eye phacoemulsification and intraocular lens implantation, under retrobulbar or sub-Tenon's anaesthesia. Participants were included in the study if they were 65 years or older, had good comprehension of the Dutch language, were sufficiently mobile in order to travel independently to the research centre, were not using psychotropic medication on a daily basis and did not previously participate in a neuropsychological research program. Exclusion criteria were a score below 24 on the Mini-Mental State 
Examination (MMSE) ((Folstein, Folstein, \& McHugh, 1975), a diagnosis of central nervous system pathology (e.g. dementia, Parkinson's disease), a major psychiatric disorder, or ocular co-morbidity that also may impair visual acuity (e.g. macular degeneration).

The Medical Ethics Committees of both the University Hospital Maastricht and the Atrium Medical Centre Heerlen approved the protocol and all participants gave their informed consent.

\section{Measures}

The outcome variables were obtained from a neuropsychological test battery that was administered before and immediately after the surgical intervention, and again 9 months later, and included cognitive tasks that tap on memory, perceptual speed, speed of information processing, mental shifting, inhibition and verbal fluency. Other measures that were obtained from all participants were demographic information such as age, sex, and educational attainment (ranging from 1=primary education to $8=$ university education (De Bie, 1987)), distant and near visual acuity, intelligence level (IO), and the Mini-Mental State Examination (MMSE) (Folstein et al., 1975), that was employed as a screening instrument for cognitive dysfunction and/or the presence of dementia. All participants were tested at the neuropsychological test laboratory of the University Hospital Maastricht.

\section{Cognitive Measures}

The Visual Verbal Learning Test (VVLT) (Brand \& Jolles, 1985) is a verbal memory task that measures the ability to learn new verbal information and to retrieve this information from memory. Fifteen low-associative words are visually presented five times. After each presentation participants are asked to recall as many words as possible, with no restriction with respect to the order of recall (immediate recall). Outcome scores of these five trials were used as an estimation of learning and were added to produce a total VVLT score. Thus, the maximum score after five successive trials is 75 . Twenty minutes after the last presentation participants are again asked to recall as many of the originally learned words as possible. The maximum number of correctly named words on this delayed recall score is 15 . 
The Stroop Colour Word Test (SCWT) is used as a measure of selective attention and speed of information processing (Houx, Jolles, \& Vreeling, 1993; Stroop, 1935). The test consists of three cards; the first card contains colour words (red, blue, yellow, and green) that are printed in black ink and participants are asked to read the words as fast and accurate as possible. The second card displays colour patches in the same four colours, which have to be named as fast and accurate as possible. The third card contains colour words that are printed in incongruously coloured ink. Participants are asked to name the colour of the ink in which the words are printed. The variables of interest in this study are the mean scores of the total time needed to complete the first two cards as an indication of simple speed (SCWT 1+2), and an interference score which reflects the capacity to inhibit a habitual response (reading the word) (SCWT Interference). The interference score is computed by subtraction of the mean score of the first and second cards from the time needed to complete the third card.

The Concept Shifting Task (CST) is a modified version of the Trail Making Test and used as an instrument to measure simple speed and cognitive flexibility (Reitan, 1958; Vink \& Jolles, 1985). The test consist of three cards containing the stimulus material, which are 16 small circles grouped in al larger circle. On the first card the smaller circles contain numbers in a fixed random order and participants are asked to cross the numbers in the right order, as fast and accurate as possible. In the second part of the test the circles contain letters, which again have to be crossed out in the right order. Finally, the third card contains both numbers and letters and participants are requested to alternate between numbers and letters. The scores correspond to the time needed to complete each card. The mean scores of the first two cards are used as a reflection of simple speed (CST A+B). The difference between the last part and the mean score of the first two cards is considered a measure of mental shifting ability and is reflected in the additional time needed to shift between both sets of stimuli (CST Interference).

The Verbal Fluency test is a subtask of the Groninger Intelligence Test (GIT) (Luteijn \& van der Ploeg, 1983) and used as a measure of the ability to recollect as many words as possible in a specific category (animals) from 
memory in an adequate and strategic manner. The outcome measure of interest is the total number of words produced in 90 seconds.

The Letter-Digit Substitution Test (LDST) is a modified version of the Symbol Digit Modalities Test and measures general information processing speed (Lezak, 1995; Smith, 1968). Participants are asked to fill in as many blank squares as possible, that correspond with a code supplied at the top of the page. The dependent variable is the total number of correctly filled in squares in 90 seconds.

Four subtasks of the Groningen Intelligence Test (GIT) were used to make a reliable estimation of formal IQ. The four subtasks involved were: the correct completion of as many addition sums as possible in 1 minute, indicating which of five alternative words is exactly synonymous with a given word, indicating which two-dimensional shapes from a larger set are needed to exactly fill up a given space, and indicating which of five alternatives is related in the same way to a given word as two words in an example.

\section{Visual measures}

Best corrected distance visual acuity for both eyes separately was measured with a Landolt-C optotype chart at a distance of 5 meters under standard luminescence. Afterwards binocular visual acuity was measured. Participants are requested to name the opening of black circles on a white background (four possible directions). The outcome measure is expressed by the logarithm of the minimal angel of resolution scale (logMAR) (Holladay, 1997). Higher scores indicate worse distance visual acuity.

Best corrected near visual acuity was measured with the Amsterdam Reading Chart (Anonymous, 1998). The chart contains short passages of text printed in ascending font sizes and participants are requested to read the text at a distance of approximately $20 \mathrm{~cm}$. Close visual acuity is scored as the font size of text that can be read without errors, in decimal units, ranging from 0.5 (optimal acuity) to 1.25 (poor acuity).

\section{Procedure}

Patients who were eligible for first time cataract surgery were invited to participate in the study. Participants in the intervention group underwent elective phacoemulsification and intraocular lens implantation and were 
neuropsychologically tested three times, 1 week before the intervention, 1 week after the intervention, and finally after a 9 months follow-up period. This procedure also applied to cataract patients who were waiting for surgery. When this study started (December, 2000) the average waiting period duration for cataract surgery was approximately 14 months, which was mainly due to capacity restrictions imposed by the Dutch government. This waiting period was not influenced by the present study or the seriousness of the visual impairment. If participants who were waiting did have cataract surgery within the study period, the follow-up assessment was advanced, if possible. The same test battery was administered before treatment, at the 1week follow-up and at the 9-month follow-up. All neuropsychological tests were administered in a fixed order at all assessments, with the use of individual optical correction (e.g. reading glasses), when appropriate.

\section{Statistical analysis}

Separate One-way Analyses of Variance (ANOVA) were performed for age, educational level, intelligence and MMSE scores in order to examine differences in baseline characteristics between the intervention group and the control group. In addition, a Chi-square test was employed to analyze the variables sex and marital status (married or cohabiting versus others). Differences in visual acuity at 9 months follow-up were examined with ANOVA, controlled for baseline visual acuity and time interval between measurements.

General Linear Model (GLM) repeated measures analysis of variance was used to assess group differences with respect to the effect of cataract surgery on cognitive performance. Analyses were performed according Intention-To-Treat (Altman, 1991) with group as the between-subjects variable and cognitive performance as the within-subjects factor. Age, sex, educational level, time interval between measurements and baseline scores were treated as covariates. Statistical outliers were identified within each group and cases with standardized z-scores larger than 3.29 were not included in the analyses (Tabachnick \& Fidell, 2001). All statistical analyses were performed using the SPSS for Macintosh program series, version 10 (SPSS-Inc., Chicago). 


\section{Results}

\section{Recruitment}

One hundred fifty-two individuals were willing to participate. Six individuals did not meet the inclusion criteria and were excluded from participation. The study population consisted of two groups, namely an intervention group who underwent cataract surgery shortly after inclusion in the study $(\mathrm{N}=69)$ and a group of cataract patients who were placed on a waiting-list $(\mathrm{N}=77)$.

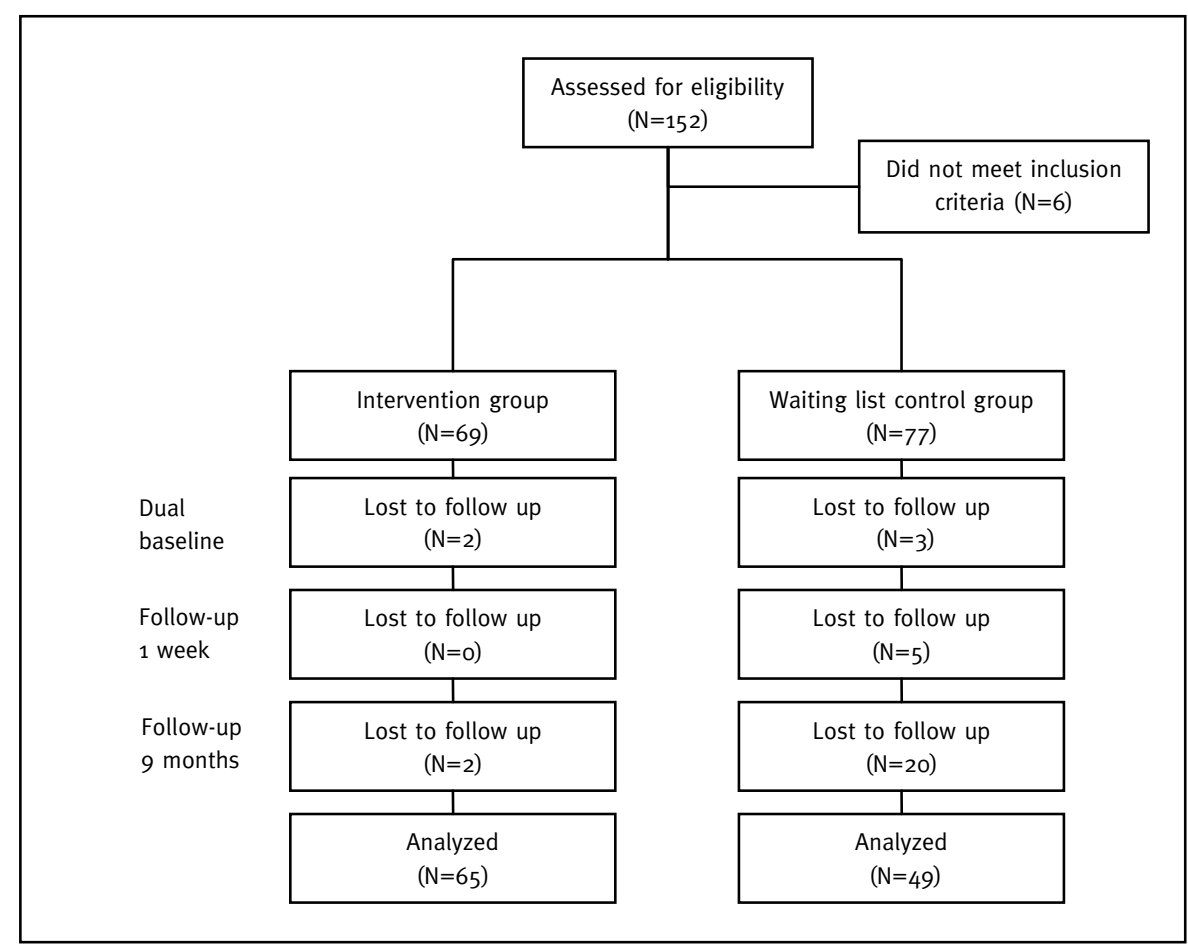

Figure 1. Results of recruitment

Thirty-two participants dropped out the study after inclusion, four of these being individuals who underwent cataract surgery and 28 persons who were control group participants. Thus the total amount of dropouts was higher in the control group because 19 participants eventually underwent surgery before the follow-up period of 9 months had been completed. This was the result of a governmental decision that expanded the capacity for cataract 
CHAPTER 7. THE EFFECT OF CATARACT SURGERY ON COGNITIVE FUNCTIONING IN OLDER ADULTS

surgery during the course of this study. Results of recruitment are displayed in Figure 1.

\section{Baseline characteristics}

There were no significant differences between the groups with respect to age, marital status, general intelligence, level of education, visual acuity and MMSE-score at baseline. Results are summarized in Table 1.

Table 1. Means and standard deviations for demographic variables at baseline (total $\mathrm{N}=146$ )

\begin{tabular}{llll}
\hline & $\begin{array}{l}\text { Intervention group } \\
(\mathrm{N}=69)\end{array}$ & $\begin{array}{l}\text { Control group } \\
(\mathrm{N}=77)\end{array}$ & $p$-value \\
\hline Age & $75.17(6.62)$ & $75.78(6.08)$ & 0.57 \\
Marital status (\% married/living together) & 65.67 & 65.28 & 0.91 \\
Gender (\% women) & 52.17 & 57.14 & 0.55 \\
Education & $2.96(1.95)$ & $2.58(1.67)$ & 0.22 \\
IQ & $114.00(15.36)$ & $110.44(17.10)$ & 0.20 \\
MMSE & $27.79(1.46)$ & $27.45(1.97)$ & 0.24 \\
Distant visual acuity & $0.56(0.28)$ & $0.59(0.25)$ & 0.44 \\
Near visual acuity & $0.77(0.23)$ & $0.74(0.19)$ & 0.37 \\
\hline
\end{tabular}

MMSE $=$ Mini Mental State Examination

Table 2. Mean visual acuity at 9 months follow-up, adjusted for baseline visual acuity and time interval

\begin{tabular}{llll}
\hline & $\begin{array}{l}\text { Intervention group } \\
(\mathrm{N}=65)\end{array}$ & $\begin{array}{l}\text { Control group } \\
(\mathrm{N}=49)\end{array}$ & $p$-value \\
\hline Distant visual acuity* & -0.08 & 0.31 & $<0.01$ \\
Near visual acuity & 0.59 & 0.77 & $<0.01$ \\
\hline
\end{tabular}

* logMAR visual acuity

\section{Visual acuity}

With respect to visual acuity, ANOVA showed a significant group effect for both distant $(F(1,104)=31.71, p<0.01)$ and near visual acuity values $(F(1,101)$ $=23.44$, pro.01), with individuals who had surgery having better acuity (see Table 2). 
Table 3. Means, standard errors* and results of tests for group differences in cognitive functioning

\begin{tabular}{|c|c|c|c|}
\hline & Intervention group & Control group & Main effect $p$-value \\
\hline WLT total & $N=65$ & $\mathrm{~N}=48$ & 0.04 \\
\hline 1-week follow-up & $46.67(1.00)$ & $45.20(1.20)$ & \\
\hline 9-month follow-up & $49.07(0.91)$ & $45.04(1.08)$ & \\
\hline WLT recall & $N=64$ & $\mathrm{~N}=48$ & $<0.01$ \\
\hline 1-week follow-up & $9.56(0.30)$ & $8.36(0.35)$ & \\
\hline 9-month follow-up & $10.38(0.29)$ & $9.10(0.35)$ & \\
\hline SCWT 1+2 & $\mathrm{N}=63$ & $N=47$ & 0.416 \\
\hline 1-week follow-up & $21.95(0.29)$ & $21.97(0.35)$ & \\
\hline 9-month follow-up & $22.53(0.37)$ & $21.72(0.43)$ & \\
\hline SCWT Interference & $\mathrm{N}=62$ & $\mathrm{~N}=45$ & 0.03 \\
\hline 1-week follow-up & $31.37(1.54)$ & $34.06(1.86)$ & \\
\hline 9-month follow-up & $29.75(1.73)$ & 37.07 (2.09) & \\
\hline $\operatorname{CST} A+B$ & $\mathrm{~N}=63$ & $\mathrm{~N}=47$ & 0.28 \\
\hline 1-week follow-up & $29.29(0.82)$ & $30.11(0.98)$ & \\
\hline 9-month follow-up & $28.55(0.99)$ & $30.17(1.18)$ & \\
\hline CST Interference & $\mathrm{N}=62$ & $\mathrm{~N}=46$ & 0.26 \\
\hline 1-week follow-up & $17.88(1.73)$ & $18.80(2.07)$ & \\
\hline 9-month follow-up & $18.07(2.23)$ & $22.58(2.80)$ & \\
\hline Fluency & $\mathrm{N}=63$ & $\mathrm{~N}=46$ & 0.29 \\
\hline 1-week follow-up & $26.56(0.63)$ & $26.57(0.76)$ & \\
\hline 9-month follow-up & $25.06(0.68)$ & $26.98(0.82)$ & \\
\hline LDST & $\mathrm{N}=62$ & $\mathrm{~N}=47$ & 0.68 \\
\hline 1-week follow-up & $36.59(0.50)$ & $36.18(0.59)$ & \\
\hline 9-month follow-up & $35.91(0.58)$ & $35.66(0.68)$ & \\
\hline
\end{tabular}

WLT = Visual Verbal Learning Test $\mid$ SCWT $=$ Stroop Color Word Test $\mid$ CST $=$ Concept Shifting Task $\mid$ LDST = Letter Digit Substitution Task

* Mean scores and standard errors adjusted for age, gender, educational level, time interval and baseline Cognitive functioning

Linear Model (GLM) repeated measures analysis of variance was used to assess group differences in cognitive performance. The results are summarized in Table 3. Of interest in this regard was a significant main effect for both the total $(F(1,106)=4.49, p=0.04$, estimated marginal mean for the 
intervention group $=47.87,95 \% \mathrm{Cl}=46.34-49.40$, estimated marginal mean for the control group $=45.12,95 \% \mathrm{Cl}=43.29-46.94)$ and the recall score of the VVLT $(F(1,106)=4.49, p=0.04$, estimated marginal mean for the intervention group $=9.97,95 \% \mathrm{Cl}=9.48-10.45$, estimated marginal mean for the control group $=8.73,95 \% \mathrm{Cl}=8.16-9.30$ ). This indicates that over time, individuals who had cataract surgery were better able to learn a word list, and remember this previously learned list after a delayed interval of 20 minutes. No group by time interactions were found, indicating that the intervention effect already present 1 week after the intervention did not increase or decrease after 9 months follow-up. In addition, a significant intervention effect was also found for the Interference score of the SCWT, with individuals who had cataract surgery performing better $(F(1,100)=4.91$, $\mathrm{p}=0.03$, estimated marginal mean for the intervention group $=30.56,95 \% \mathrm{Cl}$ $=27.93-33.19$, estimated marginal mean for the control group $=35.57,95 \%$ $\mathrm{Cl}=32.39-38.75)$. This effect again remained stable over time; results showed that there was no significant group by time interaction. Main effects of group membership on the other cognitive tasks including SCWT 1+2, CST $A+B, C S T$ Interference, Fluency and LDST were not statistically significant.

\section{Discussion}

The aim of this study was to examine the effect of cataract surgery on cognitive performance. In addition to improving visual acuity, results indicated that cataract surgery also improved verbal memory function and the ability to inhibit a habitual response, reflected in a significant effect on the VVLT total and recall scores and the Interference score of the SCWT. These findings are consistent with previous studies that demonstrated a clear relation between vision and performance on cognitive tests (Anstey et al., 1997; Anstey et al., 2001; Lindenberger \& Baltes, 1994; Lindenberger et al., 2001; Stankov \& Anstey, 1997; van Boxtel et al., 2001). Although this study was not specifically designed to test the different hypotheses about the relationship between sensory functioning and cognition, the results can provide insight into the theoretical underpinnings of this association. Our results suggest a causal relationship since we found that cataract surgery had a direct effect on cognition, which implies that it seems unlikely that the connection between visual and cognitive performance is mediated by a third 
common factor (Christensen et al., 2001; Lindenberger \& Baltes, 1994). It is more difficult however to pronounce upon the other models, since they are not mutually exclusive. It is plausible that restoration of visual functioning effects cognition because individuals now have more resources left for cognitive demanding tasks (Baltes \& Lindenberger, 1997), that extra sensory input resulted in improvement of cognitive functioning because neuronal networks are now more frequently called upon (Lindenberger \& Baltes, 1994; Sekuler \& Blake, 1987), that improved cognitive performance is a direct consequence of the fact that perceptual information delivered to the cognitive system is less degraded, or a combination of the three. However, cataract surgery did not influence all cognitive tasks under study. Following this argument, effects on a selection of the different cognitive tasks would fit better with a hypothesis that states that if vision is optimal more resources are available, thereby improving performance on the more cognitive challenging tasks. Although the intervention effects did not discriminate between more and less demanding tasks, significant effects were only found on cognitive tests that were relatively more demanding, instead of measures such as simple speed. From a practical point of view, this study illustrates that cataract surgery, besides preventing blindness (Steinberg et al., 1994) and increasing quality of life and functional status (Horowitz, 1994; Keller, Morton, Thomas, \& Potter, 1999; Lee, Smith, \& Kington, 1999; Marsiske, Klumb, \& Baltes, 1997; Reuben, Mui, Damesyn, Moore, \& Greendale, 1999; Wallhagen, Strawbridge, Shema, Kurata, \& Kaplan, 2001), also has important effects on cognitive performance, thereby providing an extra recommendation for this intervention. Moreover, results confirm that visual functioning can have significant consequences for neuropsychological test performance (Hartman, 2000; van Boxtel et al., 2001) and considering the fact that senile cataract is one of the most frequent eye diseases in old age, visual status must therefore always be taken into consideration when interpreting neuropsychological test results. 


\section{References}

Altman, D. G. (1991). Practical statistics for medical research (1st ed.). London: Chapman \& Hall

Anonymous. (1998). Amsterdamse Leeskaart [Amsterdam Reading Chart]. Groningen: Medical Workshop.

Anstey, K. J., Lord, S. R., \& Williams, P. (1997). Strength in the lower limbs, visual contrast sensitivity, and simple reaction time predict cognition in older women. Psychology and Aging, 12(1), 137-144.

Anstey, K. J., Luszcz, M. A., \& Sanchez, L. (2001). Two-year decline in vision but not hearing is associated with memory decline in very old adults in a population-based sample. Gerontology, 47(5), 289-293.

Baltes, P. B., \& Lindenberger, U. (1997). Emergence of a powerful connection between sensory and cognitive functions across the adult life span: a new window to the study of cognitive aging? Psychology and Aging, 12(1), $12-21$.

Brand, N., \& Jolles, J. (1985). Learning and retrieval rate of words presented auditorily and visually. Journal of General Psychology, 112(2), 201-210.

Christensen, H., Mackinnon, A. J., Korten, A., \& Jorm, A. F. (2001). The "common cause hypothesis" of cognitive aging: evidence for not only a common factor but also specific associations of age with vision and grip strength in a cross-sectional analysis. Psychology and Aging, 16(4), 588-599.

De Bie, S. E. (1987). Standaardvragen 1987: Voorstellen voor uniformering van vraagstellingen naar achtergrondkenmerken en interviews [Standard questions 1987: Proposal for uniformization of questions regarding background variables and interviews] (2nd ed.). Leiden: Leiden University Press.

Folstein, M. F., Folstein, S. E., \& McHugh, P. R. (1975). Mini-mental State: a practical method for grading the cognitive state of patients for the clinician. Journal of Psychiatric Research, 12, 189-198.

Fozard, J. L. (1990). Vision and hearing in aging. In J. E. Birren \& K. W. Schaie (Eds.), Handbook of the psychology of aging (3 ed., Vol. 2, pp. 150-170). San Diego: Academic Press.

Hartman, J. A. (2000). Investigation of the use of the CAMCOG in the visually impaired elderly. Internatiol Journal of Geriatric Psychiatry, 15(9), 863-869.

Holladay, J. T. (1997). Proper method for calculating average visual acuity. Journal of Refractive Surgery, 13(4), 388391.

Horowitz, A. (1994). Vision Impairment and Functional Disability Among Nursing Home Residents. The Gerontological Society of America, 34(3), 316-323.

Houx, P. J., Jolles, J., \& Vreeling, F. W. (1993). Stroop interference: aging effects assessed with the Stroop Color-Word Test. Experimental Aging Research, 19(3), 209-224.

Keller, B. K., Morton, J. L., Thomas, V. S., \& Potter, J. F. (1999). The effect of visual and hearing impairments on functional status. Journal of the American Geriatrics Society, 47(11), 1319-1325.

Lee, P., Smith, J. P., \& Kington, R. (1999). The Relationship of Self-rated Vision and Hearing to Functional Status and Well-being Among Seniors 70 Years and Older. American Journal of Ophthalmology, 127, 447-452.

Lezak, M. D. (1995). Neuropsychological Assessment (3rd ed.). New York: Oxford University Press.

Lindenberger, U., \& Baltes, P. B. (1994). Sensory functioning and intelligence in old age: a strong connection. Psychology and Aging, 9(3), 339-355. 
Lindenberger, U., Scherer, H., \& Baltes, P. B. (2001). The strong connection between sensory and cognitive performance in old age: not due to sensory acuity reductions operating during cognitive assessment. Psychology and Aging, 16(2), 196-205.

Luteijn, F., \& van der Ploeg, F. A. E. (1983). Handleiding Groninger Intelligentietest (GIT) [Manual Groningen Intelligence Test]. Lisse, The Netherlands: Swets and Zeitlinger.

Marsiske, M., Klumb, P., \& Baltes, M. M. (1997). Everyday activity patterns and sensory functioning in old age. Psychology and Aging, 12(3), 444-457.

Powe, N. R., Schein, 0. D., Gieser, S. C., Tielsch, J. M., Luthra, R., Javitt, J., et al. (1994). Synthesis of the literature on visual acuity and complications following cataract extraction with intraocular lens implantation. Cataract Patient Outcome Research Team. Archives of Ophthalmology, 112(2), 239-252.

Rabbitt, P. (1990). Mild hearing loss can cause apparent memory failures which increase with age and reduce with IQ. Acta Otolaryngologica Supplementum Stockh, 476(167), 167-175.

Reitan, R. M. (1958). Validity of the Trail Making Test as an indication of organic brain damage. Perceptual and Motor Skills, 8, 271-276.

Reuben, D. B., Mui, S., Damesyn, M., Moore, A. A., \& Greendale, G. A. (1999). The prognostic value of sensory impairment in older persons. Journal of he American Geriatrics Society, 47(8), 930-935.

Sekuler, R., \& Blake, R. (1987). Sensory underload. Psychology Today, 21, 48-51.

Smith, A. (1968). The Symbol Digit Modalities Test: A neuropsychological test for economic screening of learning and other cerebral disorders. Learning Disorders, 36, 83-91.

Stankov, L., \& Anstey, K. (1997). Health and cognitive aging: the emerging role of sensorimotor abilities. Australian Journal on Aging, 16(1), 34-39.

Steinberg, E. P., Tielsch, J. M., Schein, 0. D., Javitt, J. C., Sharkey, P., Cassard, S. D., et al. (1994). The VF-14. An index of functional impairment in patients with cataract. Archives of Ophthalmology, 112(5), 630-638.

Stroop, J. R. (1935). Studies of interference in serial verbal reactions. Journal of Experimental Psychology, 18, 643662.

Tabachnick, B. G., \& Fidell, L. S. (2001). Using multivariate statistics. Boston: Allyn \& Bacon.

Van Boxtel, M. P., ten Tusscher, M. P., Metsemakers, J. F., Willems, B., \& Jolles, J. (2001). Visual determinants of reduced performance on the Stroop color-word test in normal aging individuals. Journal of Clinical and Experimental Neuropsychology, 23(5), 620-627.

Van Boxtel, M. P. J., van Beijsterveldt, T., Houx, P. J., Anteunis, L. J. C., Metsemakers, J. F. M., \& Jolles, J. (2000). Mild hearing impairment can reduce verbal memory performance in a healthy adult population. Journal of Clinical and Experimental Neuropsychology, 22(1), 147-154.

Vink, M., \& Jolles, J. (1985). A new version of the Trail-Making Test as an information processing task. Journal of Clinical Neuropsychology, 7, 162.

Wallhagen, M. I., Strawbridge, W. J., Shema, S. J., Kurata, J., \& Kaplan, G. A. (2001). Comparative impact of hearing and vision impairment on subsequent functioning. Journal of the American Geriatrics Society, 49(8), 1086-1092. 
CHAPTER 7. THE EFFECT OF CATARACT SURGERY ON COGNITIVE FUNCTIONING IN OLDER ADULTS 


\section{Abstract}

The prevalence of visual problems rises sharply with advancing age, senile cataract being one of the most common. The objective of this study was to examine the effect of cataract surgery on quality of life. Therefore patients who underwent cataract surgery were compared with cataract patients in a waiting list control group. The outcome measures of interest were both visual related quality of life and general quality of life. Results showed that cataract surgery has beneficial effects on visual functioning and visual related quality of life. However, cataract surgery does not influence general health related quality of life. 


\section{Introduction}

Visual problems become more frequent as people grow older (Keller, Morton, Thomas, \& Potter, 1999). Impaired vision causes difficulties in the execution of tasks essential for daily living (e.g. reading, driving, watching television) (Horowitz, 1994; Marsiske, Klumb, \& Baltes, 1997; Reuben, Mui, Damesyn, Moore, \& Greendale, 1999). This can have devastating implications for individuals' perceived quality of life related to visual function. In addition, impaired vision can have more widespread consequences and may influence general health related quality of life (Swagerty, 1995; Wallhagen, Strawbridge, Shema, Kurata, \& Kaplan, 2001). Identifying effective interventions that can improve visual function may therefore also be an important step towards improving the quality of life of many older people.

One of the most frequent causes of visual impairment in old age is senile cataract, an eye disease characterized by opacification and swelling of the lens, thereby blocking the passage of light to the retina (Steinberg et al., 1994). The only effective treatment is to surgically remove the opaque lens and replace it with an artificial implant lens. It is generally agreed upon that cataract surgery is a highly effective treatment with a very low incidence rate of surgical complications (Powe et al., 1994). The increasing demand for cataract surgery has stimulated interest in outcome research and its potential impact on a broader range of functioning. Previous studies have shown that cataract surgery is not only effective in improving visual acuity, but also in improving visual function and related quality of life. Unfortunately, most studies have methodological limitations, most importantly the fact that there were no controls as a reference group (Abrahamsson, Carlsson, Tornqvist, Sterner, \& Sjostrand, 1996; Desai, Reidy, Minassian, Vafidis, \& Bolger, 1996; Fagerstrom, 1992; Lundstrom, Fregell, \& Sjoblom, 1994; Mamidipudi, Vasavada, Merchant, Namboodiri, \& Ravilla, 2003; Mangione et al., 1994; Monestam \& Wachtmeister, 2002; Pesudovs, Weisinger, \& Coster, 2003). Furthermore, the few studies that did compare the effects of cataract surgery in patients who underwent surgery to those who were untreated, used crosssectional retrospective designs (He et al., 1999; Lau, Michon, Chan, \& Ellwein, 2002; Pokharel, Selvaraj, \& Ellwein, 1998), or used patients who declined suggested treatment as a control group (McGwin, Scilley, Brown, \& Owsley, 2003). However, the only way to make absolute statements about 
whether or not cataract surgery is effective in improving visual functioning and quality of life is to employ a prospective controlled trail. Therefore, in the present study, the direct effects of cataract surgery on visual functioning, visual related and general health quality of life, were examined using data from an experiment with a waiting list controlled design. This experiment offers the unique opportunity to study the effects of cataract treatment by comparing two groups of individuals, namely elderly patients who underwent cataract surgery, and cataract patients who were waiting to have surgery during the course of the study. It was possible to execute this study due to the extraordinary circumstance that at the time of execution there was a waiting list for cataract surgery in the Netherlands of at least 12 months. This was due to governmental limitation of the number of surgical interventions allowed per year.

\section{Methods}

\section{Participants}

Participants were older individuals recruited through the department of Ophthalmology of the University Hospital Maastricht, and who were treated by the same team of ophthalmolgists working at the University Hospital Maastricht, the Medical Centre Maastricht Annadal, or the Atrium Medical Centre Heerlen, all located in the south of the Netherlands. All patients were diagnosed with senile cataract and were qualified for treatment with first-eye phacoemulsification and intraocular lens implantation, under retrobulbar or sub-Tenon's anaesthesia. Participants were included in the study if they were 65 years or older, had good comprehension of the Dutch language, were sufficiently mobile in order to travel independently to the research centre, were not using psychotropic medication on a daily basis and did not previously participate in a neuropsychological research program. Exclusion criteria were a score below 24 on the Mini-Mental State Examination (MMSE) (Folstein, Folstein, \& McHugh, 1975), a diagnosis of central nervous system pathology (e.g. dementia, Parkinson's disease), a major psychiatric disorder, or ocular co-morbidity that also may impair visual acuity (e.g. macular degeneration). 
The Medical Ethics Committees of both the University Hospital Maastricht and the Atrium Medical Centre Heerlen approved the protocol and all participants gave their informed consent.

\section{Measures}

First, best corrected distance visual acuity for both eyes separately was measured with a Landolt- $C$ optotype chart at a distance of 5 meters under standard luminescence. Binocular visual acuity was measured afterwards. Participants are requested to name the direction of the opening of black circles on a white background (four possibilities). The outcome measure is expressed by the logarithm of the minimal angle of resolution scale (logMAR) (Holladay, 1997), higher scores indicating worse distance visual acuity.

Best corrected near visual acuity was measured with the Amsterdam Reading Chart (Anonymous, 1998). The chart contains short passages of text printed in ascending font sizes and participants are requested to read the text at a preferred distance of approximately $20 \mathrm{~cm}$. Close visual acuity is scored as the font size of text that can be read without errors, in decimal units, ranging from 0.5 (optimal acuity) to 1.25 (poor acuity).

The ability to perform vision dependent daily activities was measured with the VF-14 questionnaire (Steinberg et al., 1994). In this study a Dutch version of the VF-14 was used, adapted and translated for a Dutch population by Nijkamp et al., with consideration of conceptual and cultural equivalence (Nijkamp et al., 2000). Participants are asked to rate whether the amount of difficulty they currently have with several activities (e.g. do you have any difficulty, even with glasses, reading a newspaper or book?) was 'a little', 'a moderate amount', 'a great deal', or whether they were 'unable to perform' the specific activity. Higher scores indicate better level of function, or no disability.

Vision related quality of life was measured with the VCM1, which consist of 10 'core' items derived form a 'parent' questionnaire (the VQOL) (Frost, 1998). The different domains addressed with this questionnaire include embarrassment, anger, depression, loneliness, fear of deterioration, safety, coping with everyday life, inability to perform preferred activities, and life interference. Participants are asked to rate how much their eyesight 
interfered with several items on a 6-point scale ranging from 'not at all' to 'very often'. Higher scores indicate more problems.

A Dutch translation of the MOS 36-item Short-Form Health Survey (SF36) was used to measure general health related quality of life (Ware \& Sherbourne, 1992). The SF-36 is coded into eight scales, including physical functioning, social functioning, role limitations due to physical problems, role limitations due to emotional problems, general mental health, vitality, bodily pain, and general health perceptions. Each scale is scored from o (lowest level of functioning) to 100 (highest level). The eight scales can be summarized into a physical (PCS) and a mental components summary score (MCS).

In addition, the remaining measures that were obtained from all participants were demographic information such as age, sex, and educational attainment (range $1=$ primary education to $8=$ university education (De Bie, 1987)), IQ, and the Mini-Mental State Examination (MMSE) (Folstein et al., 1975), that was employed as a screening instrument for cognitive dysfunction and/or the presence of dementia.

\section{Procedure}

Patients who were qualified for cataract surgery were asked to participate in the study. Individuals who had phacoemulsification and intraocular lens implantation were asked to fill in the three separate questionnaires three times, 1 week before the intervention, 1 month after the intervention, and at 9 months follow-up. This procedure also applies for cataract patients who were waiting to have surgery. During the course of the study, the average waiting-list for cataract surgery was approximately 14 months. This waiting period, however, was not influenced by the present study or the severity of the visual impairment, and if participants who were waiting did have cataract surgery within the study period, the follow-up assessment was advanced, if possible.

\section{Statistical analysis}

Separate One-way Analyses of Variance (ANOVA) were performed for age, educational level, intelligence and MMSE scores to examine differences in baseline characteristics between the intervention group and the control 
group. In addition, a Chi-square test was employed to analyze the variables sex and marital status (married or cohabiting, versus others). Differences in visual acuity at nine months follow-up were examined with ANOVA, controlled for baseline visual acuity and time interval between measurements.

General Linear Model (GLM) repeated measures analysis of variance was used to assess group differences regarding the effect of cataract surgery on visual functioning and quality of life. Analyses were performed with group as the between-subjects variable and visual functioning and quality of life as the within-subjects factor. Age, sex, educational level, time interval and baseline scores were treated as covariates. All statistical analyses were performed using SPSS for Macintosh, version 10 (SPSS-Inc., Chicago).

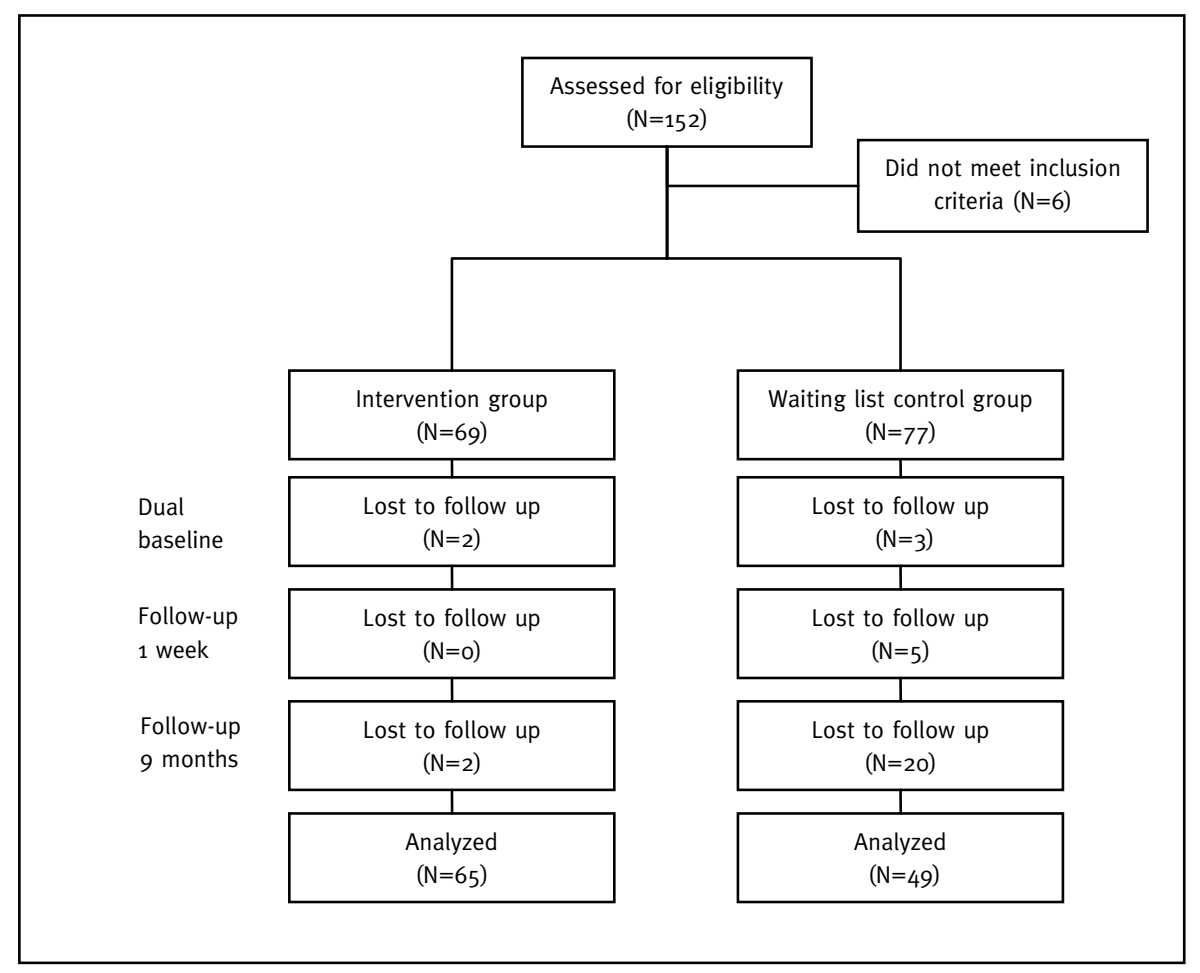

Figure 1. Results of recruitment 


\section{Results}

\section{Recruitment}

One hundred fifty-two eligible individuals were willing to participate. Six individuals did not meet the inclusion criteria and were excluded from participation. The study population consisted of two groups, namely an intervention group who underwent cataract surgery $(\mathrm{N}=69)$ and a group of cataract patients who remained on a waiting-list $(\mathrm{N}=77)$. Thirty-two participants dropped out the study, four of them were individuals who had cataract surgery and 28 persons were control group participants. The total amount of dropouts was higher in the control group because there was a large number of participants who had cataract surgery before the final assessment and could therefore no longer be regarded as controls. Results of recruitment are displayed in Figure 1 (also see Chapter 7 ).

\section{Baseline characteristics}

There were no significant differences between the groups in age, marital status, intelligence, education, visual acuity and MMSE-score at baseline. Results are summarized in Table 1 (also see Chapter 7).

Table 1. Means and standard deviations for demographic variables at baseline (total $\mathrm{N}=146$ )

\begin{tabular}{llll}
\hline & $\begin{array}{l}\text { Intervention group } \\
(\mathrm{N}=69)\end{array}$ & $\begin{array}{l}\text { Control group } \\
(\mathrm{N}=77)\end{array}$ & $p$-value \\
\hline Age & $75.17(6.62)$ & $75.78(6.08)$ & 0.57 \\
Marital status (\% married/living together) & 65.67 & 65.28 & 0.91 \\
Gender (\% women) & 52.17 & 57.14 & 0.55 \\
Education & $2.96(1.95)$ & $2.58(1.67)$ & 0.22 \\
IQ & $114.00(15.36)$ & $110.44(17.10)$ & 0.20 \\
MMSE & $27.79(1.46)$ & $27.45(1.97)$ & 0.24 \\
Distant visual acuity & $0.56(0.28)$ & $0.59(0.25)$ & 0.44 \\
Near visual acuity & $0.77(0.23)$ & $0.74(0.19)$ & 0.37 \\
\hline
\end{tabular}

MMSE = Mini Mental State Examination 


\section{Visual acuity}

With respect to visual acuity, the results indicate that there was a significant improvement in the intervention group in both distant $(F(1,104)=27.14$, pro.01) and near visual acuity values $(F(1,101)=23.44$, p<0.01), compared to individuals who did not have surgery (see Table 2 (also see Chapter 7)).

Table 2. Mean visual acuity at nine months follow-up, adjusted for baseline visual acuity and time interval

\begin{tabular}{llll}
\hline & $\begin{array}{l}\text { Intervention group } \\
(\mathrm{N}=65)\end{array}$ & $\begin{array}{l}\text { Control group } \\
(\mathrm{N}=49)\end{array}$ & $p$-value \\
\hline Distant visual acuity* & -0.08 & 0.31 & $<0.01$ \\
Near visual acuity & 0.59 & 0.77 & $<0.01$ \\
\hline
\end{tabular}

* $\log M A R$ visual acuity

\section{Visual functioning and quality of life}

Group differences in visual functioning and quality of life were assed with General Linear Model (GLM) repeated measures analysis of variance. The results show that there was a significant main effect for the total VF-14 score on both post intervention test occasions, with individuals who had cataract surgery having better visual functioning, as compared to controls $(F(1,105)=$ 21.22, pro.01, estimated marginal mean for the intervention group $=86.94$, $95 \% \mathrm{Cl}=83.73-90.15$, estimated marginal mean for the control group $=$ $74.44,95 \% \mathrm{Cl}=70.64-78.24)$.

A significant interaction indicated that this effect increased after 9 months follow-up. In addition, a significant main effect was found for the VCM1 total score, again with individuals who had cataract surgery reporting better visual related quality of life, as compared to controls $(F(1,104)=7.33, p=0.01$, estimated marginal mean for the intervention group $=0.63,95 \% \mathrm{Cl}=0.50$ 0.77 , estimated marginal mean for the control group $=0.95,95 \% \mathrm{Cl}=0.79$ 1.12). There was a significant interaction effect, indicating that the effect on the total VCM1 score increased within the 9 months follow-up period.

Main effects of group membership on the physical (PCS) and mental components summary scores (MCS) of the SF-36 were not statistically 
CHAPTER 8. THE EFFECT OF CATARACT SURGERY ON VISUAL FUNCTIONING AND QUALITY OF LIFE

significant. For this reason, no further analyses were performed on SF-36 subscales.

Table 3. Means, standard errors* and results of tests for group differences in visual functioning, visual related quality of life, and general health related quality of life

\begin{tabular}{|c|c|c|c|c|}
\hline & $\begin{array}{l}\text { Intervention } \\
\text { group }\end{array}$ & Control group & $\begin{array}{l}\text { Main effect } \\
p \text {-value }\end{array}$ & $\begin{array}{l}\text { Interaction } \\
p \text {-value }\end{array}$ \\
\hline VF-14 total score & $\mathrm{N}=64$ & $\mathrm{~N}=48$ & $<0.01$ & $<0.01$ \\
\hline 1-week follow-up & $85.14(1.88)$ & 78.39 (2.22) & & \\
\hline 9-month follow-up & $88.75(1.82)$ & $70.49(2.16)$ & & \\
\hline VCM1 total score & $\mathrm{N}=64$ & $\mathrm{~N}=47$ & 0.01 & $<0.01$ \\
\hline 1-week follow-up & $0.78(0.08)$ & $0.87(0.09)$ & & \\
\hline 9-month follow-up & $0.49(0.09)$ & $1.03(0.11)$ & & \\
\hline SF-36 (PCS) & $\mathrm{N}=60$ & $\mathrm{~N}=47$ & 0.77 & 0.18 \\
\hline 1-week follow-up & $42.52(0.75)$ & $40.97(0.87)$ & & \\
\hline 9-month follow-up & $40.32(1.10)$ & $41.11(1.27)$ & & \\
\hline SF-36 (MCS) & $\mathrm{N}=60$ & $\mathrm{~N}=47$ & 0.86 & 0.75 \\
\hline 1-week follow-up & $51.19(0.94)$ & $51.22(1.07)$ & & \\
\hline 9-month follow-up & $50.23(1.22)$ & $49.66(1.4)$ & & \\
\hline
\end{tabular}

VF-14 = visual functioning; higher scores indicate better functioning |VCM1 = visual related quality of life; lower scores indicate better functioning |PCS = physical components summary score; higher scores indicate better functioning $\mid$ MCS = mental components summary score; higher scores indicate better functioning

* Mean scores and standard errors, adjusted for age, gender, educational level, time interval and baseline scores

\section{Discussion}

The aim of this study was to examine the effect of cataract surgery on visual functioning and quality of life. Taking into account methodological problems of other previous studies, we employed a prospective controlled design with a waiting-list control group. The results of the present study indicate that cataract surgery not only has a beneficial effect on visual acuity, but also on visual functioning and visual related quality of life. These findings confirm recent studies e.g. (Mamidipudi et al., 2003; Monestam \& Wachtmeister, 2002; Pesudovs et al., 2003), but contradict with others that failed to find a positive effect of cataract surgery (He et al., 1999; Lau et al., 2002; Pokharel et al., 1998). However, Lee et al. (2003) already concluded that is difficult to 
compare international studies with respect to outcome after cataract surgery, since there are several important factors that can influence the results (e.g. differences in economic status, health care systems, cultural values, health policy). For example, they found that patients who underwent cataract surgery in the United States were older, had higher education, better visual acuity, and more favourable health outcomes than those in Korea (Lee, Fos, Zuniga, Kastl, \& Sung, 2003). Indeed, the studies of He et al. (1999), Lau et al. (2002), and Pokharel et al. (1998) were conducted in China, Hong Kong and Nepal, respectively, and it is therefore possible that cross-cultural differences may provide a plausible explanation.

With respect to general health related quality of life, our results agree with Mangione et al. (1994) in that in this study only specific, visual related effects of cataract surgery were found, i.e. the intervention did not influence general health related quality of life. It is possible that cataract is a specific problem that only influences patients' visual acuity and related quality of life, but has no effect on physical functioning, social functioning, role limitations due to physical problems, role limitations due to emotional problems, general mental health, vitality, bodily pain, and general health perceptions, factors that constitute the two overall measures of the SF-36 questionnaire. Indeed, related studies that did find a relationship between visual functioning and the SF-36 questionnaire used patients with corneal graft (Boisjoly et al., 1999) or glaucoma (Wilson et al., 1998), both eye diseases that may cause more generic problems than senile cataract. Following this argument, it is also shown that only moderate and severe visual impairment has an impact on SF-36 scores, which was defined as visual acuity of $<6 / 24$ and $<6 / 60$ in the worst eye, respectively (Chia, Mitchell, Rochtchina, Foran, \& Wang, 2003). The average visual acuity of patients in our study, however, is better, even pre-operatively.

In conclusion, in addition to visual acuity, subjective aspects of visual functioning and quality of life are indispensable in measuring treatment outcome of cataract surgery, since the assessment of post-operative visual acuity alone may underestimate the overall benefits of cataract surgery. Positive effects on subjective indicators of daily functioning and quality of life, however, are limited to visual related measurements, and do not have widespread effects on more generic health related quality of life. 


\section{References}

Abrahamsson, M., Carlsson, B., Tornqvist, M., Sterner, B., \& Sjostrand, J. (1996). Changes of visual function and visual ability in daily life following cataract surgery. Acta Ophthalmol Scandinavica, 74(1), 69-73.

Anonymous. (1998). Amsterdamse Leeskaart [Amsterdam Reading Chart]. Groningen: Medical Workshop.

Boisjoly, H., Gresset, J., Fontaine, N., Charest, M., Brunette, I., LeFrancois, M., et al. (1999). The VF-14 index of functional visual impairment in candidates for a corneal graft. American Journal of Ophthalmology, 128(1), 3844.

Chia, E. M., Mitchell, P., Rochtchina, E., Foran, S., \& Wang, J. J. (2003). Unilateral visual impairment and health related quality of life: the Blue Mountains Eye Study. British Journal of Ophthalmology, 87(4), 392-395.

De Bie, S. E. (1987). Standaardvragen 1987: Voorstellen voor uniformering van vraagstellingen naar achtergrondkenmerken en interviews [Standard questions 1987: Proposal for uniformization of questions regarding background variables and interviews] (2nd ed.). Leiden: Leiden University Press.

Desai, P., Reidy, A., Minassian, D. C., Vafidis, G., \& Bolger, J. (1996). Gains from cataract surgery: visual function and quality of life. British Journal of Ophthalmology, 80(10), 868-873.

Fagerstrom, R. (1992). Correlation Between Psychosocial Disabilities in daily Activities and Vision of Aged Cataract Operation Patients. Clinical Gerontologist, 12(2), 57-74.

Folstein, M. F., Folstein, S. E., \& McHugh, P. R. (1975). Mini-mental State: a practical method for grading the cognitive state of patients for the clinician. Journal of Psychiatric Research, 12, 189-198.

He, M., Xu, J., Li, S., Wu, K., Munoz, S. R., \& Ellwein, L. B. (1999). Visual acuity and quality of life in patients with cataract in Doumen County, China. Ophthalmology, 106(8), 1609-1615.

Holladay, J. T. (1997). Proper method for calculating average visual acuity. Journal of Refractive Surgery, 13(4), 388391.

Horowitz, A. (1994). Vision Impairment and Functional Disability Among Nursing Home Residents. The Gerontological Society of America, 34(3), 316-323.

Keller, B. K., Morton, J. L., Thomas, V. S., \& Potter, J. F. (1999). The effect of visual and hearing impairments on functional status. Journal of the American Geriatrics Society, 47(11), 1319-1325.

Lau, J., Michon, J. J., Chan, W. S., \& Ellwein, L. B. (2002). Visual acuity and quality of life outcomes in cataract surgery patients in Hong Kong. British Journal of Ophthalmology, 86(1), 12-17.

Lee, J. E., Fos, P. J., Zuniga, M. A., Kastl, P. R., \& Sung, J. H. (2003). Health-related quality of life of cataract patients: cross-cultural comparisons of utility and psychometric measures. Ophthalmic Epidemiology, 10(3), 177-191.

Lundstrom, M., Fregell, G., \& Sjoblom, A. (1994). Vision related daily life problems in patients waiting for a cataract extraction. British Journal of Ophthalmology, 78(8), 608-611.

Mamidipudi, P. R., Vasavada, A. R., Merchant, S. V., Namboodiri, V., \& Ravilla, T. D. (2003). Quality-of-life and visual function assessment after phacoemulsification in an urban indian population. Journal of Cataract and Refractive Surgery, 29(6), 1143-1151.

Mangione, C. M., Phillips, R. S., Lawrence, M. G., Seddon, J. M., Orav, E. J., \& Goldman, L. (1994). Improved visual function and attenuation of declines in health-related quality of life after cataract extraction. Archives of Ophthalmology, 112(11), 1419-1425. 
Marsiske, M., Klumb, P., \& Baltes, M. M. (1997). Everyday activity patterns and sensory functioning in old age. Psychology and Aging, 12(3), 444-457.

McGwin, G., Jr., Scilley, K., Brown, J., \& Owsley, C. (2003). Impact of cataract surgery on self-reported visual difficulties: comparison with a no-surgery reference group. Journal of Cataract and Refractive Surgery, 29(5), 941-948.

Monestam, E., \& Wachtmeister, L. (2002). Change of subjective visual function in first-eye cataract patients when the rate of surgery increases in a population. Medical Care, 40(11), 1080-1089.

Nijkamp, M. D., Nuijts, R. M., Borne, B., Webers, C. A., van der Horst, F., \& Hendrikse, F. (2000). Determinants of patient satisfaction after cataract surgery in 3 settings. Journal of Cataract and Refractive Surgery, 26(9), 13791388.

Pesudovs, K., Weisinger, H. S., \& Coster, D. J. (2003). Cataract surgery and changes in quality of life measures. Clinical and Experimental Ophthalmology, 86(1), 34-41.

Pokharel, G. P., Selvaraj, S., \& Ellwein, L. B. (1998). Visual functioning and quality of life outcomes among cataract operated and unoperated blind populations in Nepal. British Journal of Ophthalmology, 82(6), 606-610.

Powe, N. R., Schein, O. D., Gieser, S. C., Tielsch, J. M., Luthra, R., Javitt, J., et al. (1994). Synthesis of the literature on visual acuity and complications following cataract extraction with intraocular lens implantation. Cataract Patient Outcome Research Team. Archives of Ophthalmology, 112(2), 239-252.

Reuben, D. B., Mui, S., Damesyn, M., Moore, A. A., \& Greendale, G. A. (1999). The prognostic value of sensory impairment in older persons. Journal of the American Geriatrics Society, 47(8), 930-935.

Steinberg, E. P., Tielsch, J. M., Schein, O. D., Javitt, J. C., Sharkey, P., Cassard, S. D., et al. (1994). The VF-14. An index of functional impairment in patients with cataract. Archives of Ophthalmology, 112(5), 630-638.

Swagerty, D. L., Jr. (1995). The impact of age-related visual impairment on functional independence in the elderly. The Journal of the Kansas Medical Society, 96(1), 24-26.

Wallhagen, M. I., Strawbridge, W. J., Shema, S. J., Kurata, J., \& Kaplan, G. A. (2001). Comparative impact of hearing and vision impairment on subsequent functioning. Journal of the American Geriatrics Society, 49(8), 1086-1092.

Ware, J., J. E., \& Sherbourne, C. D. (1992). The MOS 36-item short-form health survey (SF-36): I. conceptual framework and item selection. Medical Care, 30(6), 473-483.

Wilson, M. R., Coleman, A. L., Yu, F., Bing, E. G., Sasaki, I. F., Berlin, K., et al. (1998). Functional status and wellbeing in patients with glaucoma as measured by the Medical Outcomes Study Short Form-36 questionnaire. Ophthalmology, 105(11), 2112-2116. 
CHAPTER 8. THE EFFECT OF CATARACT SURGERY ON VISUAL FUNCTIONING AND QUALITY OF LIFE 


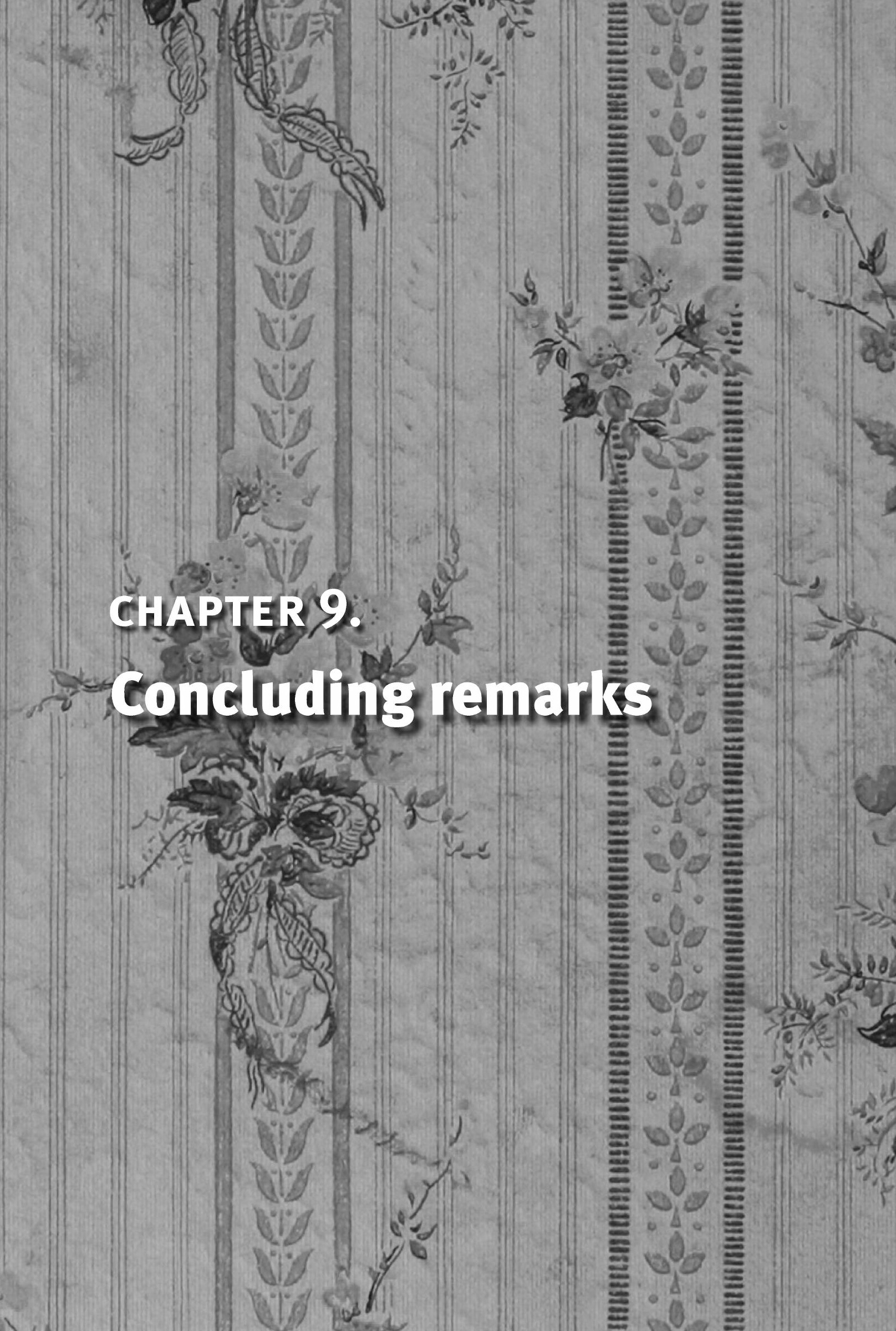


The first aim of this thesis was to identify possible determinants of successful cognitive aging, using data from the Maastricht Aging Study (MAAS). Regarding this aim, it was found that both memory self-efficacy (MSE) and visual function were predictive of cognitive performance over a 6year period. In addition, it was found that scores on a general quality of life questionnaire predict change in functional independence 3 years later. The second aim concerned the evaluation of specific interventions on cognitive performance and quality of life in older persons. With respect to this aim, we investigated the effects of a memory-training program and of cataract surgery. First of all, we showed that the memory-training program was effective in improving both subjective and objective memory performance. In a related study we could not demonstrate that personality or mood characteristics had any effect on treatment outcome. We did however identify different characteristics of individuals who participate in an intervention and those who drop out. Regarding the effect of cataract surgery, it was demonstrated that surgery had positive effects on cognitive performance and vision-related quality of life. No effects however were found on a measure of general quality of life.

In this chapter some experimental results described in this thesis will be discussed on a more general level. More specifically, the findings will be linked to current views on the relationship between memory complaints and objective memory performance, and on the association between cognitive and sensory function. Furthermore, some implications will be discussed, and the thesis ends with an evaluation of the concept of successful cognitive aging.

\section{Memory and memory self-efficacy}

An ongoing debate in the literature on cognitive aging is whether subjective feelings of memory dysfunction are caused by an actual decline in objective memory or by other variables, including MSE and personality variables. Recent studies have demonstrated that memory complaints of older individuals can predict objective performance at a later point in time, or even the precipitation of dementia (Dik et al., 2001; Jonker, Geerlings, \& Schmand, 2000). Other authors, however, have stressed the dissociation between subjective complaints and objective memory performance in older age groups 
(Birren \& Schaie, 1996; Bolla, Lindgren, Bonaccorsy, \& Bleecker, 1991; Comijs, Deeg, Dik, Twisk, \& Jonker, 2002; Commissaris, Ponds, \& Jolles, 1998; Derouesne, Lacomblez, Thibault, \& LePoncin, 1999) and have argued that there are several other factors that determine memory complaints, with MSE being one of them (Clarnette, Almeida, Forstl, Paton, \& Martins, 2001; Stevens, Kaplan, Ponds, \& Jolles, 2001).

We found that individuals who complain about forgetfulness and wish to participate in a memory intervention, actually perform better on an objective memory test than controls without such complaints. At the same time, they report more neurotic and depressive symptoms, and less MSE. Furthermore, it was shown that when individuals participate in a memorytraining program that focuses on enhancing MSE, both their subjective and objective memory performance improved. This finding clearly supports the notion that memory complaints are influenced by several factors, besides actual objective memory ability per se. On the other hand, in Chapter 2 it was shown that of the three scales that constitute the MSE measure of the Metamemory In Adulthood questionnaire (MIA), the Change scale is the most salient predictor of objective memory performance six years later. The other scales are the Capacity scale that indicates the level of perceived memory capacity, and the Anxiety scale that reflects feelings of anxiety and stress in relation to memory functioning. The Change scale, however, measures an individuals' perception of whether or not his/her memory has been deteriorating over time. As it predicts future memory decline, it may also reflect some knowledge about actual and future objective memory functioning. Thus, perceptions about memory function may at least partly be based upon ongoing changes in cognitive performance. This implies that a significant number of older individuals can indeed accurately judge whether or not their memory performance is actually declining. This is especially interesting since these results were derived from the MAAS population, and not specifically from a population sample of individuals who complained about their memory functioning. In the MAAS it was demonstrated that although there is a significant number of individuals that complain about memory functioning, the group of individuals aged 55 through 65 years that did not complain was still larger (Ponds, Commissaris, \& Jolles, 1997). This group of individuals is very interesting because they are not selected as 
people with memory complaints, but still can judge and report whether or not their memory is getting worse.

In conclusion, although memory complaints are indeed clearly influenced by psychosocial variables such as neuroticism and feelings of anxiety or incapability, complaints can nevertheless be paralleled by an actual decline in memory. As previously shown by Ponds (1997), when addressing memory complaints of older individuals, it therefore seems important to carefully look into underlying factors such as personality traits, level of confidence, and mood, in trying to understand what causes individuals to complain. Future studies on the predictive value of memory complaints should focus on finding specific characteristics of those individuals that can accurately predict that their memory is deteriorating. If we can distinguish between complaints that are caused by an actual decline and those that are caused by variables such as low MSE, it may become possible to administer a more individualised treatment regime. In any case, if an actual objective memory decline is the underlying factor that causes individuals to complain, these problems should be treated in a different manner than when low MSE is the primary cause.

\section{Cognition and sensory function}

Another highlighted topic from the recent literature on cognitive aging is concerned with the negative association between sensory function and cognition. Several models have been put forward to explain this connection. It has been proposed that there is a direct causal relationship (such as stated in the 'sensory deprivation' hypothesis (Lindenberger \& Baltes, 1994), the 'resource allocation' hypothesis (Baltes \& Lindenberger, 1997; Rabbitt, 1990), and the 'information degradation' hypothesis (Schneider \& PichoraFuller, 2000; van Boxtel, ten Tusscher, Metsemakers, Willems, \& Jolles, 2001)). On the other hand there are models which state that the association between sensory functioning and cognition is caused by a 'common', third factor, such as a neurobiological mechanism involved in degeneration in the central nervous system (Christensen, Mackinnon, Korten, \& Jorm, 2001; Lindenberger \& Baltes, 1994). Although the studies described in this thesis were not specifically designed to single out the best explanatory model(s), the results of the longitudinal study described in Chapter 3 and the 
controlled experiment reported in Chapter 7 may help to elucidate the nature of this relationship.

First of all, in Chapter 7 it was found that cataract surgery had a direct effect on cognition. As a consequence of cataract surgery, not only visual acuity improved, but patients also improved on a verbal memory task and on the ability to inhibit a habitual response. This suggests that there is a causal connection between visual function and cognitive performance. Moreover, in Chapter 3 we only found a robust and consistent relationship between visual acuity and cognition, but not between auditory acuity and cognition. Also, it was demonstrated that a change in visual function was not associated with all cognitive domains. As it seems unlikely that a common factor would distinguish between different aspects of sensory function (e.g. vision and hearing) and/or different aspects of cognition (e.g. memory, attention, fluency) (Anstey, Luszcz, \& Sanchez, 2001), this too supports the notion of a direct, causal relationship. In our studies, sensory function was defined as a purely peripheral measure of visual or auditory acuity. Although we did find a clear causal relationship between visual function and cognition, the existence of a 'common' factor cannot be ruled out. As the 'common-cause' hypothesis usually refers to impairments in the sensory system that are caused by neuronal deficits that cannot be easily rehabilitated at the level of the end organ (in case of cataract surgery: the eye), a 'common' factor still may operate on a central level of information processing.

Although the discussed hypotheses that presume a causal association between sensory function and cognition are not mutually exclusive, we can argue that both the 'resource allocation' hypothesis and the 'information degradation' hypothesis are most likely to explain our results. First, after cataract surgery, positive effects were only found on tasks that place the highest burden on higher order processing. This fits in with the 'resource allocation' hypothesis because this hypothesis states that if vision is optimal, more resources become available to perform cognitive challenging tasks. These extra resources will then be used most efficiently in tasks with the highest cognitive demands. Second, in Chapter 3 only a relationship between vision and cognitive tasks that depend on optimal vision was found. The 'information degradation' hypothesis states that individuals with a sensory impairment will have a disadvantage in the execution of psychometric tests 
as a direct result of difficulties in identification of the stimulus material, rather than as a consequence of cognitive abilities per se. Based on our results it cannot be excluded that better visual function is associated with better performance on cognitive tasks as a direct consequence of the fact that perceptual information is degraded. However, although this mechanism implies a peripheral effect on performance, the net effect for the individual is the same, as due to the intervention complex behaviour becomes more efficient.

In the previously mentioned complementary thesis by van Hooren*, a related study was conducted which examined the effects of a hearing aid use on cognition, notably executive functioning. It was found that improving auditory function did not affect cognition of older individuals. A possible explanation for this finding is that most cognitive measures have more visual than auditory components. According to both the 'degraded information' and 'resource allocation' hypothesis, improving auditory function would have a beneficial effect on cognitive tasks that depend on auditory function, rather than on tasks that depend on vision. Unfortunately, no cognitive tasks with only an auditory component were used in this study, so a differential effect of sensory intervention on cognitive measures remains quite complicated. When future studies want to address this issue we suggest that more effort is needed to identify and use tests that incorporate both visual and auditory processing.

\section{Towards an implementation of the memory-training program?}

The memory-training program that was evaluated in Chapter 5 was shown to be effective in treating memory problems; we therefore consider it to be a valuable intervention for public health care. This positive finding was also acknowledged by the Dutch Research Council (NWO), which has decided to provide further funding to implement this treatment intervention on a larger scale in the Netherlands. The aim of this new project is to provide an elaborated description of the program, which can be used by health care professionals in their daily care for older people. By implementation of this program, older adults who contact a general practitioner or specialists (e.g.

\footnotetext{
* Successful Cognitive Aging: Executive functioning, determinants, and interventions. Susan A.H. van Hooren. Thesis
} 
health care psychologist, psychiatrist or neurologist) with worries about forgetfulness or anticipated dementia can be offered a rational treatment of their complaints. Findings reported in Chapters 2 and 6, on the influence of MSE on cognition, and characteristics of memory intervention participants, as well as experiences with a Goal Management Training (GMT; see Chapter 6 thesis van Hooren), provide further knowledge that will be incorporated in the training protocol. Apart from implementation of this intervention for older individuals who complain about memory, the general approach of this course can also be of benefit for other groups of individuals that are characterized by cognitive complaints and/or impairments. The program does not only consist of training memory related functions, but also emphasizes the need for psycho-education. This method enables individuals with cognitive problems to evaluate their own performance in daily life and to make use of relevant coping and compensation mechanisms more efficiently (Commissaris, Verhey, \& Jolles, 1996; Reyersen van Buuren \& Jolles, 1990). It is increasingly recognized that training skills is not enough to induce a significant behavioural change, but that cognitive restructuring to promote adaptive beliefs about cognition should also be emphasized (Lachman, Weaver, Bandura, Elliott, \& Lewkowicz, 1992)(see also Chapter 6 in the thesis by van Hooren). This training will be offered as a collective training so individuals can benefit from the comforting and motivating effect of sharing their concerns, and learn from coping strategies of others. As also reported in Chapter 5, offering an intervention as a collective training is most effective and is preferable to individual training (Verhaeghen, Marcoen, \& Goossens, 1992). Relevant patient groups for an intervention such as described here are patients with cognitive problems after Mild Traumatic Brain Injury, patients with Mild Cognitive Impairment $(\mathrm{MCl})$ and patients with Attention Deficit/Hyperactivity Disorder (ADHD, recognised both in children and adults).

\section{Successful cognitive aging; where to go from here?}

The major objective of the present thesis was to develop more insight in the domain of successful cognitive aging. It has become clear through the years that the concept of successful aging is very diverse and can be investigated from various angles of investigation, according to the specific interests of different research groups. Although the concept is very appealing in its 
comprehensiveness, the fact that many definitions are used makes it very difficult to interpret and integrate the results from the various studies available in this field. This is clearly illustrated by recent efforts to identify determinants of successful aging. Several predictors have already been found, and they range from higher education (Berkman et al., 1993; Strawbridge, Cohen, Shema, \& Kaplan, 1996; Vaillant \& Mukamal, 2001), higher income (Berkman et al., 1993; Guralnik \& Kaplan, 1989), and nonsmoking (Berkman et al., 1993; Guralnik \& Kaplan, 1989; Jorm et al., 1998; Vaillant \& Mukamal, 2001) to marital stability (Roos \& Havens, 1991; Vaillant \& Mukamal, 2001). Thus, which specific factors are identified as determinants of successful aging strongly depends on how successful aging is operationally defined. It is important to note that the majority of research performed up till now was devoted to successful aging in a broader sense and thus encompasses also aspects of physical functioning, and social functioning.

Our research questions specifically focused on successful cognitive aging and possible determinants and interventions, an area of successful aging that received relatively little attention so far. This thesis was part of a larger research program on successful cognitive aging, and together with the results described in a complementary thesis by van Hooren, it provides evidence for several determinants and beneficial interventions suitable for older individuals, thereby making some new contributions to the existing literature. However, a consistent pattern in most recent aging studies, including our own research, is that in all age remains the most influential explaining variable. Thus, many age related factors are yet to be disclosed and deserve systematic research with respect to their proneness to modify cognitive aging. Our results with respect to the importance of MSE and sensory function provide avenues for further study of this subject.

The findings of the present studies are of possible relevance because data have been used from both a large longitudinal study in normal aging adults (MAAS), in addition to the data obtained in older individuals with subjective complaints (the participants in the treatment studies). This makes our findings relevant for the vast majority of older people who are not characterized by frank disease or age-related somatic dysfunction, but have cognitive complaints which affects their quality of life. Yet, the nature of 
these populations makes it imperative for future studies to put effort in evaluating the generalisability of the findings done in the present study in more detail. In sum, we feel that the findings presented in this thesis provide additional knowledge with respect to mechanisms of successful cognitive aging by identifying some relevant mediating factors and by demonstrating two effective intervention strategies. 


\section{References}

Anstey, K. J., Luszcz, M. A., \& Sanchez, L. (2001). Two-year decline in vision but not hearing is associated with memory decline in very old adults in a population-based sample. Gerontology, 47(5), 289-293.

Baltes, P. B., \& Lindenberger, U. (1997). Emergence of a powerful connection between sensory and cognitive functions across the adult life span: a new window to the study of cognitive aging? Psychology and Aging, 12(1), 12-21.

Berkman, L. F., Seeman, T. E., Albert, M., Blazer, D., Kahn, R., Mohs, R., et al. (1993). High, usual and impaired functioning in community-dwelling older men and women: findings from the MacArthur Foundation Research Network on Successful Aging Journal of Clinical Epidemiology, 46(10), 1129-1140.

Birren, J. E., \& Schaie, K. W. E. (1996). Handbook of the psychology of aging (4 ed.). San Diego: Academic Press.

Bolla, K. I., Lindgren, K. N., Bonaccorsy, C., \& Bleecker, M. L. (1991). Memory complaints in older adults. Fact or fiction? Archives of Neurology, 48, 61-64.

Christensen, H., Mackinnon, A. J., Korten, A., \& Jorm, A. F. (2001). The "common cause hypothesis" of cognitive aging: evidence for not only a common factor but also specific associations of age with vision and grip strength in a cross-sectional analysis. Psychology and Aging, 16(4), 588-599.

Clarnette, R. M., Almeida, O. P., Forstl, H., Paton, A., \& Martins, R. N. (2001). Clinical characteristics of individuals with subjective memory loss in Western Australia: results from a cross-sectional survey. International Journal of Geriatric Psychiatry, 16(2), 168-174.

Comijs, H. C., Deeg, D. J., Dik, M. G., Twisk, J. W., \& Jonker, C. (2002). Memory complaints; the association with psycho-affective and health problems and the role of personality characteristics. A 6-year follow-up study. Journal of Affective Disorders, 72(2), 157-165.

Commissaris, C. J. A. M., Ponds, R. W. H. M., \& Jolles, J. (1998). Subjective forgetfulness in a normal Dutch population: possibilities for health education and other interventions. Patient Education and Counseling, 34, 2532.

Commissaris, C., Verhey, F. R., \& Jolles, J. (1996). A controlled study into the effects of psychoeducation for patients with cognitive disturbances. Journal of Neuropsychiatry and Clinical Neurosciences, 8(4), 429-435.

Derouesne, C., Lacomblez, L., Thibault, S., \& LePoncin, M. (1999). Memory complaints in young and elderly subjects. International Journal of Geriatric Psychiatry, 14(4), 291-301.

Dik, M. G., Jonker, C., Comijs, H. C., Bouter, L. M., Twisk, J. W., van Kamp, G. J., et al. (2001). Memory complaints and APOE-epsilon4 accelerate cognitive decline in cognitively normal elderly. Neurology, 57(12), 2217-2222.

Guralnik, J. M., \& Kaplan, G. A. (1989). Predictors of healthy aging: prospective evidence from the Alameda County study. American Journal of Public Health, 79(6), 703-708.

Jonker, C., Geerlings, M. I., \& Schmand, B. (2000). Are memory complaints predictive for dementia? A review of clinical and population-based studies. International Journal of Geriatric Psychiatry, 15(11), 983-991.

Jorm, A. F., Christensen, H., Henderson, A. S., Jacomb, P. A., Korten, A. E., \& Mackinnon, A. (1998). Factors associated with successful aging. Australasian Journal on Ageing, 17(1), 3337.

Lachman, M.E., Weaver, S.L., Bandura, M., Elliott, E., \& Lewkowicz, C.J. (1992). Improving memory and control beliefs through cognitive restructuring and self-generated strategies. Journal of Gerontology, 47(5), 293-299. 
Lindenberger, U., \& Baltes, P. B. (1994). Sensory functioning and intelligence in old age: a strong connection. Psychology and Aging, 9(3), 339-355.

Ponds, R. W. H. M., Commissaris, C. J. A. M., \& Jolles, J. (1997). Prevalence and covariates of subjective forgetfulness in a normal population in the Netherlands. International Journal of Aging and Human Development, 45(3), 207221.

Rabbitt, P. (1990). Mild hearing loss can cause apparent memory failures which increase with age and reduce with IQ. Acta Otolaryngol Suppl Stockh, 476(167), 167-175.

Reyersen van Buuren, E. J., \& Jolles, J. (1990). Function-Oriented Guidance as a form of neuropsychological rehabilitation for memory disturbed patients. In Z. L. Groswasser (Ed.), Rehabilitation of the Brain Injured (pp. 87-103). London: Freund.

Roos, N. P., \& Havens, B. (1991). Predictors of successful aging: a twelve-year study of Manitoba elderly. American Journal of Public Health, 81(1), 63-68.

Schneider, B. A., \& Pichora-Fuller, M. K. (2000). Implications of perceptual deterioration for cognitive aging research. In T. A. Salthouse (Ed.), The handbook of aging and cognition (pp. 155-219). Mahwah, NJ: Erlbaum.

Stevens, F. C. J., Kaplan, C. D., Ponds, R. W. H. M., \& Jolles, J. (2001). The importance of active lifestyles for memory performance and memory self-knowledge. Basic and applied social psychology, 23(2), 137-145.

Strawbridge, W. J., Cohen, R. D., Shema, S. J., \& Kaplan, G. A. (1996). Successful aging: predictors and associated activities. American Journal of Epidemiology, 144(2), 135-141.

Vaillant, G. E., \& Mukamal, K. (2001). Successful aging. American Journal of Psychiatry, 158(6), 839-847.

Van Boxtel, M. P., ten Tusscher, M. P., Metsemakers, J. F., Willems, B., \& Jolles, J. (2001). Visual determinants of reduced performance on the Stroop color-word test in normal aging individuals. Journal of Clinical and Experimental Neuropsychology, 23(5), 620-627.

Verhaeghen, P., Marcoen, A., \& Goossens, L. (1992). Improving memory performance in the aged through mnemonic training: a meta-analytic study. Psychology and Aging, 7(2), 242-251. 
CHAPTER 9. CONCLUDING REMARKS 


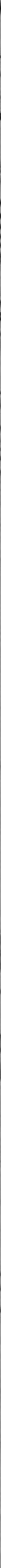


The objectives of this thesis were to identify determinants of successful cognitive aging, and in addition to report on interventions that can have a positive effect on cognitive performance and quality of life of normal aging, older adults. This thesis is divided in two parts. Part 1 addresses the studies on potential determinants, using longitudinal data from the Maastricht Aging Study (MAAS). Part 2 describes several intervention studies, which are part of a larger research program on successful aging.

Chapter 1 provides background information, the rationale, aims and outlines of this thesis.

\section{Part 1}

In chapter 2 we examined the relationship between memory self-efficacy (MSE) and a 6-year follow-up assessment of memory functioning in a sample of MAAS participants. We found that the total MSE score predicts memory performance 6 years later. A separate analysis of the different MSE subscales indicated that the MIA Change scale is the most salient feature of MSE. An extreme group analysis of the MIA Change score revealed that individuals who perceived that their memory is deteriorating, scored worse at three trials of a verbal learning task. The results of this study confirm that MSE is an important mediator of objective memory performance and supports the notion that it should play a crucial role in interventions designed to treat memory problems of older people.

In chapter 3 it was demonstrated that a change in visual acuity is associated with change in memory performance (total and recall scores of the Visual Verbal Learning Task (VVLT)). In addition positive effects were found on most other cognitive measures, including simple speed and information processing (mean score of the first two Stroop cards, mean score of the first two Concept Shifting Test (CST) cards and Letter Digit Substitution Task (LDST)). Moreover, change in auditory acuity was also found to be associated with change in memory performance (VVLT total and recall scores).

A related question in this study addressed the hypothesis that selfinitiated interventions to improve visual or auditory function (cataract surgery and a hearing aid, respectively) would have a positive effect on cognitive performance. However, we did not find cataract surgery or hearing aid use 
affect cognitive performance. Some methodological issues could not be sufficiently resolved in this study, such as the relatively small sample size of individuals who undertook steps to improve their vision or hearing, and the limited availability of information about the success of these interventions. Therefore, we suggested that the effect of interventions aimed at improving sensory function should be studied by means of a controlled experiment.

Chapter 4 deals with the predictive value of a general health questionnaire on functional independence. Results indicated that the Physical Functioning (PF) scale of this questionnaire can predict change in assistance need for daily activities three years later, i.e. lower scores were associated with the emergence of assistance need in daily activities. The PF scale contains several items that are reflective of activities of daily living including leisure/sport activities, grocery shopping, dressing, and bathing. In each case, the item content is based on the extent to which a respondent believes that the performance of these tasks is restricted (or limited) due to one's health. This makes the PF scale a suitable measure of change in the explicit acknowledgement of assistance need to function independently.

\section{Part 2}

Chapter 5 addresses the evaluation of a memory-training program designed to improve objective memory performance as well as MSE. This program was offered both as a collective training and as an individual training. We found that in particular the collective variant of the program is effective in improving subjective and objective memory performance. Compared to controls, participants in the collective training group reported more stability in memory functioning and had fewer feelings of anxiety and stress in relation to memory functioning. In addition, positive effects were found on an objective memory functioning test; compared with the other two groups, the collective training group participants showed an improved recall of items from a previously learned word list. These conclusions were based on between-group comparisons; however, in individual cases there may be even more substantial intervention effects. This makes it interesting to find out whether particular variables can predict maximal treatment outcome.

In chapter 6 we investigated whether personality (neuroticism) and mood (anxiety, depression) could predict which individuals did benefit most 
from the memory-training program. We did not find these variables to affect treatment outcome, showing that the intervention is equally effective for persons with and without mental distress or neuroticism. However, we did find that elderly individuals who are more neurotic, or who reported more depressive or anxiety symptoms were less compliant and more prone to drop out of the training-program. This indicates that levels of neuroticism and distress are indeed important variables with respect to memory-training programs. In order to determine whether participation in a memory-training program is associated with specific behavioural characteristics, we compared memory intervention participants with individuals enrolled in the MAAS. Results indicated that participants of the memory-training program report significantly more depressive symptoms and have higher levels of neuroticism than the control population.

In chapter 7 we conducted a controlled study into the effects of cataract surgery on memory and other cognitive variables. Two groups of individuals were compared, namely, patients who underwent cataract surgery (intervention group), and cataract patients in a waiting list control group. The results indicated that in addition to improving visual acuity, cataract surgery also improves verbal memory function and the ability to inhibit a habitual response, as measured by the Stroop test, in the intervention group. These results confirm that visual function can have significant consequences for cognitive test performance and must therefore be taken into consideration when interpreting neuropsychological test results.

Chapter 8 covers a related study on the effects of cataract surgery. Again, the two groups of individuals were compared (patients who underwent cataract surgery versus cataract patients in a waiting list control group). The outcome measures of interest in this study were both visual related quality of life and general quality of life. Results showed that cataract surgery has beneficial effects on visual functioning and visual related quality of life. However, cataract surgery does not influence general health related quality of life.

Finally, in chapter 9 this thesis closes with some concluding remarks. The major findings of the experimental studies are summarised and discussed in light of current views in the literature. In addition, this chapter addresses methodological issues and recommendations for future studies. 
De eerste doelstelling van dit onderzoek was het identificeren van voorspellers van succesvolle cognitieve veroudering. Hiervoor werd gebruik gemaakt van data uit de Maastricht Aging Study (MAAS). De onderzoeksresultaten worden beschreven in deel 1 van dit proefschrift. Daarnaast werden interventies die een positieve bijdrage kunnen leveren aan cognitieve prestaties en kwaliteit van leven van gezonde ouderen geëvalueerd. De resultaten hiervan worden beschreven in het tweede deel van dit proefschrift. Alle bestudeerde interventies zijn onderdeel van het onderzoeksprogramma ‘Succesvol Ouder Worden' (SOW).

In hoofdstuk 1 worden de achtergrond, de doelstellingen en de opzet van dit proefschrift besproken.

\section{Deel 1}

In hoofdstuk 2 is de longitudinale relatie tussen geheugenzelfvertrouwen (GZV) en geheugenprestaties onderzocht binnen een groep deelnemers aan de MAAS studie. Uit de resultaten blijkt dat de totale GZV score voorspelt hoe iemand 6 jaar later presteert op een geheugentaak. De resultaten van een additionele analyse van de verschillende GZV subschalen laten zien dat de Stabiliteitsschaal (Change) de beste voorspeller is. Uit een analyse waarin extreme groepen met elkaar worden vergeleken blijkt bovendien dat personen, die aangeven dat zij ervaren dat hun geheugen achteruit gaat, minder goed presteren op een geheugentaak dan personen die geen achteruitgang ervaren.

In hoofdstuk 3 is binnen de MAAS studie de relatie tussen sensorisch functioneren en cognitieve prestaties onderzocht. De resultaten laten zien dat verandering in gezichtsscherpte is geassocieerd met verandering in geheugenprestaties. Daarnaast is ook een relatie gevonden met de meeste andere onderzochte cognitieve taken, waaronder snelheid en informatieverwerking. Bovendien blijkt dat ook verandering in gehoorsscherpte geassocieerd is met verandering in het functioneren van het geheugen. Tenslotte werd in deze studie onderzocht of zelfgeïnitieerde interventies om de visus of het gehoor te verbeteren een gunstige invloed hebben op het cognitief functioneren. Uit de resultaten komt dit niet naar voren. Echter, een aantal methodologische problemen kon in deze studie niet worden opgelost 
en had mogelijk invloed op de resultaten. Ten eerste was de grootte van de groep mensen die initiatief nam om het sensorisch functioneren te meten relatief klein. Daarnaast was weinig informatie bekend over het succes van de interventie. Daarom is geconcludeerd dat het effect van een interventie beter onderzocht kan worden met een experimentele studie.

Hoofdstuk 4 handelt over de voorspellende waarde van een algemene gezondheidsvragenlijst (SF-36) voor functionele afhankelijkheid binnen de MAAS studie. Het onderzoek toont aan dat met de Fysiek Functioneren (FF) schaal van deze vragenlijst, veranderingen in de mate van behoefte aan hulp bij dagelijkse activiteiten voorspeld kan worden. Lage scores op de FF schaal zijn geassocieerd met meer hulpbehoevendheid 3 jaar later. De FF schaal bestaat uit een aantal items die dagelijkse activiteiten omvatten, zoals vrije tijd of sportactiviteiten, boodschappen doen, aankleden en wassen. De items zijn steeds gebaseerd op de mate waarin respondenten aangeven dat ze door hun gezondheid beperkt zijn om de betreffende activiteit uit te voeren. Dit maakt de FF schaal een geschikt instrument om te meten of personen hulp behoeven om zelfstandig dagelijkse activiteiten uit te voeren.

\section{Deel 2}

In hoofdstuk 5 wordt een experimentele studie naar het effect van een geheugentrainingprogramma besproken. Dit programma is gericht op het verbeteren van zowel het subjectieve als het objectieve geheugen. De geheugencursus werd aangeboden als een groepstraining en als een individuele training. Uit de resultaten blijkt dat met name de groepstraining effectief is in het verbeteren van het geheugen. In vergelijking met de controlegroep ervaren deelnemers aan deze groepstraining meer stabiliteit en minder stress en angst in relatie tot het geheugen. Daarnaast worden ook positieve effecten gevonden op het objectieve geheugen; deelnemers aan de groepstraining waren beter in staat om eerder geleerde woorden te onthouden dan de andere twee groepen. De conclusies van dit onderzoek zijn gebaseerd op vergelijkingen tussen groepen. In individuele gevallen kunnen de effecten groter zijn en dit maakt het interessant om uit te zoeken met welke variabelen een maximaal interventie effect voorspeld kan worden.

In hoofdstuk 6 is onderzocht of met persoonlijkheid (neuroticisme) of stemmingsvariabelen (angst en depressie) voorspeld kan worden welke 
individuen het meest profiteren van een geheugentrainingprogramma. Uit de resultaten komt naar voren dat deze variabelen geen invloed hebben en dat de interventie dus even effectief is voor personen met meer of minder neurotische kenmerken en stemmingsproblemen. Wel is gevonden dat participanten die meer neurotisch zijn en meer depressieve en angst symptomen rapporteren eerder geneigd zijn om voortijdig met de interventie te stoppen. De mate van neuroticisme en depressieve en angst symptomen zijn dus toch van belang voor het slagen van geheugeninterventies. Om te bepalen of deelname aan een geheugeninterventie is geassocieerd met specifieke gedragskenmerken zijn deelnemers aan het geheugentrainingsprogramma vergeleken met een controlegroep van deelnemers aan de MAAS studie. De deelnemers aan de training bleken meer neurotische kenmerken en depressieve symptomen te rapporteren dan de controlegroep uit de MAAS studie.

In hoofdstuk 7 wordt een gecontroleerd experiment beschreven naar de effecten van een staaroperatie op het geheugen en andere cognitieve functies. Daartoe werd een groep patiënten die een staaroperatie onderging vergeleken met een groep patiënten die op de wachtlijst stond voor deze operatie. De operatie blijkt niet alleen een gunstige invloed te hebben op gezichtsscherpte, maar ook op het geheugen en op het vermogen om een automatische respons te onderdrukken. Deze resultaten bevestigen dat het cognitief functioneren in belangrijke mate kan worden beïnvloed door het visueel functioneren en dat hiermee rekening moet worden gehouden bij het neuropsychologisch onderzoek.

Hoofdstuk 8 beschrijft een gerelateerd onderzoek naar het effect van een staaroperatie op kwaliteit van leven (algemeen en gerelateerd aan visus). Weer werd een groep patiënten die een staaroperatie onderging vergeleken met een groep patiënten die op de wachtlijst stond voor deze operatie. Uit deze studie blijkt dat een staaroperatie een positief effect heeft op visueel gerelateerde kwaliteit van leven. Er werd echter geen effect gevonden op algemene kwaliteit van leven.

In hoofdstuk 9 wordt tenslotte een overzicht gegeven van de belangrijkste resultaten van dit proefschrift en worden deze bevindingen besproken tegen de achtergrond van huidige inzichten in de literatuur. Daarnaast worden 
enkele methodologische aandachtspunten besproken en worden suggesties gedaan voor verder onderzoek. 
SAMENVATING 


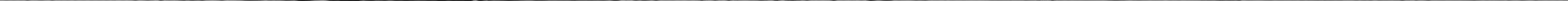


DANKWOORD

\section{Met dank aan...}

Alle proefpersonen voor hun medewerking aan dit onderzoek.

Zonder de inzet van alle staarpatiënten, mensen met geheugenklachten en MAAS deelnemers had dit onderzoek nooit kunnen plaatsvinden.

Mijn promotor en co-promotores voor hun begeleiding.

Jelle Jolles, ik wil je graag bedanken voor je enthousiasme over het SOW onderzoek. Ik ben blij dat je me kans hebt gegeven om aan dit project mee te werken en me te ontwikkelen als onderzoeker.

Rudolf Ponds, ik heb veelvuldig gebruik kunnen maken van jouw ervaring en je proefschrift als naslagwerk. Mijn dank daarvoor.

Martin van Boxtel, heel erg bedankt voor je deskundigheid, kritische commentaar, betrokkenheid, gezellige lunches en natuurlijk de prettige samenwerking.

Hans Bosma, Henny Beckers en Bob Hill voor hun waardevolle bijdrage aan de totstandkoming van dit proefschrift.

Hans, ontzettend bedankt voor al je 'statistische hulp' en het feit dat je altijd bereid was om even tijd vrij te maken en mee te denken.

Henny, ik ben je dankbaar voor je enthousiasme, je deskundigheid en alle klinische consulten.

Bob Hill, thank you very much for all your valuable input and feedback, but most importantly for your never-ending support. I hope we can continue working together in the future.

Susan van Hooren voor de super prettige samenwerking.

Lieve Susan, we hebben samen veel gedeeld (vooral onze voorliefde voor winkelen, chocolade en roze), we hebben veel van elkaar kunnen leren en hebben elkaar ook kunnen steunen als het even tegenzat. Ik wil je daar graag voor bedanken en ben heel blij samen met jou 'de Susannes' te hebben mogen vormen.

Alle stagiaires en onderzoeksmedewerkers voor hun hulp bij de dataverzameling en de logistiek van dit onderzoek. 
Joyce Belgers, Vivian Nijst, Janneke Spauwen, Jaimie Luermans, Viviane Thewissen, Lia van der Kooi, Rubia Bloo, Suzanne Zuiderveld, Astrid Quist en Dory Touw, heel hartelijk bedankt voor jullie inzet, enthousiasme en gezelligheid. We hadden ons geen betere stagiaires en medewerkers kunnen wensen.

Marjan Nijkamp voor al haar betrokkenheid bij het staarproject.

Lieve Marjan, je hebt me wegwijs gemaakt op de polikliniek Oogheelkunde en niemand kan dat zo enthousiast als jij!

Alle medewerkers van de poli Oogheelkunde van het azM, het Medisch Centrum Annadal en het Atrium Heerlen en het opnamebureau van het azM voor de fijne samenwerking.

Het Groene Kruis Heuvelland voor het totstandkomen van het geheugenproject.

In het bijzonder Annemarie Zeelen en Lilian Houben ben ik zeer erkentelijk voor de collegiale samenwerking.

Alle aio's voor de leuke sfeer, het uitwisselen van ideeën en het meedenken bij onverhoopte problemen en vooral Sascha Rasquin. Lieve Sas, omdat je gewoon een geweldige collega was!

Alle overige collega's voor de prettige werksfeer.

Onze groep is te groot om iedereen afzonderlijk te bedanken, maar Carla Brandts, Nico Rozendaal en Elsa Misdom wil ik graag speciaal bedanken voor hun oneindige bereidheid 'even' te helpen. En natuurlijk Jeroen Schmitt, vooral voor alle gezelligheid na werktijd.

Annique Schins, Miriam Dietvorst, Inez Ramakers en Heidi Lansdaal omdat ze gewoon hele leuke kamergenoten zijn.

Geert Leenders voor zijn enorme enthousiasme en het onvermoeibare prwerk voor dit onderzoek. 
DANKWOORD

Jane Sykes voor het corrigeren van mijn 'Nederlandse’ Engels.

Dymphie Scholtissen, Sven Stapert, Margot Krook, Floor van Bergen en Ian Robertson voor hun onmisbare bijdrage aan het GMT project (beschreven in het proefschrift van Susan van Hooren).

Johannes Verheijen voor de geweldige kaft.

Alard Weisscher voor de finishing touch van de lay-out.

Opa en Oma van Orsouw omdat ze model staan voor 'Succesvol Oud' en Ton van Zantvoort omdat hij dat zo mooi op een foto heeft vastgelegd.

Petra Hurks en Marjolein de Vugt omdat ze mijn paranimf willen zijn.

Lieve Petra, duizendmaal dank omdat je al 10 jaar altijd voor me klaarstaat en mijn discussietechnieken scherp houdt.

Lieve Marjolein, ook duizendmaal dank omdat jij het tenminste wel vaak met me eens bent en ik altijd overal met je over kan praten.

Ik hoop dat we nog heel lang met z'n drie-en ATWT avondjes, weekendjes weg, etentjes, borrels en weddenschappen met Bijenkorfbrownies als inzet blijven organiseren.

De families Valentijn en van Zantvoort omdat ze altijd achter me staan. In het bijzonder 'ons pap, ons moek en onze Johnny', die onvoorwaardelijk in mij geloven.

En natuurlijk Corné, voor alles!

Lieve Corné, ik heb geen idee hoe ik je ooit kan bedanken voor het feit dat je echt altijd voor me klaarstaat, maar ik ga het in ieder geval proberen.... 
Susanne Valentijn werd geboren op 19 maart 1976 in Oss. Na het behalen van haar VWO diploma aan het Maaslandcollege in Oss ging zij in 1994 Psychologie studeren aan de Katholieke Universiteit Nijmegen met als afstudeerrichting Neuro-en Revalidatiepsychologie. Na een klinische stage in psychiatrisch ziekenhuis Veldwijk te Ermelo en een wetenschappelijke stage in ziekenhuis De Gelderse Vallei te Ede, behaalde zij in 1999 haar diploma.

In maart 2000 werd zij als assistent in opleiding aangesteld bij de vakgroep Psychiatrie en Neuropsychologie van de Universiteit Maastricht. Na het afronden van haar onderzoek is zij momenteel als neuropsycholoog werkzaam op de geheugenpolikliniek van het academisch ziekenhuis Maastricht en de academische afdeling neuropsychologie van het PsychoMedisch Streekcentrum Vijverdal. In januari 2005 start zij met de postdoctorale opleiding tot GZ psycholoog in het Catharina ziekenhuis te Eindhoven. 